RICARDO HAUCH RIBEIRO DE CASTRO

\title{
ESTUDO DA INFLUÊNCIA DE ADITIVOS NA TRANSFORMAÇÃO DE FASE GAMA-ALFA DA ALUMINA
}

Tese apresentada à Escola Politécnica da Universidade de São Paulo para obtenção do título de Doutor em Engenharia.

Área de Concentração

Engenharia de Materiais

Orientador:

Prof. Dr.

Douglas Gouvêa

SÃO PAULO 
RICARDO HAUCH RIBEIRO DE CASTRO

\section{ESTUDO DA INFLUÊNCIA DE ADITIVOS NA TRANSFORMAÇÃO DE FASE GAMA-ALFA DA ALUMINA}

Tese apresentada à Escola Politécnica da Universidade de São Paulo para obtenção do título de Doutor em Engenharia.

Área de Concentração

Engenharia de Materiais

Orientador:

Prof. Dr.

Douglas Gouvêa

SÃO PAULO 
FICHA CATALOGRÁFICA

Castro, Ricardo Hauch Ribeiro de

Estudo da influência de aditivos na transformação de fase gama-alfa da alumina / R.H.R. de Castro. -- São Paulo, 2005.

$92 \mathrm{p}$.

Tese (Doutorado) - Escola Politécnica da Universidade de São Paulo. Departamento de Engenharia Metalúrgica e de Materiais.

1.Materiais cerâmicos 2.Transformação de fase 3.Alumina 4.Aditivos 5.Energia de superfície I.Universidade de São Paulo. Escola Politécnica. Departamento de Engenharia Metalúrgica e de Materiais II.t. 
"The significant problems we face cannot be solved by the same level of thinking that created them."

\author{
Albert Einstein
}




\section{Agradecimentos}

Agradeço a Deus acima de tudo.

Aos meus Pais que sempre me apoiaram nos meus sonhos me dando condições para realizá-los me mostraram o grande valor do estudo e do trabalho.

À Luciana Carolina, que com seu imenso amor esteve sempre ao meu lado me incentivando.

Ao amigo e Prof. Dr. Douglas Gouvêa, que com sabedoria e idéias pouco ortodoxas faz com que a perspectiva de mudar mundo se torne alcançável. A todos os amigos do Departamento de Engenharia Metalúrgica e de Materiais pela forte amizade, incentivo e discussões sempre salutares.

À Profa. Dra. Alexandra Navrotsky do Thermochemistry Facility, Universidade da Califórnia, EUA, pela oportunidade de desenvolver parte do trabalho sob sua co-orientação.

Ao Dr. Marlu César Steil e ao Dr. Leon Gengembre do Laboratoire de Catalyse de Lille - École Nationale Supérieure de Chimie de Lille, França, pelas análises de XPS.

À FAPESP (proc. 01/10053-7) e CAPES pelo apoio financeiro.

À Escola Politécnica da USP pela oportunidade concedida

e a todos que direta ou indiretamente colaboraram para a realização deste trabalho. 


\section{RESUMO}

O controle da temperatura de transformação de fase $\gamma-\alpha$ da alumina pelo uso de aditivos iônicos tem sido alvo de diversos estudos nas ultimas décadas. No entanto, os efeitos destes aditivos são usualmente explicados considerando apenas parâmetros cinéticos e de difusão e a conseqüência destas impurezas nas energias dos polimorfos e nas energias de superfície são geralmente desconsideradas. Neste trabalho, o efeito termodinâmico do $\mathrm{Zr}, \mathrm{Mg}$ e $\mathrm{Mn}$ na transformação $\gamma-\alpha$ é estudado para pós de $\mathrm{Al}_{2} \mathrm{O}_{3}$ preparados pelo método do precursor polimérico. Microcalorimetria de adsorção acoplada com calorimetria de dissolução de alta temperatura mostraram que os íons $\mathrm{Zr}$ diminuem a energia de superfície do $\gamma$ $\mathrm{Al}_{2} \mathrm{O}_{3}$, aumentando a estabilidade da fase de transição, que é fortemente dependente desta energia. Utilizando as mesmas técnicas, mostrou-se que o íon $\mathrm{Mg}$ aumenta a estabilidade termodinâmica do $\gamma-\mathrm{Al}_{2} \mathrm{O}_{3}$, também aumentando a temperatura de transformação. $\mathrm{O}$ efeito do $\mathrm{Mg}$, no entanto, foi também relacionado a efeitos cinéticos tais como a diminuição de difusão pela rede. A ação do íon Mn na diminuição da temperatura de transformação foi sugerida como fortemente relacionada a parâmetros de difusão. Vacâncias geradas pela substituição de $\mathrm{Al}^{3+}$ por $\mathrm{Mn}^{4+}$ seriam responsáveis pelo aumento do processo difusional atômico pela rede, fazendo com que o sistema atinja o tamanho crítico pré-determinado para esta reação em temperaturas mais baixas. Estas importantes conclusões abrem novas perspectivas no estudo da ação de aditivos em processos de alta temperatura, que devem ser avaliados considerando ambos efeitos termodinâmico e difusional. 


\begin{abstract}
The control of the $\gamma-\alpha$ alumina transformation temperature using ionic additives has been the subject of several studies in the past decades. In this sense, the influence of these additives is usually explained considering only kinetic and diffusional parameters. Effects of these impurities on energetics of polymorphism and surface energies are usually disregarded. In this work, the thermodynamic effect of $\mathrm{Zr}, \mathrm{Mg}$ and $\mathrm{Mn}$ on the $\gamma-\alpha$ transformation is reported on $\mathrm{Al}_{2} \mathrm{O}_{3}$ powders prepared by the polymeric precursor method. Adsorption microcalorimetry coupled with high temperature oxide melt solution calorimetry showed that $\mathrm{Zr}$ ions dramatically decrease the surface energy of $\gamma-\mathrm{Al}_{2} \mathrm{O}_{3}$, increasing the stability of the transition phase as which has been described to have its stability considerably related to the surface energy. By the same techniques, $\mathrm{Mg}$ was shown to increase the thermodynamic stability of $\gamma$-alumina, also increasing the transformation temperature. The role of $\mathrm{Mg}$ on the control of the transformation temperature, however, was also related to kinetic factors, such as the bulk diffusion decreasing. The effect of $\mathrm{Mn}$ on decreasing the transformation temperature, however, was considered to be almost completely related to diffusion parameters, and vacancies generated by the substitution of $\mathrm{Al}^{3+}$ by $\mathrm{Mn}^{4+}$ would be responsible for the increase in bulk diffusion, allowing the system to reach a predetermined critical particle size at lower temperatures. These important conclusions opened new perspectives in the role of additives in the hightemperature processes that should now on be evaluated from both thermodynamic effects and kinetics viewpoints.
\end{abstract}




\section{LISTA DE FIGURAS}

Figura 1.1 - Empacotamento dos íons de Al e O no plano basal. A camada superior de íons $\mathrm{O}$ não é mostrada. Vetores e direções da célula hexagonal estão indicados. 2

Figura 1.2 - Seqüência de desidratação dos hidratos de alumina [5] ..................... 5

Figura 1.3 - Cálculo das entalpias de polimorfos de alumina relativa a corundum coalescida e baseadas nas energias de superfície calculadas por dinâmica molecular [1-2]

Figura 1.4 - Calor de adsorção química de $\mathrm{H}_{2} \mathrm{O}$ diferencial (A) e integral (B) em $\alpha-\mathrm{Al}_{2} \mathrm{O}_{3}\left[36 \mathrm{~m}^{2} \mathrm{~g}^{-1}(\bullet), 61 \mathrm{~m}^{2} \mathrm{~g}^{-1}(\boldsymbol{\bullet})\right]$ e $\gamma-\mathrm{Al}_{2} \mathrm{O}_{3}\left[72 \mathrm{~m}^{2} \mathrm{~g}^{-1}(\boldsymbol{\Delta}), 161\right.$ $\left.\mathrm{m}^{2} \mathrm{~g}^{-1}(\boldsymbol{\nabla})\right]$ em função da cobertura de hidroxilas na superfície......... 22

Figura 1.5 - Entalpias de polimorfos de alumina relativas a corundum coalescida determinadas por calorimetria de solução de alta temperatura [5327] . No gráfico $\gamma-\mathrm{Al}_{2} \mathrm{O}_{3}$ é representado pelas esferas fechadas $(\bullet$ ou $\boldsymbol{\nabla}) \mathrm{e}$ $\alpha-\mathrm{Al}_{2} \mathrm{O}_{3}$ pelos quadrados abertos ( $\left.\square\right)$. 23

Figura 3.1 - Representação esquemático do equipamento de DTA construído neste trabalho para avaliação da influência da umidade na transformação de fase da alumina. 28

Figura 3.2 - Representação esquemática do calorímetro de solução de alta temperatura $[1-2]$. 29

Figura 3.3 - Representação esquemática do equipamento de medida de entalpia de adsorção de $\mathrm{H}_{2} \mathrm{O}$. 32 
Figura 4.1 - Curva de DTA das amostras de $\mathrm{Al}_{2} \mathrm{O}_{3}$ contendo $10 \mathrm{~mol} \% \mathrm{Mn}$ sintetizadas pelo método dos precursores poliméricos em atmosfera seca e contendo $\mathrm{H}_{2} \mathrm{O}$

Figura 4.2 - Difração de raios X das amostras contendo 10 mol\% Mn sintetizadas em ar seco (a) e contendo $\mathrm{H}_{2} \mathrm{O}$ (b) após ensaio de DTA em atmosfera seca. A legenda das fases presentes é mostrada no gráfico. 36

Figura 4.3 - Curva de DTA das amostras de $\mathrm{Al}_{2} \mathrm{O}_{3}$ contendo $5 \mathrm{~mol} \% \mathrm{Mg}$ sintetizadas pelo método dos precursores poliméricos em atmosfera seca e contendo $\mathrm{H}_{2} \mathrm{O}$.

Figura 4.4 - Difração de raios X das amostras contendo 5 mol\% Mg sintetizadas em ar seco (a) e contendo $\mathrm{H}_{2} \mathrm{O}$ (b) após ensaio de DTA em atmosfera seca. A legenda das fases presentes é mostrada no gráfico. 38

Figura 4.5 - Curva de DTA sob atmosfera seca e úmida das amostras de $\mathrm{Al}_{2} \mathrm{O}_{3}$ sem aditivos, sintetizadas pelo método dos precursores poliméricos em atmosfera contendo $\mathrm{H}_{2} \mathrm{O}$ 40

Figura 4.6 - Temperatura em função do tempo mostrando a taxa de subida de temperatura do forno utilizado para os ensaios de DTA. .41

Figura 4.7 - Análise térmica diferencial (DTA) e áreas de superfície específica de amostras de $\mathrm{Al}_{2} \mathrm{O}_{3}$ sem aditivos $(\Delta)$ sintetizadas pelo método dos precursores poliméricos e calcinadas em diferentes temperaturas a uma taxa de $10^{\circ} \mathrm{C}$ $\min ^{-1}$. No detalhe a derivada da curva de DTA mostrando a temperatura de início da transformação. 44

Figura 4.8 - Difração de raios $\mathrm{X}$ de amostras de $\mathrm{Al}_{2} \mathrm{O}_{3}$ sem aditivos calcinada em uma temperatura anterior $\left(1015{ }^{\circ} \mathrm{C}\right)$ e imediatamente posterior $\left(1045{ }^{\circ} \mathrm{C}\right)$ à transformação de fase. 
Figura 4.9 - Entalpia de adsorção de $\mathrm{H}_{2} \mathrm{O}$ na superfície de $\gamma-\mathrm{Al}_{2} \mathrm{O}_{3}$ sem aditivos em função da cobertura de OH. (A) Entalpia de adsorção medida para cada adsorção. (B) Integral das medidas de calor de adsorção. 49

Figura 4.10 - Entalpia de adsorção de $\mathrm{H}_{2} \mathrm{O}$ na superfície do $\gamma-\mathrm{Al}_{2} \mathrm{O}_{3}$ referência em função da cobertura de $\mathrm{OH}$. (A) Entalpia de adsorção medida para cada adsorção reportado na literatura $(\bullet)$ e medido neste trabalho $(\nabla)$. (B) Integral das medidas de calor de adsorção reportado na literatura $(\bullet)$ e medido neste trabalho $(\nabla)$ 50

Figura 4.11 - Calor de dissolução em função da área de superfície específica do $\gamma$ $\mathrm{Al}_{2} \mathrm{O}_{3}$. Resultados corrigidos com os valores de entalpia de quimissorção de $\mathrm{H}_{2} \mathrm{O}$ reportados na literatura $(\bullet)$, valores corrigidos utilizando as medidas deste trabalho $(\Delta)$ e valores comparativos da literatura $(\nabla)[5327]$ 52

Figura 4.12 - Análise térmica diferencial (DTA) e áreas de superfície específicas das amostras de $\gamma-\mathrm{Al}_{2} \mathrm{O}_{3}$ contendo $\mathrm{Mg}$ como aditivo. As áreas de superfície específicas são referentes às amostras contendo $5 \mathrm{~mol} \% \mathrm{de}$ $\operatorname{Mg}(\Delta)$ e $3 \mathrm{~mol} \% \mathrm{Mg}(\boldsymbol{\square})$. No detalhe a derivada da curva de DTA para a amostra $\mathrm{Al}_{2} \mathrm{O}_{3} 5 \mathrm{~mol} \% \mathrm{Mg}$. 54

Figura 4.13 - Difração de raios $\mathrm{X}$ de amostras de $\gamma-\mathrm{Al}_{2} \mathrm{O}_{3}$ contendo $\mathrm{Mg}$ como aditivo e tratadas em temperaturas à $10^{\circ} \mathrm{C}$ do início da transformação de fase. 54

Figura 4.14 - Entalpia de adsorção de $\mathrm{H}_{2} \mathrm{O}$ na superfície do $\gamma-\mathrm{Al}_{2} \mathrm{O}_{3}$ em função da cobertura de $\mathrm{OH}$. (A) Entalpia de adsorção medida para $\gamma-\mathrm{Al}_{2} \mathrm{O}_{3}(\bullet)$ e 
$\gamma-\mathrm{Al}_{2} \mathrm{O}_{3}$ contendo $5 \mathrm{~mol} \% \mathrm{Mg}(\Delta)$. (B) Integral das medidas de calor de adsorção para $(\bullet) \gamma-\mathrm{Al}_{2} \mathrm{O}_{3}$ e $(\Delta) \gamma-\mathrm{Al}_{2} \mathrm{O}_{3}$ contendo 5 mol\% $\mathrm{Mg} \ldots . .58$

Figura 4.15 - Difração de raios $\mathrm{X}$ da $\gamma-\mathrm{Al}_{2} \mathrm{O}_{3}$ e $\gamma-\mathrm{Al}_{2} \mathrm{O}_{3}$ contendo $\mathrm{Mg}$. No detalhe os picos referentes aos planos (220) e (222) são alterados com a introdução do aditivo.

Figura 4.16 - Calor de dissolução em função da área de superfície específica da $\gamma$ $\mathrm{Al}_{2} \mathrm{O}_{3}$ e $\gamma-\mathrm{Al}_{2} \mathrm{O}_{3}$ contendo $\mathrm{Mg}$ como aditivo. Neste resultado os dados para $\gamma-\mathrm{Al}_{2} \mathrm{O}_{3}$ são corrigidos para a fórmula $\mathrm{Al}_{8 / 3} \mathrm{O}_{4}$. 60

Figura 4.17 - Análise térmica diferencial (DTA) e áreas de superfície da $\mathrm{Al}_{2} \mathrm{O}_{3}$ contendo $\mathrm{Zr}$ como aditivo. As áreas de superfície específicas são referentes as amostras contendo ( $\Delta) 1 \mathrm{~mol} \%$ de $\mathrm{Zr}$ e (口) $2 \mathrm{~mol} \% \mathrm{Zr}$. O pico de DTA de maior temperatura é relativo à amostra contendo $2 \%$ Zr. No detalhe a derivada da curva de DTA da amostra contendo 1 $\mathrm{mol} \% \mathrm{Zr}$.

Figura 4.18 - Difração de raios $\mathrm{X}$ de amostras de $\gamma-\mathrm{Al}_{2} \mathrm{O}_{3}$ contendo $\mathrm{Zr}$ como aditivo e tratadas à $10{ }^{\circ} \mathrm{C}$ abaixo da temperatura de início da transformação de fase. 64

Figura 4.19 - Entalpia de adsorção de $\mathrm{H}_{2} \mathrm{O}$ na superfície do $\gamma-\mathrm{Al}_{2} \mathrm{O}_{3}$ e $\gamma-\mathrm{Al}_{2} \mathrm{O}_{3}$ contendo $\mathrm{Zr}$ em função da cobertura de $\mathrm{OH}$. (A) Entalpia de adsorção medida para $\gamma-\mathrm{Al}_{2} \mathrm{O}_{3}(\bullet)$ e $\gamma-\mathrm{Al}_{2} \mathrm{O}_{3}$ contendo $\mathrm{Zr}(\boldsymbol{\Delta})$. (B) Integral das medidas de calor de adsorção $(\bullet) \gamma-\mathrm{Al}_{2} \mathrm{O}_{3}$ e $(\boldsymbol{\Delta}) \gamma-\mathrm{Al}_{2} \mathrm{O}_{3}$ contendo $\mathrm{Zr}$. 
Figura 4.20 - Calor de dissolução em função da área de superfície específica do $\gamma$ $\mathrm{Al}_{2} \mathrm{O}_{3}$ contendo $\mathrm{Zr}$. A linha reta contínua mostra os valores extrapolados de $\gamma-\mathrm{Al}_{2} \mathrm{O}_{3}$ sem aditivos. 66

Figura 4.21 - Análise Térmica Diferencial (DTA) e áreas de superfície da $\mathrm{Al}_{2} \mathrm{O}_{3}$ contendo Mn como aditivo. As áreas de superfície específica são referentes a $(\Delta) 5$ mol\% Mn e (口) $10 \mathrm{~mol} \% \mathrm{Mn}$. No detalhe a derivada da curva de DTA para amostra contendo $10 \mathrm{~mol} \% \mathrm{Mn}$ para determinação da temperatura de início da reação. 73

Figura 4.22 - Entalpia de adsorção de $\mathrm{H}_{2} \mathrm{O}$ na superfície da $\gamma-\mathrm{Al}_{2} \mathrm{O}_{3} 5 \mathrm{~mol} \% \mathrm{Mn}$ em função da cobertura de OH. (A) Entalpia de adsorção medida da $\gamma$ $\mathrm{Al}_{2} \mathrm{O}_{3}$ pura $(\bullet)$ e $\gamma-\mathrm{Al}_{2} \mathrm{O}_{3}$ contendo $\mathrm{Mn}(\Delta)$. (B) Integral das medidas de calor de adsorção $(\bullet) \gamma-\mathrm{Al}_{2} \mathrm{O}_{3}$ pura e $(\Delta) \gamma-\mathrm{Al}_{2} \mathrm{O}_{3}$ contendo $\mathrm{Mn}$..... 76

Figura 4.23 - Difração de raios $\mathrm{X}$ de amostras de $\gamma-\mathrm{Al}_{2} \mathrm{O}_{3}$ contendo $\mathrm{Mn}$ como aditivo e tratadas à $10{ }^{\circ} \mathrm{C}$ da temperatura de início da transformação de fase. 78

Figura 4.24 - Difração de raios $\mathrm{X}$ de amostras de $\gamma-\mathrm{Al}_{2} \mathrm{O}_{3}$ e $\gamma-\mathrm{Al}_{2} \mathrm{O}_{3}$ contendo $5 \%$ Mn como aditivo e tratadas anteriormente à transformação de fase. Nos detalhes a diminuição dos picos de reflexão. 79 


\section{LISTA DE TABELAS}

Tabela 4.1A - Sumário dos resultados obtidos para as amostras de $\gamma-\mathrm{Al}_{2} \mathrm{O}_{3}$ sem aditivos com seus respectivos conteúdos de $\mathrm{H}_{2} \mathrm{O}$ e dados de calorimetria de dissolução de alta temperatura. Os erros relatados são desvios padrões. $\Delta H_{s o l}$ é o valor não corrigido do calor de dissolução. $\Delta H_{c l}$ é $\Delta H_{s o l}$ corrigido usando os dados de calor de adsorção de $\mathrm{H}_{2} \mathrm{O}$ reportado por McHale et al. $\Delta H_{c 2}$ é $\Delta H_{s o l}$ corrigido usando os dados de calor de adsorção de $\mathrm{H}_{2} \mathrm{O}$ obtidos neste trabalho. * $\mathrm{O}$ conteúdo de $\mathrm{H}_{2} \mathrm{O}$ adsorvido foi medido por perda de massa (gramas de $\mathrm{H}_{2} \mathrm{O}$ por grama de $\mathrm{Al}_{2} \mathrm{O}_{3}$ ) e transformado calculando o número de moléculas de $\mathrm{H}_{2} \mathrm{O}$ dividido pela área de superfície específica de cada amostra em $\mathrm{nm}^{2}$

Tabela 4.1B - Caracterização das amostras preparadas nas temperaturas indicadas na tabela. As fases foram identificadas como exclusivamente de $\gamma$ $\mathrm{Al}_{2} \mathrm{O}_{3}$ por difração de raios $\mathrm{X}$ e a área de superfície específica foi medida por adsorção de $\mathrm{N}_{2}(\mathrm{BET})$

Tabela 4.2A - Sumário dos resultados das análises de calorimetria de dissolução de alta temperatura e os conteúdos de $\mathrm{H}_{2} \mathrm{O}$ das amostras de $\mathrm{Al}_{2} \mathrm{O}_{3}$ contendo $\mathrm{Mg}$. As amostras de 5M1 a 5M6 são $\gamma-\mathrm{Al}_{2} \mathrm{O}_{3} 5 \mathrm{~mol} \% \mathrm{Mg}$, e $3 \mathrm{M} 1$ a $3 \mathrm{M} 3$ são $\gamma-\mathrm{Al}_{2} \mathrm{O}_{3} 3 \mathrm{~mol} \% \mathrm{Mg}$. $\Delta H_{\text {sol }}$ é o calor de dissolução e $\Delta H_{c 2}$ é o valor corrigido para o conteúdo $\mathrm{H}_{2} \mathrm{O}$. Os erros apresentados são desvios padrões. * $\mathrm{O}$ conteúdo de $\mathrm{H}_{2} \mathrm{O}$ adsorvido foi medido por perda de massa (gramas de $\mathrm{H}_{2} \mathrm{O}$ por grama de $\mathrm{Al}_{2} \mathrm{O}_{3}$ ) e transformado calculando o número de moléculas de $\mathrm{H}_{2} \mathrm{O}$ dividido pela área de superfície específica de cada amostra em $\mathrm{nm}^{2}$ 
Tabela 4.2B - Caracterização das amostras preparadas nas temperaturas indicadas na tabela. As fases foram identificadas como exclusivamente de $\gamma$ $\mathrm{Al}_{2} \mathrm{O}_{3}$ por difração de raios $\mathrm{X}$ e a área específica foi medida por adsorção de $\mathrm{N}_{2}(\mathrm{BET})$ 58

Tabela 4.3A - Sumário dos dados de calorimetria de dissolução de alta temperatura das amostras dopadas com $\mathrm{Zr}$ e dos resultados dos conteúdos de $\mathrm{H}_{2} \mathrm{O}$. As amostras de $1 \mathrm{Z1}$ a $1 \mathrm{Z} 4$ são $\gamma-\mathrm{Al}_{2} \mathrm{O}_{3}$ contendo $1 \mathrm{~mol} \% \mathrm{Zr}$, de $2 \mathrm{Z1}$ a $2 \mathrm{Z} 4$ são $\gamma-\mathrm{Al}_{2} \mathrm{O}_{3}$ contendo $2 \mathrm{~mol} \% \mathrm{Zr}$. $\Delta H_{\text {sol }}$ é o calor de dissolução e $\Delta H_{c 2}$ é o valor corrigido para o conteúdo $\mathrm{H}_{2} \mathrm{O}$. Os erros apresentados são desvios padrões. * $\mathrm{O}$ conteúdo de $\mathrm{H}_{2} \mathrm{O}$ adsorvido foi medido por perda de massa (gramas de $\mathrm{H}_{2} \mathrm{O}$ por grama de $\mathrm{Al}_{2} \mathrm{O}_{3}$ ) e transformado calculando o número de moléculas de $\mathrm{H}_{2} \mathrm{O}$ dividido pela área de superfície específica de cada amostra em

$\mathrm{nm}^{2}$

Tabela 4.3B - Áreas de superfície específica das amostras preparadas nas temperaturas indicadas na tabela. As fases foram identificadas como exclusivamente $\gamma-\mathrm{Al}_{2} \mathrm{O}_{3}$ por difração de raios $\mathrm{X}$ e as áreas de superfície foram medidas por adsorção de $\mathrm{N}_{2}(\mathrm{BET})$ 70

Tabela 4.4 - Resultados das medidas XPS das amostras de $\gamma-\mathrm{Al}_{2} \mathrm{O}_{3}$ contendo $\mathrm{Zr}$ (tratadas a $50{ }^{\circ} \mathrm{C}$ da temperatura de início da transformação de fase) mostrando a razão entre o número de mols calculado segundo a concentração de preparação das amostras e aquele obtido por XPS.

Tabela 4.5 - Resultados das medidas XPS das amostras de $\gamma-\mathrm{Al}_{2} \mathrm{O}_{3}$ contendo $\mathrm{Mn}$ mostrando a razão entre o número de mols calculado segundo a concentração de preparação das amostras e aquele obtido por XPS 


\title{
LISTA DE ABREVIATURAS E SIGLAS
}

\author{
XPS - X-rays Photoelectron Spectroscopy \\ DTA - Differential Thermal Analysis \\ BET - Brunauer-Emmett-Teller \\ DRX - Difração de Raios X \\ PMT-I - Equipamento de DTA construído durante o doutorado
}




\title{
LISTA DE SÍMBOLOS
}

\author{
T $\quad$ - Temperatura \\ $\mathrm{T}_{\mathrm{ci}} \quad-$ Temperatura crítica \\ $\Delta \mathrm{G}_{\mathrm{vol}}$ - Variação da Energia Livre de volume \\ $\Delta \mathrm{G}_{\text {sup }}$ - Variação da Energia Livre da superfície \\ $\Delta \mathrm{H} \quad$ - Variação de Entalpia \\ $\Delta \mathrm{S} \quad$ - Variação de Entropia \\ $\mathrm{A}_{\mathrm{s}} \quad$ - Área de superfície específica molar \\ r $\quad$ - Raio de uma partícula \\ $r_{c} \quad$ - Raio crítico para transformação de uma partícula \\ $\Delta \mathrm{r} \quad$ - Diferença de raio iônico em relação ao do $\mathrm{Al}^{3+}$
}




\section{Sumário}

1 REVISÃO BIBLIOGRÁFICA ................................................................1

1.1 Aplicações e estruturas da alumina ......................................................... 1

$1.2 \quad$ Síntese da alumina ................................................................................... 4

$1.3 \quad$ Transformações de fase da alumina ......................................................9

1.4 Aditivos para controle da transformação $\gamma-\alpha$........................................ 13

1.5 Calorimetria de dissolução de alta temperatura.................................... 19

2 OBJETIVOS …………...............................................................................24

3 PROCEDIMENTO EXPERIMENTAL ..................................................25

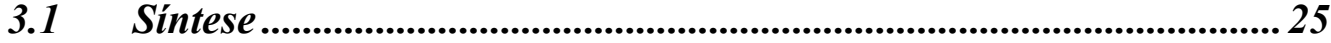

3.2 Análise da reação de transformação .....................................................26

3.3 Efeito da $\mathrm{H}_{2} \mathrm{O}$ na síntese e transformação de fase da alumina .......... 27

3.4 Calorimetria de dissolução de alta temperatura......................................29

3.5 Microcalorimetria de adsorção de $\mathrm{H}_{2} \mathrm{O}$................................................. 31

3.6 XPS (X-ray Photoelectron Spectroscopy) ............................................. 32

4 RESULTADOS E DISCUSSÃO …………...............................................34

4.1 Estudo do efeito da $\mathrm{H}_{2} \mathrm{O}$ na síntese da alumina..................................... 34

4.2 Estudo do efeito da $\mathrm{H}_{2} \mathrm{O}$ na transformação de fase $\gamma-\alpha$ da alumina 39

4.3 Estudo da transformação de fase da alumina sem aditivos................. 42

4.4 Efeito do ion $\mathrm{Mg}$ na transformação de fase $\gamma-\alpha \mathrm{da} \mathrm{Al}_{2} \mathrm{O}_{3} \ldots . . . . . . . . . . . .53$

4.5 Efeito do íon $\mathrm{Zr}$ na transformação de fase $\gamma-\alpha \mathrm{da} \mathrm{Al}_{2} \mathrm{O}_{3}$..................... 62

4.6 Deteç̧ão da segregação do íon $\mathrm{Zr}$ na superfície da $\gamma-\mathrm{Al}_{2} \mathrm{O}_{3} \ldots . . . . . . . . . .71$

4.7 Efeito do ion Mn na transformação de fase $\gamma-\alpha$ da $\mathrm{Al}_{2} \mathrm{O}_{3} \ldots \ldots . . . . . . . . . . .73$

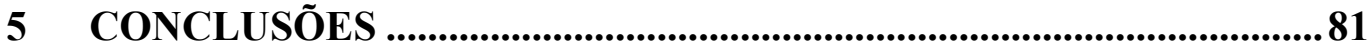

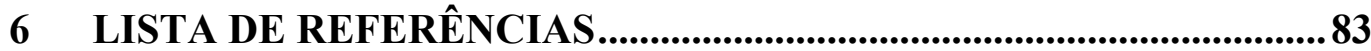




\section{REVISÃO BIBLIOGRÁFICA}

\subsection{Aplicações e estruturas da alumina}

O desenvolvimento de pesquisas em materiais cerâmicos à base de óxido de alumínio (alumina) tem se intensificado nas últimas décadas, principalmente motivado pelo baixo custo associado a esta matéria-prima e pelas suas interessantes características físicas e químicas . Grande parte destes estudos surge na tentativa de explorar ao máximo os potenciais da alumina que, embora possua uma vasta gama de aplicações, tem boa parcela de suas propriedades aproveitadas apenas parcialmente.

Apesar de suas relevantes propriedades mecânicas, notadamente alta resistência que lhe confere extenso uso, a primeira aplicação prática da alumina data do início século XX como isolante para velas de ignição e equipamentos de laboratório, seguida da aplicação no campo da eletrônica e engenharia mecânica . As aplicações eletrônicas estão principalmente relacionadas com sua propriedade de manter-se com alta resistividade elétrica a temperaturas relativamente elevadas. Aplicações em micro-circuitos, que surgem com problemas de transferência de calor, necessidade de precisão de dimensões e de superfícies extremamente lisas de substratos, são exemplos da perfeita aplicabilidade de compostos de alumina em elementos tecnológicos.

Atualmente novas aplicações despertam o interesse na utilização da alumina e seus derivados, sendo comum o uso como catalisadores e suportes destes [5,1,2] . No entanto, diferentes fases cristalinas da alumina estão relacionadas com as diversas propriedades e aplicações. Apesar da aparente simplicidade da fórmula $\mathrm{Al}_{2} \mathrm{O}_{3}$, a alumina tem sua natureza consideravelmente dependente de uma série de fatores, tais como sua forma cristalina, impurezas na estrutura e microestrutura. Estudos revelam a existência de pelo menos sete fases cristalográficas para alumina calcinada livre de água [7,2] : fases alfa, gama, delta, eta, teta, kappa, e chi.

Dentre estas fases, $\alpha-\mathrm{Al}_{2} \mathrm{O}_{3}$ é a mais comum e termodinamicamente estável, remetendo-se usualmente a esta fase quando referindo-se simplesmente a alumina. Esta se destaca pela elevada resistência ao calor e à corrosão e resistência 
mecânica. Aplicações estruturais para a alumina são limitadas quase inteiramente a esta fase, também chamada corundum ou, na sua forma monocristalina, safira, que usualmente apresenta íons $\mathrm{Fe}^{+2}$ e $\mathrm{Ti}^{+4}$ como impurezas na estrutura, conferindo-lhe uma coloração azul característica ou ainda rubi, que apresenta coloração avermelhada devido à presença de íons $\mathrm{Cr}^{3+}$. Sendo um sólido de forte característica iônica, suas ligações são fortes e, deste modo o ponto de fusão do material é bastante alto, estando por volta de $2054{ }^{\circ} \mathrm{C}$. Além disto, sua condutividade elétrica é bastante baixa, devido ao tipo de ligação.

Sua estrutura consiste de planos compactos de íons oxigênio empilhados na seqüência $A-B-A-B$ formando, portanto, um arranjo hexagonal compacto dos ânions . Os cátions são dispostos nos sítios octaédricos deste arranjo e formam outro tipo de planos empacotados, que são inseridos entre as camadas de oxigênio. No entanto, para manter neutralidade elétrica, apenas dois terços dos sítios octaédricos disponíveis são ocupados. A Figura 1.1 ilustra o empacotamento do $\mathrm{Al}$ e $O$ no plano basal.

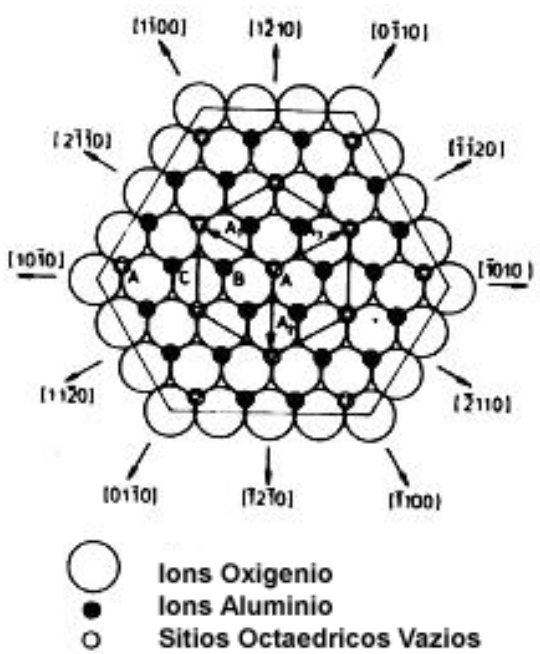

Figura 1.1 - Empacotamento dos íons de Al e O no plano basal. A camada superior de íons O não é mostrada. Vetores e direções da célula hexagonal estão indicados.

Desde que os sítios octaédricos não ocupados também formam um arranjo hexagonal regular, três tipos diferentes de planos de cátions podem ser definidos 
dependendo da posição das lacunas de cátion na camada, $a, b$ e $c$, e estão empilhados na seqüência $a-b-c-a-b-c$. Isto confere a completa seqüência de empilhamento para cátions e ânions $A-a-B-b-A-c-B-a-A-b-B-c-A$. Tal seqüência só é reproduzida após a sexta camada de oxigênio ou após a seqüência $a-b-c$ ser repetida duas vezes. A estrutura da $\alpha-\mathrm{Al}_{2} \mathrm{O}_{3}$ resulta nos números de coordenação 6 e 4 para o cátion e o ânion, respectivamente. Os raios iônicos para esta coordenação são $0,053 \mathrm{~nm}$ para $\mathrm{Al}^{3+}$ e $0,138 \mathrm{~nm}$ para $\mathrm{O}^{2-}$. Os parâmetros de rede para a $\mathrm{Al}_{2} \mathrm{O}_{3}$ são, portanto, $a=4,75 \AA$ e $c=13,00 \AA$.

Apesar da estabilidade da estrutura da $\alpha-\mathrm{Al}_{2} \mathrm{O}_{3}$, outras fases metaestáveis são comumente presentes à temperatura ambiente. Estas fases são chamadas aluminas de transição e são estabilizadas pelas suas baixas energias de superfície como será visto com mais detalhes posteriormente quando tratando das transformações de fase [5327]. A estrutura de transição mais comumente estudada na literatura é a $\gamma-\mathrm{Al}_{2} \mathrm{O}_{3}$, uma forma policristalina com alta área de superfície específica e propriedades estruturais e aplicações bastante diferenciadas da $\alpha-\mathrm{Al}_{2} \mathrm{O}_{2}$, estando estas principalmente relacionadas a catalisadores .

Embora amplamente utilizada, os dados disponíveis sobre a estrutura da $\gamma$ alumina ainda são bastante contraditórios. Grande parte da literatura estabelece a estrutura como tipo espinélio com defeito, sendo muito próxima da estrutura do espinélio $\mathrm{MgAl}_{2} \mathrm{O}_{4}[7,8,1]$. Este espinélio tem 24 cátions e 32 ânions numa célula unitária cúbica. Os íons oxigênio estão organizados de forma compacta, com os átomos de magnésio ocupando os sítios tetraédricos $\left(T_{d}\right)$ e os íons alumínio ocupando os sítios octaédricos $\left(O_{h}\right)$. Na $\gamma$-alumina, os íons $\mathrm{Al}^{3+}$ ocupam tanto posições catiônicas tetraédricas como octaédricas na estrutura cúbica compacta dos oxigênios [8] . No entanto, para satisfazer a estequiometria do óxido de alumínio, $2 \frac{2}{3}$ dos 24 sítios catiônicos devem ser lacunas. A fórmula da $\gamma$-alumina é, portanto usualmente descrita como $\square_{22 / 3} A l_{21 \frac{1}{3}} O_{32}$ (ou $\mathrm{Al}_{8 / 3} \mathrm{O}_{4}$ ), onde $\square$ significa uma lacuna . Quanto a distribuição das vacâncias sobre as duas sub-redes catiônicas, desde que o íon $\mathrm{Al}^{3+}$ em circunstancias normais favorece coordenação octaédrica, aproximadamente $75 \%$ dos cátions $\mathrm{Al}^{3+}$ devem ocupar sítios octaédricos, e as vacâncias catiônicas estariam preferencialmente confinadas nos sítios tetraédricos . 
Apesar desta última estrutura ser coerente com diversos resultados experimentais, algumas publicações têm apontado a presença de hidrogênio na composição da $\gamma$-alumina. Dowden [20] sugeriu que os prótons deveriam residir nas lacunas de cátions presentes na estrutura. A situação foi mais esclarecida após a proposta de que a sub-rede de oxigênio é sempre completa, mas falta uma fração de átomos de alumínio na estrutura, sendo compensada pela presença de $\mathrm{H}^{+}$[33] . Deste modo, foi proposta uma nova fórmula $\mathrm{H}_{3 m} \mathrm{Al}_{2-m} \mathrm{O}_{3}$, onde $m=2 n /(n+3)$, sendo $n$ o número de hidratação baseado em cálculos teóricos de densidade. Esta fórmula captura uma fascinante propriedade da $\gamma$-alumina, na qual ela se comporta como uma "esponja", mas com a peculiaridade de que a água absorvida é decomposta e restituída na superfície. Isto é, quando uma molécula de água chega à superfície ela é dissociada de modo que o íon $\mathrm{H}^{+}$entra na rede e o íon $\mathrm{O}^{2-}$ permanece na superfície. Íons de $\mathrm{Al}^{3+}$ imediatamente contra-migram para a superfície, onde recombinam com os novos íons de $\mathrm{O}^{2-}$ e estendem a matriz do cristal, sendo o processo reverso também possível. Este tipo de comportamento resulta da propriedade do sistema em manter a valência adequada sobre um certo intervalo estequiométrico, com diferentes quantidades de $\mathrm{H}^{+}$, ainda mantendo a estrutura espinélio [33].

Entretanto, sendo a presença de $\mathrm{H}^{+}$na estrutura ainda controversa e não existindo provas experimentais definitivas, neste trabalho será considerado o resultado apresentado por Zhou e Snyder que aponta pequenas quantidades de hidrogênio nas aluminas de transição, insuficientes para a formação de um espinélio de hidrogênio. A presença destas quantidades de $\mathrm{H}^{+}$poderia ser atribuída as diversas hidroxilas superficiais [23,11,8] que seriam também responsáveis pelos diferentes comportamentos catalíticos da $\gamma$-alumina aliados a presença de cátions $\mathrm{Al}^{3+}$ coordenados anormalmente na superfície .

\subsection{Síntese da alumina}

Atualmente, a principal matéria-prima para a produção de alumina é a bauxita, disponível em quantidades quase ilimitadas por todo o mundo . A bauxita é formada basicamente de óxido de alumínio hidratado contendo óxido de ferro e outras impurezas. O método mais econômico para o seu beneficiamento é baseado 
no processo Bayer, que foi desenvolvido para o refinamento do alumínio no século XIX . Neste processo, após o aquecimento da matéria-prima em soda cáustica e dissolução do alumínio, ocorre a separação de $\mathrm{Fe}_{2} \mathrm{O}_{3}, \mathrm{TiO}_{2}, \mathrm{SiO}_{2}$ e outros resíduos insolúveis. Segue então a precipitação do alumínio pela mudança do $\mathrm{pH}$ através da passagem de $\mathrm{CO}_{2}$ pela solução. Em seguida, o hidróxido formado é aquecido a $1200{ }^{\circ} \mathrm{C}$ para a formação de $\alpha-\mathrm{Al}_{2} \mathrm{O}_{3}$.

Dependendo do depósito de bauxita, hidratos de alumina intermediários no processo são produzidos com diferentes teores de água de cristalização. A estrutura passa por um certo número de transições durante a desidratação dos hidratos na fase de aquecimento. A seqüência de transições pela qual o hidrato deve passar dependerá de seu grau de hidratação. Segundo Stumpf e colaboradores [7] a seqüência de transformações de fase que ocorrem em atmosfera de ar seco ou durante a evaporação, quando hidratos de alumina são aquecidos sucessivamente a altas temperaturas, são:

- $\quad \alpha$-Trihidrato passa a $\alpha$-monohidrato, $\chi-, \gamma-, \kappa-, \theta-, \alpha$-alumina.

- $\quad \beta$-Trihidrato passa a $\alpha$-monohidrato, $\eta-, \theta$-, $\alpha$-alumina.

- $\quad \alpha$-Monohidrato passa a $\gamma-, \delta-, \theta-, \alpha$-alumina.

- $\quad \beta$-Monohidrato passa a $\alpha$-alumina.

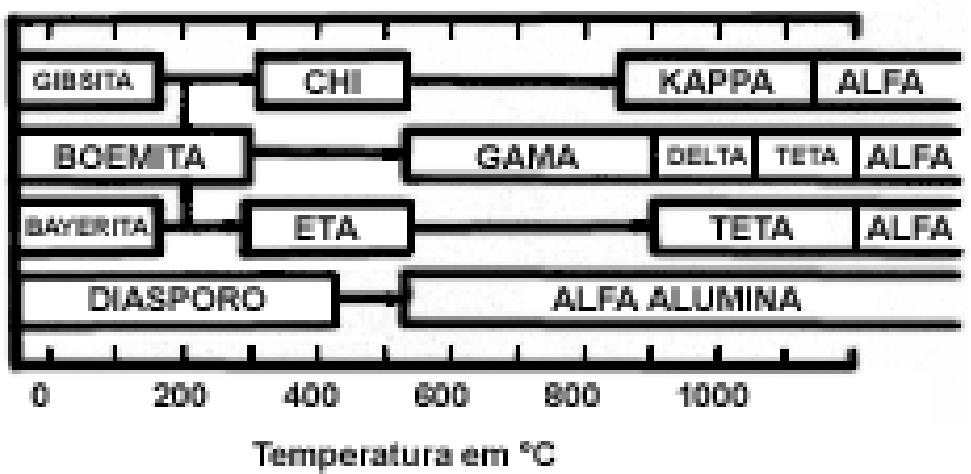

Figura 1.2 - Seqüência de desidratação dos hidratos de alumina [5] 
A Figura 1.2 mostra a seqüência de desidratação em função da temperatura. As temperaturas de transformação são, entretanto, dependentes da taxa de aquecimento, atmosfera, tamanho e pureza das partículas do hidrato.

Desde que K. J. Bayer desenvolveu o método em 1888, não houve mudanças essenciais no processo de refinamento. A alumina obtida tem um diâmetro de partícula que varia de 40 a $100 \mu \mathrm{m}$, sendo, normalmente, $\alpha$-alumina a principal forma cristalina. A alumina produzida desta forma possui em torno de $0,3 \% \mathrm{Na}_{2} \mathrm{O}$ e $0,01 \% \mathrm{SiO}_{2}$ como impurezas e $\mathrm{Al}_{2} \mathrm{O}_{2}$ com pureza de $99,6 \%$ ou mais pode ser obtida. Para muitas aplicações, como matéria-prima para cerâmicas, a alumina pode ser usada quantitativamente neste grau de pureza. No entanto, para aplicações que requerem alto grau de isolamento elétrico, tais como materiais eletrônicos e velas de ignição, alumina de baixo sódio, com menos de $0,1 \%$ de impurezas de $\mathrm{Na}_{2} \mathrm{O}$, é utilizada.

Nos últimos anos, alumina $3 \mathrm{~N}$ (pureza de $99,9 \%$ ou mais) tem sido obtida por um aperfeiçoamento do processo Bayer. Outros processos, além do Bayer, têm sido também aplicados na produção de alumina $4 \mathrm{~N}$ e $5 \mathrm{~N}$, gerando cristalitos de diâmetro variando de 0,2 a 1,0 $\mu \mathrm{m}$. Estes novos produtos têm atraído o interesse como materiais para monocristais de alumina e cerâmicas transparentes. Outros métodos de síntese incluem a pirólise de aluminato de amônia, nitratos e sulfatos de alumínio, hidrólise de compostos orgânicos de alumínio entre muitos outros $[9,3-4,1,4,8,12,2]$.

Atualmente, o método de produção de alumina a partir de um precursor polimérico [3,2], baseado na patente de Pechini [3330697,5], tem demonstrado bastante eficácia na preparação de pós com alta homogeneidade e reatividade química. Sua vantagem está principalmente ligada à nucleação múltipla e isolada durante a pirólise do polímero e a formação dos óxidos, bem como na facilidade da inclusão de dopantes, bastando para isto a utilização de soluções dos sais dos metais aditivos.

O método se baseia na formação de quelatos entre cátions dissolvidos em solução de um ácido hidroxi-carboxílico (ácido cítrico, por exemplo) com um poli(álcool hidroxílico). Nitratos são preferidos pela relativamente fácil eliminação durante a calcinação. Os nitratos e o ácido cítrico são misturados com 
um poli(álcool hidroxílico), podendo ser etileno glicol ou di-etileno glicol, e agitado enquanto aquecido a temperaturas de $70{ }^{\circ} \mathrm{C}$ a $110^{\circ} \mathrm{C}$ até solução completa dos componentes. Aquecimento a temperaturas moderadas $\left(120\right.$ a $\left.250{ }^{\circ} \mathrm{C}\right)$ causa assim uma reação de condensação entre o ácido cítrico e o etileno glicol com a formação de moléculas de $\mathrm{H}_{2} \mathrm{O}$ como sub-produto. Durante esse aquecimento moderado há poliesterificação e a maior parte do excesso de $\mathrm{H}_{2} \mathrm{O}$ é eliminado, resultando numa resina polimérica.

A idéia geral deste método é distribuir os átomos aleatoriamente pela estrutura do polímero. A calcinação da resina sob ar ou outros gases causa a quebra do polímero e a conseqüente estruturação a $400{ }^{\circ} \mathrm{C}$. Os cátions são então oxidados para formar os cristalitos das mistura dos óxidos de $500{ }^{\circ} \mathrm{C}$ a $900{ }^{\circ} \mathrm{C}$. O processo é bastante complexo e uma série de variáveis experimentais afetam o produto final [5]. Nessas variáveis contamos as impurezas incluídas nos precursores, bem como as condições de pirólise e calcinação. Isto inclui a atmosfera utilizada, que pode favorecer oxidações e outros processos químicos, e a velocidade e tempo de aquecimento, que podem beneficiar um determinado fator cinético ou estado termodinâmico.

Contudo, o processo baseado na patente de Pechini é potencialmente interessante, pois o único tipo de ânion presente no momento da oxidação pode ser também pirolisado. Ademais, a presença da água no momento da cristalização dos óxidos pode ser controlada, o que é um grande desafio quando tratando dos métodos de precipitação em soluções aquosas. Por esses motivos, a atividade da água e de diferentes cátions e ânions durante a cristalização dos óxidos é possível de ser verificada sob condições controladas [5] . Outra característica importante desse método no estudo da cristalização e do crescimento cristalino com relação aos aditivos é que a formação dos óxidos é independente de suas solubilidades. Deste modo, a preparação de óxidos com concentrações variadas e podendo conter diferentes cátions e ânions torna-se possível e com produtos bastante homogêneos e de estequiometria precisa e conhecida.

A presença de $\mathrm{H}_{2} \mathrm{O}$ na atmosfera de síntese e na transformação de fase da alumina tem implicação fundamental na morfologia e polimorfismo do óxido e na ação dos aditivos no controle da microestrutura [2,4,1-3,2]. Uma comparação do 
efeito da rota de síntese na atividade do íon Ti como aditivo na alumina mostrou claramente esta diferença. Utilizando o método de Pechini para síntese da alumina contendo $1 \%$ Ti foi observada a evolução de estrutura a partir da fase amorfa para fase $\kappa-\mathrm{Al}_{2} \mathrm{O}_{3}$. A mesma composição sintetizada tanto pelo método de sol-gel como por co-precipitação em solução aquosa, calcinada na mesma temperatura, mostrou uma evolução para a fase $\gamma-\mathrm{Al}_{2} \mathrm{O}_{3}$. Não foi proposta relação entre este fenômeno e o fato de que uma diferença marcante entre os métodos é que no método Pechini a presença de $\mathrm{H}_{2} \mathrm{O}$ é desprezível [5]. Entretanto, observando o efeito da $\mathrm{H}_{2} \mathrm{O}$ na cristalização da alumina a partir da boemita [2] e na cristalização da $\gamma-\mathrm{Al}_{2} \mathrm{O}_{3}$, pode-se derivar essa conclusão, fazendo necessário um controle do teor de $\mathrm{H}_{2} \mathrm{O}$ em todos os ensaios de síntese, o que é praticamente impossível quando tratando de co-precipitação em meio aquoso ou sol-gel.

O efeito da presença de água na atmosfera de transformação da alumina já foi alvo de alguns estudos encontrados na literatura. $\mathrm{O}$ efeito de $\mathrm{H}_{2} \mathrm{O}$ no sistema é descrito não apenas como diminuidor local da temperatura na superfície da partículas, que pode diminuir a velocidade de cristalização, mas também como também modificador de fluxos difusionais $[2,8,4]$. No entanto, sabe-se ainda que moléculas de $\mathrm{H}_{2} \mathrm{O}$ sobre a superfície da alumina podem diminuir significativamente as energias das interfaces [11], o que pode gerar alguns problemas experimentais principalmente quando o objetivo do estudo é uma avaliação sistemática do efeito de aditivos nas energias do sistema. Isto porque as moléculas de $\mathrm{H}_{2} \mathrm{O}$ afetam diferentemente as energias de superfície de diferentes fases [5327] , podendo induzir a formação de um determinado polimorfo durante a síntese e diminuindo, ou ainda aumentando, a temperatura de transformação entre eles.

Neste trabalho será avaliada a ação da água na cristalização e transformação de fase da alumina sintetizada pelo método Pechini, de modo a isolar a ação dos aditivos iônicos no sistema. Serão assim estudados pós de $\mathrm{Al}_{2} \mathrm{O}_{3}$ livre de aditivos e contendo Mn e Mg sintetizados em atmosfera úmida e seca. Em seguida será também avaliado o efeito da atmosfera durante a transformação de fase $\gamma-\alpha$ da alumina em particular. 


\subsection{Transformações de fase da alumina}

A transformação $\gamma$ - $\alpha$ tem sido alvo de intensos estudos nos últimos anos [7,2] . Esta transição mostra-se importante para sinterização e controle da microestrutura de cerâmicas de alumina. O interesse está principalmente relacionado ao controle da temperatura da transformação, o que pode levar ao beneficiamento da alumina no que se referente tanto as propriedades da $\gamma$-alumina quanto a $\alpha$-alumina. Com o aumento da temperatura de transformação, $\gamma$-alumina pode ser observada a temperaturas acima de $1290{ }^{\circ} \mathrm{C}$ [3] . Isto amplia o campo de utilização desta fase como catalisadores, principalmente com aplicações a temperaturas elevadas $\left(800-1200{ }^{\circ} \mathrm{C}\right)$, tal como catalisadores para jato propulsores, conversores de escapamento de automóveis e muitos sistemas práticos de combustão [5,1]. Com relação à fase alfa, altas temperaturas de transformação sempre resultam no coalescimento das partículas e formação de aglomerados fortes no pó. A presença destes aglomerados dificulta a sinterização e densificação do material e prejudicando suas propriedades mecânicas [5] .

Os primeiros estudos relativos aos mecanismos de transformação de fase $\gamma$ $\alpha$ consideram um controle cinético da reação, tratando-a como uma transformação termodinamicamente favorável baseando-se na estabilidade relativa da rede cristalina da $\alpha-\mathrm{Al}_{2} \mathrm{O}_{3}$. Assim, a transformação ocorreria pela nucleação e crescimento de colônias de $\alpha$-alumina $[3,10,12]$. Segundo Dynys e colaborador [9] , as seguintes observações sobre a microestrutura de alfa seriam relevantes no estudo da formação desta fase: (a) As colônias são monocristais; (b) Os cristais são porosos e têm uma microestrutura vermicular como resultado da diferença no volume específico entre a fase tratada e as fases de transição. Isto é, a porosidade se distribui como canais entre os núcleos de $\alpha$-alumina dendrítica, formando a microestrutura vermicular devido à necessidade das fases estarem diretamente em contato para que ocorra o transporte de massa (ex: por difusão superficial); (c) Um considerável coalescimento acompanha a transformação. Com o crescimento das colônias, uma determinada fração de porosidade é exigida num sólido com estrutura interconectada e com separações fixas de partículas. Este quadro torna razoável que o corpo assuma uma morfologia com pequenos gradientes de 
curvatura e uma área superficial minimizada alcançada pelo coalescimento. Este processo é limitado pelo transporte de massa; (d) O tamanho das partículas nas colônias é comum devido à elevada energia do processo de nucleação que provoca o crescimento das colônias em poucos núcleos.

Esta discussão, no entanto, desconsidera a ação da energia de superfície no sistema. De certo, para quaisquer materiais nanocristalinos, as elevadas áreas de superfície fazem com que esta última exerça uma influência significativa na estrutura e nas propriedades físico-químicas . Em particular para materiais que apresentam polimorfismo, o efeito da energia de superfície tem função fundamental na determinação da fase . Este é o caso para o titanato de bário [23], zirconia , hafnia $[3,10]$, titânia e, recentemente, para alumina $[5327,4]$. As baixas energias de superfície nestes compostos induzem mudanças na rede cristalina permitindo a presença de fases metaestáveis.

Sabe-se que a fase $\alpha-\mathrm{Al}_{2} \mathrm{O}_{3}$ é a fase termodinamicamente estável de partícula coalescidas de óxido de alumínio. No entanto, em condições normais de temperatura e pressão, a síntese de alumina usualmente resulta em $\gamma-\mathrm{Al}_{2} \mathrm{O}_{3}[12,3-$ 4] devido a elevada área de superfície específica e às suas baixas energias relativas. Blonski e Garofalini [1-2] através de simulações de dinâmica molecular de diversas superfícies de $\gamma-\mathrm{Al}_{2} \mathrm{O}_{3}$ e $\alpha-\mathrm{Al}_{2} \mathrm{O}_{3}$ determinaram que as energias de superfície de $\alpha-\mathrm{Al}_{2} \mathrm{O}_{3}$ eram consideravelmente maiores que as de $\gamma-\mathrm{Al}_{2} \mathrm{O}_{3}$, independentemente dos planos expostos. De acordo com seus dados, assumindo exposta a superfície de menor energia, $\gamma-\mathrm{Al}_{2} \mathrm{O}_{3}$ se tornaria o polimorfo energeticamente estável em relação ao $\alpha-\mathrm{Al}_{2} \mathrm{O}_{3}$ para áreas de superfície maiores que $\sim 125 \mathrm{~m}^{2} \mathrm{~g}^{-1}$ (Figura 1.3). A estabilidade termodinâmica, no entanto, seria ainda maior se considerada a entropia do sistema. Como resultado da presença de sitos tetraédricos e octaédricos na estrutura espinélio da $\gamma$-alumina, uma distribuição randômica dos ions $\mathrm{Al}^{3+}$ e lacunas pelos sítios gera uma diferença de entropia na transição. Essa entropia pode ser calculada assumindo a entropia do sistema sobrepor a entalpia na temperatura de fusão da alumina alfa $\left(2054{ }^{\circ} \mathrm{C}\right)$ [5327]. Deste modo, a entropia é cerca de $+5,7 \mathrm{~J} \mathrm{~K}^{-1} \mathrm{~mol}^{-1}$, o que implica no fato de que a $527{ }^{\circ} \mathrm{C} \gamma$-alumina pode ser termodinamicamente estável até áreas de superfície de apenas $75 \mathrm{~m}^{2} \mathrm{~g}^{-1}$ (Figura 1.3). Estes dados foram comprovados 
experimentalmente utilizando técnicas de microcalorimetria [5327,4], mostrando a real relevância de se considerar os efeitos da energia de superfície na estrutura do óxido de alumínio. Maiores detalhes da técnica utilizada para avaliação das energias de superfície serão apresentados posteriormente.

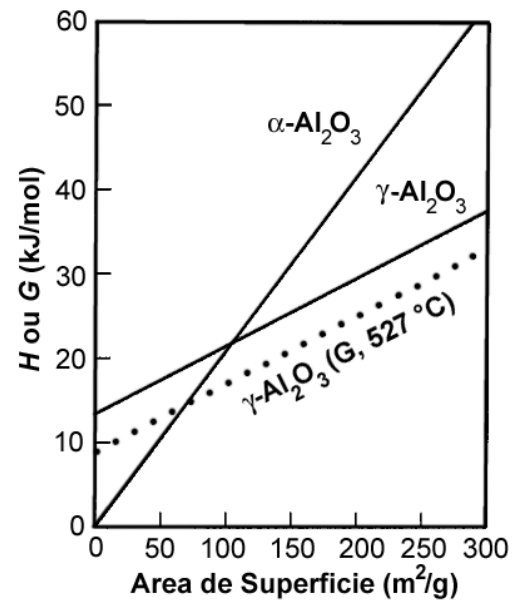

Figura 1.3 - Cálculo das entalpias de polimorfos de alumina relativa a corundum coalescida e baseadas nas energias de superfície calculadas por dinâmica molecular [1-2] .

Deduz-se dos dados apresentados na Figura 1.3 a presença de um tamanho crítico para a transição semelhante aquele observado para zircônia [4] . Isto é, sendo a energia livre de superfície da estrutura tetragonal da zircônia menor que da estrutura monoclínica, se um monocristal coalescido é sujeito a um processo de subdivisão, resultará uma competição entre a mudança na energia livre da rede cristalina e a energia de superfície associada à transformação. Em algum ponto, ao passo que a razão de átomos de superfície e da rede se aproxima de um valor crítico, a forma tetragonal será estável mesmo em uma temperatura $\mathrm{T}<<\mathrm{T}_{\mathrm{ci}}$, onde $\mathrm{T}_{\mathrm{ci}}$ significa a temperatura de transição de um cristal infinito. Pode-se quantificar a discussão equacionando a variação de energia livre de um monocristal e igualando a zero no valor crítico de partícula. Para um cristal esférico de raio r:

$$
\Delta \mathrm{G}_{0}=(4 / 3) \pi \mathrm{r}_{\mathrm{c}}^{3} \Delta \mathrm{G}_{\mathrm{vol}}+4 \pi \mathrm{r}_{\mathrm{c}}^{2} \Delta \mathrm{G}_{\mathrm{sup}}=0
$$


onde $\Delta \mathrm{G}_{\mathrm{vol}}$ e $\Delta \mathrm{G}_{\text {sup }}$ se referem às mudanças na energia livre por unidade de volume e por unidade de área, respectivamente, associadas à transição. $r_{c}$ denota $o$ valor do raio crítico da partícula necessário para transição. A Equação (1.1) demonstra a dependência do tamanho crítico, tanto nas energias das redes cristalinas como nas energias de superfície, sejam elas da fase inicial ou da fase após a transformação. Note que apesar da discussão ser baseada inicialmente na consideração de partículas esféricas, a idéias de um balanço energético entre a rede cristalina e a energia de superfície deve ser válida mesmo para cristais planares como aqueles observados para $\gamma-\mathrm{Al}_{2} \mathrm{O}_{3}$ produzida pela decomposição da boemita [4] . Desta forma, a diminuição da variação entre as energias das redes cristalinas das fases envolvidas na transição leva a um aumento do tamanho crítico. Por outro lado, a diminuição da variação das energias de superfície ocasiona uma diminuição do raio crítico. Nos dois casos as modificações de composição química devem influenciar de forma determinante a transição. Isto porque a formação de solução sólida é relacionada a diminuição da energia da rede, enquanto a segregação de um aditivo ou a adsorção de uma espécie química à superfície leva à diminuição da energia de superfície $[5,2,24]$.

As mudanças de energia podem ser alteradas então pela presença de íons aditivos ao sistema [1], emergindo assim como uma interessante ferramenta para controle termodinâmico do processo de transformação de fase e que não fora explorada com detalhes como mostra a literatura.

Neste ponto é preciso ter em mente que a solubilidade de um determinado aditivo pode ser bastante diferente para as duas fases envolvidas na transição, e ao mesmo tempo os efeitos de excesso de superfície podem ser muito particulares para cada fase envolvida na transformação com seu respectivo aditivo. Um aditivo que forma solução sólida em uma fase pode não ser solúvel após a transformação, ao mesmo tempo em que um aditivo que segrega na superfície de uma fase pode não segregar após a transformação. Pode-se considerar, contudo, que a fase estável a menores temperaturas, e que tem maiores áreas de superfície especifica, seja mais suscetível às variações de energia de superfície que aquelas de alta temperatura. 
Assim como para a zircônia, as diferenças marcantes nas estruturas e superfícies das fases da alumina sugerem a aplicabilidade do modelo também a este sistema. Apesar da coerência dos resultados sugerindo um tamanho crítico de partícula relacionado às energias do sistema, alguns autores consideram que o tamanho crítico é apenas um resultado do tempo de incubação necessário para a formação de núcleos de $\alpha-\mathrm{Al}_{2} \mathrm{O}_{3}$. Desta maneira, a transformação ocorreria por mecanismos de difusão clássicos [7] . As medidas diretas de energia de superfície no entanto enfraquecem tal hipótese [5327] .

A presença de um tamanho crítico conduz a dúvidas nos mecanismos cinéticos propostos e amplamente utilizados na explicação e no controle da transformação de fase da alumina. Não há evidências suficientes para a afirmação de tratar-se de uma transformação martensítica, onde há reorientação cooperativa das ligações da $\gamma-\mathrm{Al}_{2} \mathrm{O}_{3}$ durante o processo assim como para a zircônia $[10,3]$. Porém, a transformação não pode ser considerada puramente como nucleação e crescimento, desde que isso implicaria a formação de partículas de $\alpha-\mathrm{Al}_{2} \mathrm{O}_{3}$ com tamanhos menores que o tamanho crítico de partícula, o que não pôde ser observado. Deste modo, sugere-se que haja uma combinação destes mecanismos, onde a reorientação das ligações com migração de curto alcance dá origem a núcleos de alfa nas partículas de gama, seguindo um rápido crescimento [2] .

Vale notar que, além da dependência termodinâmica da transformação de fase, a formação de solução sólida em óxidos acarreta também um desequilíbrio de cargas e a formação de defeitos puntiformes que modificam os coeficientes de difusão. Os possíveis efeitos cinéticos ocasionados a este fenômeno podem afetar a temperatura de transição de fase, permitindo que as partículas alcancem um tamanho crítico mais rapidamente a uma dada temperatura ou ainda a temperaturas menores, contudo o raio crítico será sempre determinado pelos fatores termodinâmicos.

\subsection{Aditivos para controle da transformação $\gamma-\alpha$}

Um dos meios mais eficazes para o controle da temperatura de transformação da alumina é o uso de aditivos. Estes aditivos são usualmente íons incorporados na estrutura que promovem tanto o aumento quanto a diminuição da 
temperatura de transformação de fase. Os mecanismos pelos quais esses aditivos agem ainda são bastante controversos, mas de maneira geral considera-se tão somente a ação destes nos mecanismos de difusão envolvidos no processo. A seguir apresenta-se uma revisão dos trabalhos mais relevantes considerando a presença de aditivos para a transformação $\gamma-\alpha$ da alumina.

Um aditivo comum utilizado na síntese da alumina com efeito na redução da temperatura de transição $\gamma$ - $\alpha$ é o nitrato de amônia [4]. Durante a calcinação da alumina, o nitrato é decomposto a $320^{\circ} \mathrm{C}$ (formando óxidos de nitrogênio e ácido nítrico) e uma grande quantidade de energia é liberada. Esta energia pode (1) induzir uma quantidade considerável de defeitos na matriz da alumina de transição. Quando destruídos, parcialmente ou totalmente, estes defeitos liberam energia que podem contribuir para a superar a energia de ativação para a nucleação da $\alpha$-alumina. (2) Pode induzir a conversão de certa quantidade de alumina de transição para alfa numa temperatura relativamente baixa e, portanto o material contendo o nitrato sempre terá uma pequena quantidade extra de núcleos de $\alpha$-alumina, funcionando como sementes de nucleação. (3) Esta energia pode ainda destruir o arranjo normal dos átomos e produzir uma desordem estrutural nas aluminas de transição, o que contribui para a redução na energia de ativação da transformação de fase e a energia de nucleação da fase alfa.

Muitos outros estudos têm sido realizados na avaliação de aditivos para a modificação da temperatura de transformação $\gamma-\alpha$ da alumina $[8,8,3,5,4]$. Dentre os óxidos estudados, o $\mathrm{ZrO}_{2}$ mostrou-se o maior retardador da reação juntamente com o $\mathrm{B}_{2} \mathrm{O}_{3}$ e o $\mathrm{SiO}_{2}$ com menor efeito. $\mathrm{ZnO}_{2}$ mostrou-se um bom aditivo de aceleração. De acordo com Xue [8] , os aditivos de aceleração de reação (Zn, $\mathrm{Ti}+\mathrm{Cu}, \mathrm{Ti}+\mathrm{Mn}, \mathrm{Cu}, \mathrm{V}$, e $\mathrm{Li}$ ) devem formar uma fase líquida a temperaturas menores que a temperatura normal de transformação. O processo deve ser assim acelerado pela fase líquida que permite um aumento no transporte de massa via mecanismo de solução-precipitação, desde que ocorria por nucleação e crescimento. O mecanismo geral pelo qual os aditivos de retardo agem não foi especificado com clareza por Xue [8], e explicações isoladas para cada agente foram dadas. Por exemplo, no caso do $\mathrm{ZrO}_{2}$, trabalhos apontam que precipitados de $\mathrm{ZrO}_{2}$ podem suprimir a interface de reação da alumina no transporte e na 
sinterização e o mesmo mecanismo pode estar atuando na supressão da transformação.

De outras publicações, $\mathrm{Ba}^{2+}, \mathrm{La}^{3+}$ e $\mathrm{Si}^{4+}$ são reportados como retardadores

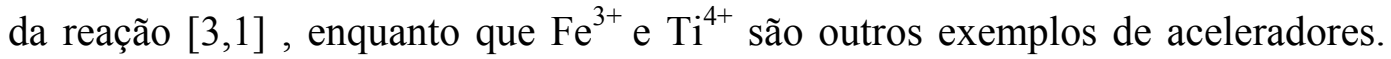
Um estudo sistemático foi desenvolvido avaliando o efeito de cátions divalentes como aditivos para a transição de fase e tentando racionalizar o efeito em função do raio dos íons [4]. Neste estudo diversos cátions foram impregnados na superfície utilizando-se soluções apropriadas dos nitratos, mediante mistura numa suspensão aquosa de $\gamma-\mathrm{Al}_{2} \mathrm{O}_{3}$ e seguida da precipitação. Os aditivos foram classificados em três grupos baseando-se nos dados de análise térmica e área de superfície específica: (1) aditivos aceleradores $\left(\mathrm{Cu}^{2+} \mathrm{e} \mathrm{Mn}^{2+}\right),(2)$ aditivos com pouco ou nenhum efeito $\left(\mathrm{Co}^{2+}, \mathrm{Ni}^{2+}, \mathrm{Mg}^{2+}\right.$ e $\left.\mathrm{Zn}^{2+}\right)$, e (3) aditivos retardadores $\left(\mathrm{Ca}^{2+}, \mathrm{Sr}^{2+}, \mathrm{e} \mathrm{Ba}^{2+}\right)$. O efeito dos elementos do grupo (2) apresentou correlação com a diferença entre o raio iônico do $\mathrm{Al}^{3+}$ e do íon teste $(\Delta r)$, sendo que a temperatura de transição aumentava linearmente com $\Delta r$. Acredita-se que os elementos do grupo (2) são inicialmente incorporados pela matriz de $\gamma-\mathrm{Al}_{2} \mathrm{O}_{3}$; e deste modo, quanto maior o raio iônico mais efetiva a supressão da difusão do $\mathrm{Al}^{3+}$ e $\mathrm{O}^{2-}$ na rede diminuindo o crescimento de grão da $\gamma$-alumina e retardando a transformação. Os íons do grupo (1) não seguiram o padrão em função do raio, sendo dadas explicações paralelas para cada um deles. Acredita-se que o efeito de aceleração do $\mathrm{Mn}^{2+}$ esteja relacionado com a formação de grãos de $\mathrm{Mn}_{2} \mathrm{O}_{3}$ e $\mathrm{MnAl}_{2} \mathrm{O}_{4}$ que funcionariam como sítios de nucleação heterogêneos. $\mathrm{O}$ efeito do $\mathrm{Cu}^{2+}$ pode estar relacionado com uma fase líquida presente numa temperatura eutética em $\mathrm{Cu}_{2} \mathrm{O}-\mathrm{CuO}-\mathrm{Al}_{2} \mathrm{O}_{3}$ derivada da presença inicial de $\mathrm{CuAl}_{2} \mathrm{O}_{3}$. Sem a formação de óxidos secundários, os elementos do grupo (2) mostram pouco efeito na temperatura de transição em relação ao grupo (1). $\mathrm{O} \quad \mathrm{Sr}^{2+} \mathrm{e}$ demais componentes do grupo (3) formaram como o grupo (1) estruturas do tipo $\mathrm{MAl}_{2} \mathrm{O}_{3}$, mas sendo que estes aluminatos não devem agir como núcleos heterogêneos como os elementos do grupo (1). Contudo, o mecanismo pelo qual eles agem na transição é ainda incerto.

Trabalho semelhante foi publicado com o intuito de avaliar diferentes cátions monovalentes [5]. Todos os aditivos estudados retardaram a temperatura 
de transição e seu efeito segue a seqüência de raios iônicos dos cátions: $\mathrm{Li}^{+}<\mathrm{Na}^{+}$ $<\mathrm{K}^{+}<\mathrm{Rb}^{+}<\mathrm{Cs}^{+}$. A fase $\beta-\mathrm{Al}_{2} \mathrm{O}_{3}$ foi identificada devido à reação dos aditivos com a alumina na região próxima a temperatura de transição de fase para todos os cátions, exceto para $\mathrm{o} \mathrm{Li}^{+}$. $\mathrm{O}$ mecanismo proposto é a supressão da difusão do $\mathrm{Al}^{3+}$ nos grãos através da formação de uma camada amorfa ou uma barreira de $\beta$ $\mathrm{Al}_{2} \mathrm{O}_{3}$.

Abrangendo de um outro enfoque, grandes diferenças no efeito da adição de metais $3 d$ na transição da fase $\gamma-\alpha$ são apontadas na literatura [7]. Bye e Simpkin [8,2] discutiram em detalhes a diferença entre os efeitos do $\mathrm{Fe}$ e $\mathrm{Cr}$, acelerador e retardador de transição, respectivamente. Sugere-se que o íon $\mathrm{Cr}^{6+}$ deve ocupar sítios tetragonais nas camadas empacotadas dos íons $\mathrm{O}^{2-}$ e esta substituição poderia explicar a inibição da formação de $\alpha$-alumina. De acordo com sua discussão, pequenos íons seriam capazes de ocupar sítios tetragonais da estrutura espinélio e prevenir o rearranjo estrutural. No entanto, o raio iônico não parece ser um fator crítico para explicar a influência na formação da fase alfa, desde que tanto íons grandes como o $\mathrm{Mn}^{2+}$ (raio iônico $=0,080 \mathrm{~nm}$, quanto pequenos como o $\mathrm{Fe}^{3+}$ ( raio iônico $=0,063 \mathrm{~nm}$ ) têm efeitos de aceleração comparáveis. Propõe-se assim em outro estudo [5] a existência de efeitos superficiais, principalmente relacionados com o controle da difusão e a formação dos cristalitos referentes ao rearranjo durante a transição de fase da $\gamma-\mathrm{Al}_{2} \mathrm{O}_{3}$. No entanto, não há relato de uma correlação com o tipo de íon aditivo. Outros trabalhos foram ainda publicados analisando-se a interferência de terras-raras na transição para alumina corundum [5,1,1-2], mas nenhuma nova explicação do fenômeno foi proposta.

A consideração vista de um único ponto de vista baseada na cinética de cristalização e descrita como fator principal para a ação dos aditivos parece, no entanto, ser incompleta em se considerando as dependências da transformação nas energias do sistema. Isto é, sendo a transformação dependente de um tamanho critico [4,8,7] e relacionada com as energias de superfície e rede cristalina [5327] , a presença dos aditivos pode certamente influenciar as energias modificando a temperatura da transformação. Um elemento solubilizado na rede da alumina de transição poderia modificar a entalpia da rede, tornando-a mais ou menos estável e 
alterando a temperatura de transformação. A presença de íons segregados na superfície também pode ser relacionada com diminuição da energia de superfície $[5,9,15,1-4]$, o que influenciaria o tamanho crítico e portanto a temperatura final da transformação. Esta hipótese é o objeto principal deste trabalho que visa ampliar a ótica dos possíveis mecanismos pelos quais os aditivos agem na transformação de fase da alumina, viabilizando assim um controle mais eficiente da reação.

Mediante à revisão bibliográfica prévia foram escolhidos os íons $\mathrm{Mn}, \mathrm{Mg} \mathrm{e}$ $\mathrm{Zr}$ como representantes dos aditivos causadores de diminuição, pouco aumento e aumento representativo na temperatura de transição da alumina, respectivamente [4] . O efeito acelerador do Mn já foi verificado por diversos trabalhos, sendo que a temperatura de início de cristalização da $\alpha-\mathrm{Al}_{2} \mathrm{O}_{3}$ decrescida a $700{ }^{\circ} \mathrm{C}$ com a adição de $7 \%$ em mol de óxido de manganês [2,3,4]. A explicação para o fenômeno é controversa e sendo por vezes relacionada com a formação de grãos de $\mathrm{Mn}_{2} \mathrm{O}_{3}$ e $\mathrm{MnAl}_{2} \mathrm{O}_{4}$ que funcionariam como sítios de nucleação heterogêneos [4] . No entanto, outro trabalho afirma que, assim como em estudos de dopantes para $\mathrm{SnO}_{2}$, durante a homogeneização dos íons precursores há segregação do aditivo na superfície do pó, sem a formação de fase secundária [6] . Esta fase seria formada apenas num excesso de concentração de dopantes. O íon $\mathrm{Mg}$ é geralmente descrito com efeito pouco pronunciado de retardo da transformação, sendo atribuído a um bloqueio da difusão na rede cristalina da $\gamma-\mathrm{Al}_{2} \mathrm{O}_{3}$ devido à solubilização [4] . Isto é, a presença do íon na rede associada ao seu elevado raio iônico diminui os fluxos de matéria pela rede, aumentando a temperatura necessária para a transformação. A explicação do efeito inibidor pronunciado do $\mathrm{Zr}$ ainda é incerta, mas há indícios de que precipitados de $\mathrm{ZrO}_{2}$ suprimem reações interfaciais da alumina na sinterização. Xue e colaboradores [8] sugerem que efeito semelhante deve inibir a transformação de fase, no entanto não são apresentadas comprovações experimentais para tal argumentação. Outro trabalho sugere que o íon induz modificações estruturais no sistema pela solubilização na rede cristalina, tornado a estrutura mais compacta, mas novamente poucas evidências são apresentadas [3] . 
Portanto neste trabalho toma-se como hipótese que os íons aditivos agem nas energias de volume ou de superfície da alumina modificando a temperatura de transformação pela termodinâmica do sistema, ademais aos fatores cinéticos. Isto é, a ação de cada aditivo estará relacionada a sua localização na estrutura do sistema. Quando adicionados durante a síntese, íons aditivos podem seguir três caminhos básicos: (a) difundir na rede cristalina, formando uma nova fase cristalográfica ou solução sólida com o material matriz; (b) migrar para a superfície das partículas (segregação superficial ou excesso de superfície); ou (c) nuclear uma segunda fase. Em verdade não há uma rígida separação entre esses caminhos durante a síntese, podendo dois ou mais deles estar ocorrendo simultaneamente. Entretanto, cada posição do aditivo leva a mudanças distintas na energia livre total do sistema. O local de acomodação do aditivo será assim determinado por um balanço energético entre esses fenômenos. A configuração final observada, considerando os sistemas em equilíbrio termodinâmico, será portanto interpretada como a distribuição de menor energia. Esta distribuição estará intimamente ligada à transformação de fase pelas energias das componentes do sistema. Um excesso de superfície de um aditivo nas partículas anteriores à transformação, por exemplo, estará relacionado a uma diminuição da energia de superfície [5], podendo estabilizar a estrutura e postergando a temperatura de transformação.

Pós à base de alumina contento diferentes quantidades de aditivos foram preparados pelo método dos precursores poliméricos [3330697] e submetidos a ensaios para estudo da transformação de fase na tentativa de se provar a hipótese de que efeitos relacionados à superfície podem ser determinantes na temperatura de transição de fase. A temperatura de transformação foi determinada por Análise Térmica Diferencial (DTA) e amostras foram preparadas em temperaturas próximas à transformação para avaliação das energias do sistema e dos tamanhos críticos por medidas de área de superfície específica por adsorção de nitrogênio (método BET). As energias de rede e de superfície das amostras foram medidas por calorimetria de dissolução de alta temperatura [1-2] . Os detalhes desta técnica são apresentados no parágrafo a seguir. 


\subsection{Calorimetria de dissolução de alta temperatura}

A calorimetria de dissolução de óxidos a elevadas temperaturas é comumente utilizada para determinação de entalpias de formação, entalpias de transformação de fase e reações de ordem-desordem. A utilização em medição de energias de superfície foi primeiramente sugerida por Navrotsky e colaboradores . As medidas são realizadas em um microcalorímetro gêmeo do tipo Tian-Calvet utilizando borato de chumbo fundido como o solvente do calorímetro. Detalhes técnicos do calorímetro são apresentados na seção experimental. O calor de dissolução de mergulho (drop solution) é medido mergulhando a amostra desde a temperatura ambiente ao solvente a $700{ }^{\circ} \mathrm{C}$. Assim como na calorimetria de dissolução aquosa, uma séria de amostras bem caracterizadas e de mesma estrutura, mas com diferentes áreas de superfície específica são necessárias para a medição da entalpia de superfície de um dado composto. No entanto, é usualmente impossível prevenir a adsorção de água nas superfícies de nanopartículas e correções envolvendo o conteúdo de água devem ser feitas através de ciclos termodinâmicos [11-12] .

McHale e colaboradores [5327,4] relataram o uso da calorimetria de dissolução de alta temperatura na alumina sem aditivos com o objetivo de medir estas energias e as estabilidades relativas das nanofases em função da área de superfície específica e da cobertura de $\mathrm{H}_{2} \mathrm{O}$ adsorvido [5327,4] . A estratégia inicial baseou-se na obtenção de informação direta sobre a estabilidade relativa pela comparação dos ensaios calorimétricos das amostras hidratadas de áreas de superfície similares. Se a diferença de entalpia entre as fases gama e alfa de áreas de superfície semelhantes diminui com o aumento das áreas, isto implicaria uma menor energia livre de superfície para gama alumina. No entanto, nos primeiro ensaios foi observada uma diferença constante, não aparecendo evidência alguma para uma diferença significativa na energia de superfície entre os polimorfos hidratados. Isto é facilmente explicável considerando as moléculas de $\mathrm{H}_{2} \mathrm{O}$ adsorvidos "curando" os defeitos de superfície ao se ligar aos íons de coordenação incompleta [5327]. Este resultado inicial vai contra a diferença esperada nas energias de superfície anidras, devendo ser corrigido pelo efeito de calor devido a $\mathrm{H}_{2} \mathrm{O}$ adsorvido. 
Dois tipos de adsorção de $\mathrm{H}_{2} \mathrm{O}$ ocorrem na superfície da $\mathrm{Al}_{2} \mathrm{O}_{3}$. O primeiro tipo é fortemente ligado quimicamente, existindo como íons hidroxila ligados a $\mathrm{Al}^{3+}$ em várias configurações. Moléculas de $\mathrm{H}_{2} \mathrm{O}$ quimissorvida (por pontes de hidrogênio) também podem existir . Camadas adicionais de $\mathrm{H}_{2} \mathrm{O}$ fisicamente adsorvidas podem estar presentes dependendo da temperatura e da pressão parcial de $\mathrm{H}_{2} \mathrm{O}$. $\mathrm{O}$ calor diferencial de adsorção para estas moléculas fisicamente adsorvidas é da ordem da entalpia de condensação de $\mathrm{H}_{2} \mathrm{O}$, mas o calor para moléculas de $\mathrm{H}_{2} \mathrm{O}$ quimissorvidas deve ser significativamente maior.

Um gráfico de entalpia de solução de mergulho (drop solution) versus fração molar de $\mathrm{H}_{2} \mathrm{O}$ pode determinar a entalpia de adsorção de moléculas fisicamente adsorvidas e suporta o uso de $70,09 \mathrm{~kJ} \mathrm{~mol}^{-1}$ para $\mathrm{H}_{2} \mathrm{O}$ adsorvido na superfície da alumina [4] . Para $\mathrm{H}_{2} \mathrm{O}$ quimicamente adsorvido, no entanto, é necessário um estudo mais detalhado. Neste caso, os calores de adsorção química de $\mathrm{H}_{2} \mathrm{O}$ de duas amostras de $\gamma-\mathrm{Al}_{2} \mathrm{O}_{3}$ e duas de $\alpha-\mathrm{Al}_{2} \mathrm{O}_{3}$ foram medidos num microcalorímetro do tipo Calvet. Cerca de $100 \mathrm{mg}$ de alumina foram termicamente ativadas sob vácuo. A temperatura foi aumentada até $750{ }^{\circ} \mathrm{C}$ a $2{ }^{\circ} \mathrm{C}$ $\min ^{-1}$, mantida ali por 2 horas e resfriada até a temperatura de adsorção de $25^{\circ} \mathrm{C}$. A amostra foi então exposta a sucessivas doses de vapor de $\mathrm{H}_{2} \mathrm{O}$. A pressão residual foi aumentada de $6,67 \mathrm{mPa}$ para $66,7 \mathrm{~Pa}$ em 15 a 20 passos. O calor liberado e o volume de $\mathrm{H}_{2} \mathrm{O}$ adsorvido foi medido a cada passo. A área de superfície específica e o conteúdo residual de $\mathrm{H}_{2} \mathrm{O}$ e a pureza das fases foram medidos após as amostras serem submetidas ao procedimento de degaseificação apresentado acima. A análise termogravimétrica (TG) revelou que uma média de $2,6 \mathrm{OH} \mathrm{nm}{ }^{-2}$ não fora removido sob as condições de degaseificação. O resultado deste ensaio é apresentado na Figura 1.4. $\mathrm{O}$ calor diferencial de adsorção de $\mathrm{H}_{2} \mathrm{O}$ em $\gamma-\mathrm{Al}_{2} \mathrm{O}_{3}$ decresce em função logarítmica com o aumento da cobertura. Em contraste, o calor diferencial de adsorção de $\mathrm{H}_{2} \mathrm{O}$ em $\alpha-\mathrm{Al}_{2} \mathrm{O}_{3}$ não mostra decaimento logarítmico e decresce menos rapidamente com o aumento da cobertura. Os primeiros $10 \mathrm{OH} \mathrm{nm}{ }^{-2}$ adsorvidos a superfície da alumina alfa produzem calores de adsorção acima de $-150 \mathrm{~kJ} \mathrm{~mol}^{-1}$, no entanto, apenas $5 \mathrm{OH}$ $\mathrm{nm}^{-2}$ excedem este valor em $\gamma-\mathrm{Al}_{2} \mathrm{O}_{3}$. Esta diferença indica um maior número de sítios de alta energia em $\alpha-\mathrm{Al}_{2} \mathrm{O}_{3}$ por unidade de área que são "relaxados" pelas 
hidroxilas mais fortemente ligadas quimicamente. Esta observação já evidencia que a energia de superfície de $\alpha-\mathrm{Al}_{2} \mathrm{O}_{3}$ é maior que a de $\gamma-\mathrm{Al}_{2} \mathrm{O}_{3}$ como esperado por cálculos de dinâmica molecular [1-2,5327] .

Assumindo que o calor de dessorção é a contribuição negativa do calor de adsorção, estes dados podem então ser utilizados para a correção da $\mathrm{H}_{2} \mathrm{O}$ quimicamente adsorvida nos calores de dissolução. Isto é, o efeito calorimétrico total medido foi uma combinação do conteúdo térmico (heat content), calor resultante da remoção de $\mathrm{H}_{2} \mathrm{O}$ e calor de dissolução do $\mathrm{Al}_{2} \mathrm{O}_{3}$. A reação é representada pela reação (1.2), onde x é a fração molar de $\mathrm{H}_{2} \mathrm{O}$ adsorvido e $\mathrm{A}_{\mathrm{s}}$ é a área de superfície específica. A diferença de entalpia à temperatura ambiente entre as nanofases anidras e corundum coalescida pode ser obtida por um ciclo termoquímico:

$\alpha$ ou $\gamma-\mathrm{Al}_{2} \mathrm{O}_{3}\left(\mathrm{~A}_{\mathrm{s}}, 25^{\circ} \mathrm{C}\right)+\mathrm{x} \mathrm{H}_{2} \mathrm{O}$ (absorvido em $\left.\mathrm{Al}_{2} \mathrm{O}_{3}, 25^{\circ} \mathrm{C}\right) \rightarrow$

$\rightarrow \mathrm{Al}_{2} \mathrm{O}_{3}$ (dissolvido em $\left.2 \mathrm{PbO} \cdot \mathrm{B}_{2} \mathrm{O}_{3}, 700{ }^{\circ} \mathrm{C}\right)+\mathrm{x} \mathrm{H}_{2} \mathrm{O}\left(\mathrm{g}, 700{ }^{\circ} \mathrm{C}\right.$ )

$\mathrm{H}_{2} \mathrm{O}$ (adsorvido em $\left.\mathrm{Al}_{2} \mathrm{O}_{3}, 25^{\circ} \mathrm{C}\right) \rightarrow \mathrm{x} \mathrm{H}_{2} \mathrm{O}\left(\mathrm{g}, 700^{\circ} \mathrm{C}\right.$ )

$\alpha-\mathrm{Al}_{2} \mathrm{O}_{3}$ (corundum, 298K) $\rightarrow \mathrm{Al}_{2} \mathrm{O}_{3}$ (dissolvida em $2 \mathrm{PbO} \mathrm{B}_{2} \mathrm{O}_{3}, 700{ }^{\circ} \mathrm{C}$ )

$\alpha-\mathrm{Al}_{2} \mathrm{O}_{3}$ (corundum, $\left.25^{\circ} \mathrm{C}\right) \rightarrow \alpha$ ou $\gamma-\mathrm{Al}_{2} \mathrm{O}_{3}\left(\mathrm{~A}_{\mathrm{s}}, 25^{\circ} \mathrm{C}\right.$ )

$\Delta \mathrm{H}_{5}=-\Delta \mathrm{H}_{2}+\mathrm{x} \Delta \mathrm{H}_{3}+\Delta \mathrm{H}_{4}$

A Equação 1.3 e $\Delta \mathrm{H}_{3}$ representam a correção para o efeito de calor devido a $\mathrm{H}_{2} \mathrm{O}$ adsorvido, que é a soma do calor integral de dessorção para todos $\mathrm{H}_{2} \mathrm{O}$ adsorvidos e o conteúdo térmico de $\mathrm{H}_{2} \mathrm{O}$ vapor entre $25^{\circ} \mathrm{C}$ e $700{ }^{\circ} \mathrm{C}$.

Antes da calorimetria de alta temperatura as amostras foram deixadas para alcançar o equilíbrio de conteúdo de $\mathrm{H}_{2} \mathrm{O}$ a $25{ }^{\circ} \mathrm{C}$ e $55 \%$ de umidade. Foi determinado que cerca de $40 \%$ da $\mathrm{H}_{2} \mathrm{O}$ era quimicamente adsorvido o que em média faz $16,5 \mathrm{OH} \mathrm{nm}{ }^{-2}$ para $\gamma-\mathrm{Al}_{2} \mathrm{O}_{3}$ e $17,4 \mathrm{OH} \mathrm{nm}{ }^{-2}$ para $\alpha-\mathrm{Al}_{2} \mathrm{O}_{3}$. O calor integral de adsorção química de $\mathrm{H}_{2} \mathrm{O}$ para estas coberturas pôde ser obtido dos dados apresentados na figura abaixo (Figura 1.4B): 

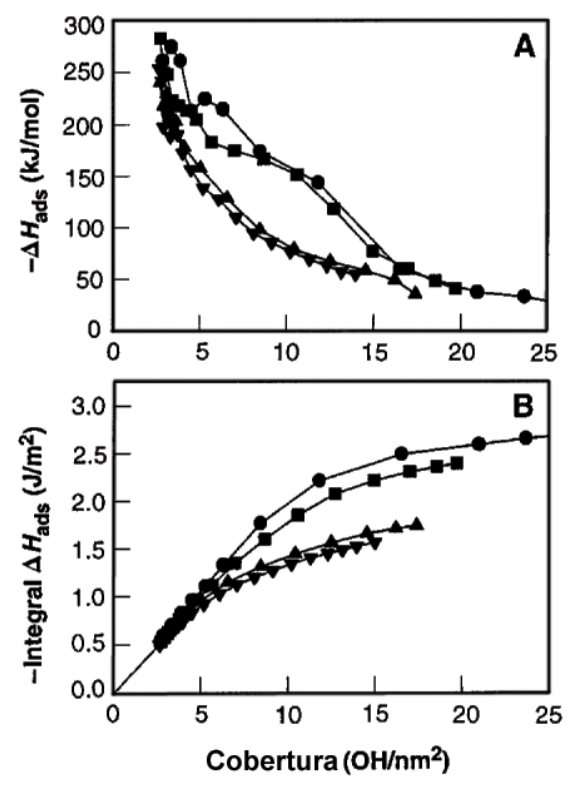

Figura 1.4 - Calor de adsorção química de $\mathrm{H}_{2} \mathrm{O}$ diferencial (A) e integral (B) em $\alpha-\mathrm{Al}_{2} \mathrm{O}_{3}\left[36 \mathrm{~m}^{2} \mathrm{~g}^{-1}(\bullet), 61 \mathrm{~m}^{2} \mathrm{~g}^{-1}(\boldsymbol{\bullet})\right]$ e $\gamma-\mathrm{Al}_{2} \mathrm{O}_{3}\left[72 \mathrm{~m}^{2} \mathrm{~g}^{-1}(\boldsymbol{\Delta}), 161 \mathrm{~m}^{2} \mathrm{~g}^{-1}(\boldsymbol{\nabla})\right]$ em função da cobertura de hidroxilas na superfície.

De modo a contar as $2,6 \mathrm{OH} \mathrm{nm}^{-2}$ não removidos, a curva da Figura 1.4B foi extrapolada linearmente abaixo de $6 \mathrm{OH} \mathrm{nm}{ }^{-2}$ até a concentração zero de hidroxilas, e adicionado $0,490 \mathrm{~J} \mathrm{~m}^{-2}$ a cada ponto medido, a fim de alcançar interceptação na origem. $\mathrm{O}$ calor médio de $\mathrm{H}_{2} \mathrm{O}$ quimicamente adsorvido para estas coberturas é portanto $-163,7 \mathrm{~kJ} \mathrm{~mol}^{-1} \mathrm{de}_{2} \mathrm{O}$ em $\alpha-\mathrm{Al}_{2} \mathrm{O}_{3} \mathrm{e}-122,5 \mathrm{~kJ} \mathrm{~mol}^{-1}$ de $\mathrm{H}_{2} \mathrm{O}$ em $\gamma-\mathrm{Al}_{2} \mathrm{O}_{3}$. Os valores podem então ser utilizados na correção $\Delta \mathrm{H}_{3}$, sendo ainda adicionado o calor conteúdo de vapor de $\mathrm{H}_{2} \mathrm{O}$ entre $25^{\circ} \mathrm{C}$ e $700{ }^{\circ} \mathrm{C}$.

As entalpias das aluminas nanofásicas com relação a corundum coalescida podem ser obtidas pelo ciclo termoquímico apresentado acima. Em áreas de superfície específicas maiores que $125 \mathrm{~m}^{2} \mathrm{~g}^{-1}, \gamma-\mathrm{Al}_{2} \mathrm{O}_{3}$ possui menor entalpia que $\alpha-\mathrm{Al}_{2} \mathrm{O}_{3}$ (Figura 1.5). As energias de superfície obtidas da derivada das linhas obtidas são 2,64 $\mathrm{J} \mathrm{m}^{-2}$ para alfa e $1,67 \mathrm{~J} \mathrm{~m}^{-2}$ para gama alumina. 


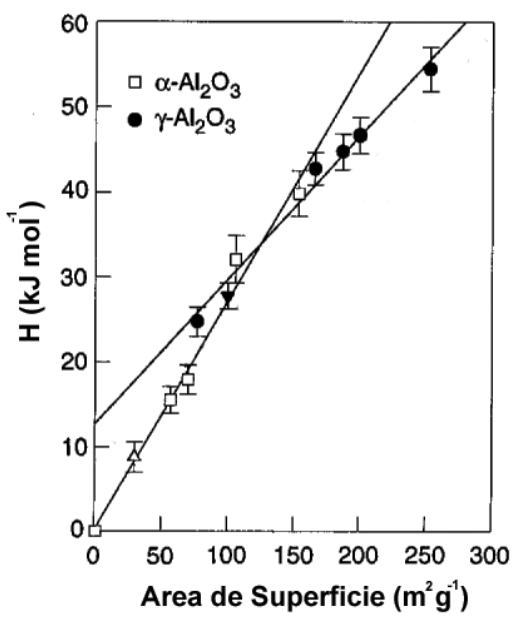

Figura 1.5 - Entalpias de polimorfos de alumina relativas a corundum coalescida determinadas por calorimetria de solução de alta temperatura [5327] . No gráfico $\gamma-\mathrm{Al}_{2} \mathrm{O}_{3}$ é representado pelas esferas fechadas $(\bullet$ ou $\boldsymbol{\nabla})$ e $\alpha-\mathrm{Al}_{2} \mathrm{O}_{3}$ pelos quadrados abertos $(\square)$.

Nota-se, portanto, que as correções devido à presença de $\mathrm{H}_{2} \mathrm{O}$ têm uma função fundamental na confiabilidade dos resultados de calorimetria, mas que a técnica é bastante satisfatória para a avaliação das variações de tamanho de partícula crítica de transição com relação aos aspectos de química de superfície. Com base em resultados apresentados na literatura será utilizado um procedimento semelhante para se avaliar a influência dos aditivos na entalpia de rede e na energia de superfície da alumina durante este trabalho. Assim, ensaios de calorimetria de dissolução de alta temperatura em borato de chumbo, bem como medidas de calor de adsorção de $\mathrm{H}_{2} \mathrm{O}$ na superfície do material foram realizados e os resultados são apresentados no desenvolvimento deste trabalho. 


\section{OBJETIVOS}

Apresenta-se abaixo um sumário dos objetivos e dos métodos utilizados para alcançá-los:

- Estudo do efeito da atmosfera seca e contendo vapor de $\mathrm{H}_{2} \mathrm{O}$ na síntese e transformação de fase da alumina livre de aditivos e contendo $\mathrm{Mn}$ ou $\mathrm{Mg}$ para determinar um procedimento experimental no qual apenas os aditivos influenciam a transformação, tornando a avaliação confiável.

- Avaliação do efeito dos íons $\mathrm{Mn}, \mathrm{Mg}$ e Zr na transformação de fase da alumina preparada pelo método do precursor polimérico por Análise Térmica Diferencial (DTA) e difração de raios X (DRX);

- Estudo do efeito dos íons nos tamanhos críticos da transformação avaliando as áreas de superfície específica imediatamente anteriores à transformação por adsorção de $\mathrm{N}_{2}$ (BET);

- Determinação da energia de superfície da alumina sem aditivos por calorimetria de dissolução de alta temperatura associada a microcalorimetria de adsorção de $\mathrm{H}_{2} \mathrm{O}$ para comparação com resultado da literatura e avaliação do procedimento;

- Determinação das energias de rede e superfície nos sistemas dopados com $\mathrm{Mg}, \mathrm{Zr}$ e $\mathrm{Mn}$ por calorimetria de dissolução de alta temperatura e microcalorimetria de adsorção de $\mathrm{H}_{2} \mathrm{O}$ e relacionamento destes resultados com a posição do aditivo na estrutura; e verificação da segregação dos íons através de análise de XPS. 


\section{PROCEDIMENTO EXPERIMENTAL}

Nesta seção são apresentados os equipamentos e detalhes das técnicas que foram aplicadas neste trabalho.

\subsection{Síntese}

Para produção da alumina foi utilizado método baseado na patente de Pechini [5] . Pechini [3330697] propôs uma via de preparação química de óxidos que limita a adição de contra íons inorgânicos e permite a cristalização lenta das partículas. O precursor polimérico foi preparado pela adição de $\mathrm{Al}\left(\mathrm{NO}_{3}\right)_{3}$ anidro P.A. (Synth - >98 \%) à uma solução de ácido cítrico anidro P.A. (Synth - >99,5 \%) e etileno glicol P.A. (Synth) na proporção $25 \%$, $45 \%$ e $30 \%$ em massa, respectivamente. Essa composição foi determinada de modo a maximizar a oxigenação do sistema [5]. Seguiu-se um processo de solubilização total dos componentes a $\sim 70{ }^{\circ} \mathrm{C}$ e polimerização a $\sim 120{ }^{\circ} \mathrm{C}$. A resina polimérica obtida foi então calcinada a $400{ }^{\circ} \mathrm{C}$ por 4 horas para decomposição térmica do polímero [5] . Após desaglomeração em almofariz de ágata, o material obtido foi calcinado novamente a $650{ }^{\circ} \mathrm{C}$ por 15 horas para oxidação dos cátions e formação dos cristalitos. Esta última oxidação foi feita sob atmosfera com fluxo constante de $\sim 60 \mathrm{~mL} \mathrm{~min}^{-1}$ de ar passante por um recipiente contendo volume fixo de água para cada amostra na temperatura ambiente $\left(25^{\circ} \mathrm{C}\right)$. A razão para tal procedimento é descrita numa próxima seção. A temperatura de calcinação final de $650{ }^{\circ} \mathrm{C}$ foi determinada por termogravimetria como sendo a temperatura a partir da qual não há perdas significativas de massa $(<0,01 \%)$.

Aluminas contendo diferentes concentrações dos aditivos $\mathrm{Mn}, \mathrm{Mg}$ e $\mathrm{Zr}$ foram preparadas utilizando como precursores o carbonato de manganês (II) P.A. (Alfa Aesar 99,9\%), óxido de magnésio (Alfa Aesar 99,95 \%) e carbonato de zircônio (Alfa Aesar 99.9\%). Soluções dos precursores em concentrações calculadas para atingir 5 e $10 \mathrm{~mol} \% \mathrm{Mn}, 3$ e $5 \mathrm{~mol} \% \mathrm{Mg}$ e 1 e $2 \mathrm{~mol} \% \mathrm{Zr}$ foram adicionadas à resina na etapa anterior a decomposição térmica, garantindo assim boa homogeneidade de distribuição química do aditivo no pó de $\mathrm{Al}_{2} \mathrm{O}_{3}$. 


\subsection{Análise da reação de transformação}

Para determinação da temperatura de transformação dos pós de alumina sem e com aditivos foi realizada Análise Térmica Diferencial (DTA) à taxa de 10 ${ }^{\circ} \mathrm{C} \min ^{-1}$ em atmosfera de ar sintético partindo da temperatura ambiente até 1400 ${ }^{\circ} \mathrm{C}$. Equipamento especialmente desenvolvido neste projeto, nomeado PMT-I, bem como um Netzsch 449 TGA/DSC com fluxo de ar de $40 \mathrm{~mL} \mathrm{~min}^{-1}$ foram utilizados para o desenvolvimento deste projeto. Uma apresentação mais detalhada do equipamento PMT-I e a razão para a construção deste segue em uma seção ulterior.

Amostras de alumina e alumina contendo diferentes concentrações dos aditivos foram calcinadas em um forno tubular a uma taxa de $10{ }^{\circ} \mathrm{C} \mathrm{min}{ }^{-1}$ partindo da temperatura ambiente até temperaturas ao longo da transformação. Baseandose na curva de análise térmica de cada pó, que foi realizada na mesma taxa de aquecimento, as amostras foram retiradas do forno e resfriadas rapidamente para manter as características de estrutura e microestrutura do pó nas temperaturas determinadas. Desta forma foi possível avaliar a área de superfície específica e as fases presentes durante a transformação de fase na taxa de aquecimento utilizada para a análise térmica diferencial.

A caracterização dos materiais obtidos foi realizada pela determinação da área de superfície específica por adsorção de $\mathrm{N}_{2}$ utilizando método BET (Brunauer-Emmett-Teller) em um equipamento Micromeritics ASAP 2020 após tratamento a $450{ }^{\circ} \mathrm{C}$ sob vácuo $\left(>10^{-5} \mathrm{~mm}\right.$ de $\left.\mathrm{Hg}\right)$ por 2 horas.

A determinação das fases cristalinas das amostras foi realizada através de ensaios de difração de raios $\mathrm{X}$. Dois equipamentos foram utilizados para realização dos ensaios: difratômetro INEL-CPS120 e Bruker AXS Modelo D8 Advance, ambos utilizando tubos de $\mathrm{Cu}$ (radiação $\mathrm{K} \alpha=1,5418 \mathrm{~nm}$ ). Para as amostras utilizando este último foi usado passo de 0,05 por $5 \mathrm{~s}$ no intervalo de $20^{\circ}$ a $80^{\circ}$. No equipamento INEL-CPS120, que utiliza sistema de medição estático com cobertura simultânea de 10 a $120^{\circ}$, as amostras foram expostas por 15 minutos ao feixe de raios $\mathrm{X}$ com $30 \mathrm{kV}$ de potência e $30 \mathrm{~mA}$ de corrente. 


\subsection{Efeito da $\mathrm{H}_{2} \mathrm{O}$ na síntese e transformação de fase da alumina}

Para avaliar o efeito da presença de $\mathrm{H}_{2} \mathrm{O}$ na síntese dos pós à base de alumina foi utilizado um controle de atmosfera durante a cristalização e crescimento das partículas. Isto é, a atmosfera foi controlada na etapa de calcinação a $650{ }^{\circ} \mathrm{C}$ por 15 horas do processo, quando ocorre a oxidação dos cátions e formação dos cristalitos [5] . O controle para obtenção de atmosfera de ar seco foi feito fazendo passar ar sintético superseco com um fluxo de $60 \mathrm{~mL}$ $\min ^{-1}$ pelo tubo cerâmico do forno de calcinação. A presença de $\mathrm{H}_{2} \mathrm{O}$ na atmosfera de queima foi controlada fazendo passar um fluxo também de $60 \mathrm{~mL}$ $\min ^{-1}$ por um recipiente com quantidade fixa de $\mathrm{H}_{2} \mathrm{O}$ à $25{ }^{\circ} \mathrm{C}$ antes de ser injetado no tubo do forno. O sistema foi completamente vedado em ambos os casos e um borbulhador na extremidade de saída de ar garantiu uma pressão positiva e constante no interior do tubo.

Pós de $\mathrm{Al}_{2} \mathrm{O}_{3}$ livre de aditivos e contendo $\mathrm{Mn}$ ou $\mathrm{Mg}$ como aditivos foram sintetizados sob cada atmosfera e então submetidos à análise de DTA à $10{ }^{\circ} \mathrm{C}$ $\min ^{-1}$ com atmosfera seca para avaliar as diferenças entre os pós produzidos pelos dois procedimentos. Como os resultados para as duas atmosferas foram diferentes, adotou-se a síntese sob atmosfera úmida para avaliação da ação dos aditivos por razões que serão detalhadas quando da apresentação dos resultados.

Para estudar o efeito da umidade durante a transformação de fase $\gamma-\alpha$ da alumina sintetizada sob atmosfera úmida foi construído um equipamento de DTA - nomeado PMT-I - para realização de ensaios com controle de umidade na câmara de amostra. Não foi utilizado equipamento comercial pela indisponibilidade para uso com atmosfera com excesso de $\mathrm{H}_{2} \mathrm{O}$ que poderia promover corrosão interna, comprometendo os componentes.

O equipamento PMT-I segue o princípio básico de um equipamento de análise térmica diferencial, onde um termopar tipo $\mathrm{R}$ é posto em contato com a amostra e outro em contato com um material referência, no caso $\alpha-\mathrm{Al}_{2} \mathrm{O}_{3}$ coalescida. Neste equipamento, as amostras são prensadas no termopar para ampliar o sinal elétrico medido devido às reações do material, melhorando a confiabilidade do sinal. Um esquema do equipamento é mostrado na Figura 3.1 abaixo. 


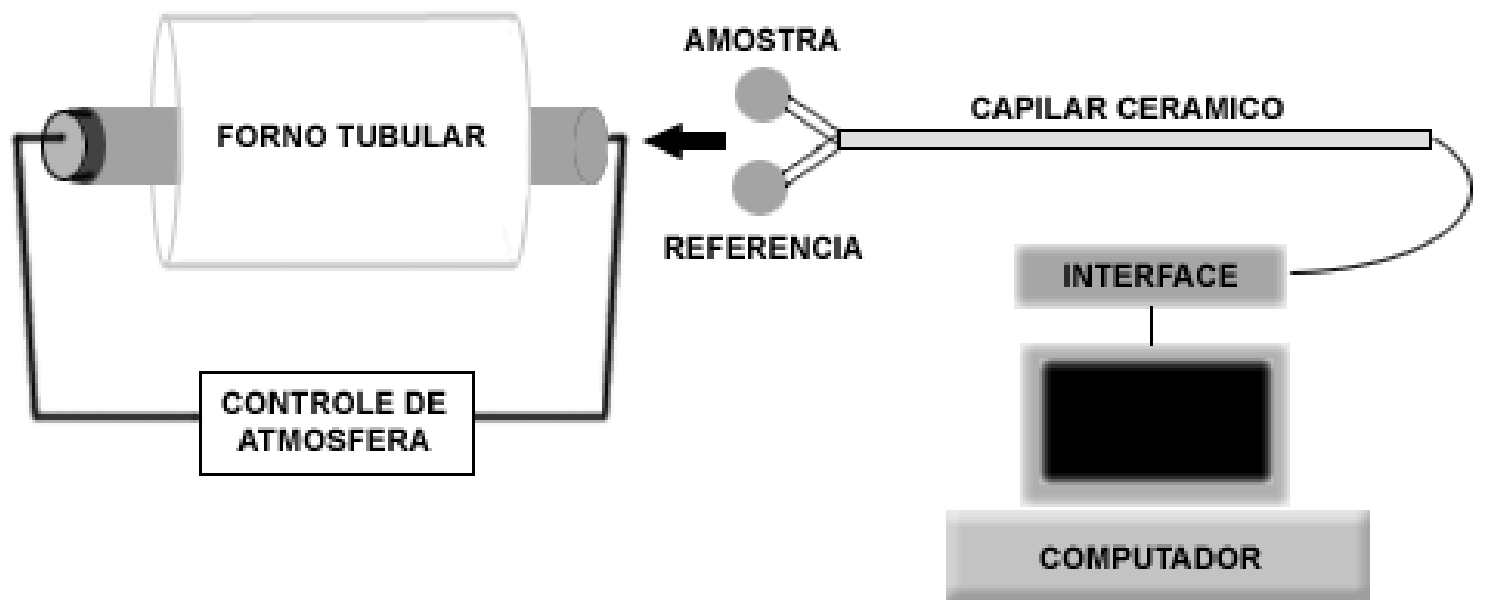

Figura 3.1 - Representação esquemático do equipamento de DTA construído neste trabalho para avaliação da influência da umidade na transformação de fase da alumina.

Apesar da simplicidade do equipamento, este mostrou-se bastante confiável ao reproduzir fielmente as análises de DTA realizadas no equipamento comercial sob atmosfera de ar seco para alumina sem aditivos. A atmosfera de ar seco foi obtida com a passagem e ar sintético superseco com um fluxo de $60 \mathrm{~mL}$ $\min ^{-1}$ pelo tubo cerâmico do forno da mesma forma que para a síntese dos materiais.

Para analisar o efeito da umidade na temperatura de transformação de fase $\gamma-\alpha$ da alumina sem aditivos realizou-se um DTA a partir da temperatura ambiente até $1400{ }^{\circ} \mathrm{C}$, à $10^{\circ} \mathrm{C} \min ^{-1}$ no equipamento PMT-I. A atmosfera do forno foi controlada passando um fluxo de $60 \mathrm{~mL} \mathrm{~min}^{-1}$ de ar por um recipiente com quantidade fixa de $\mathrm{H}_{2} \mathrm{O}$ à $25^{\circ} \mathrm{C}$ antes de ser injetado no tubo do forno.

As taxas de aquecimento dos experimentos com atmosfera úmida e seca foram medidas e comparadas para garantir que a presença do vapor de água não diminui a taxa de aquecimento, e assim, muda a temperatura de transformação observada. Isto é, uma taxa mais lenta de subida acarretaria na diminuição da temperatura do pico exotérmico de transformação. Um maior tempo de calcinação em uma dada temperatura leva a um maior crescimento de grãos , o que pode levar o sistema a atingir o tamanho crítico de transformação [7] mais 
rapidamente e invalidar os resultados.

\subsection{Calorimetria de dissolução de alta temperatura}

A técnica de calorimetria de dissolução de alta temperatura foi utilizada para o estudo das modificações das entalpias associadas às amostras com diferentes áreas de superfície específica, como apresentadas anteriormente. O equipamento utilizado foi um microcalorímetro gêmeo do tipo Tian-Calvet [1-2] ajustado com modificações para altas temperaturas . A Figura 3.1 mostra uma representação esquemática do equipamento composto de duas câmaras de amostra sendo cada uma com $2,5 \mathrm{~cm}$ de diâmetro e circundadas por termopares compostos de 56 termopares Pt-Pt13Rh em série. Os dois termopares são conectados em oposição e imersos em um bloco maciço de refratário que é mantido a temperatura constante e uniforme por um aquecedor cilíndrico e duas placas aquecedoras, uma na parte superior e outra na inferior.

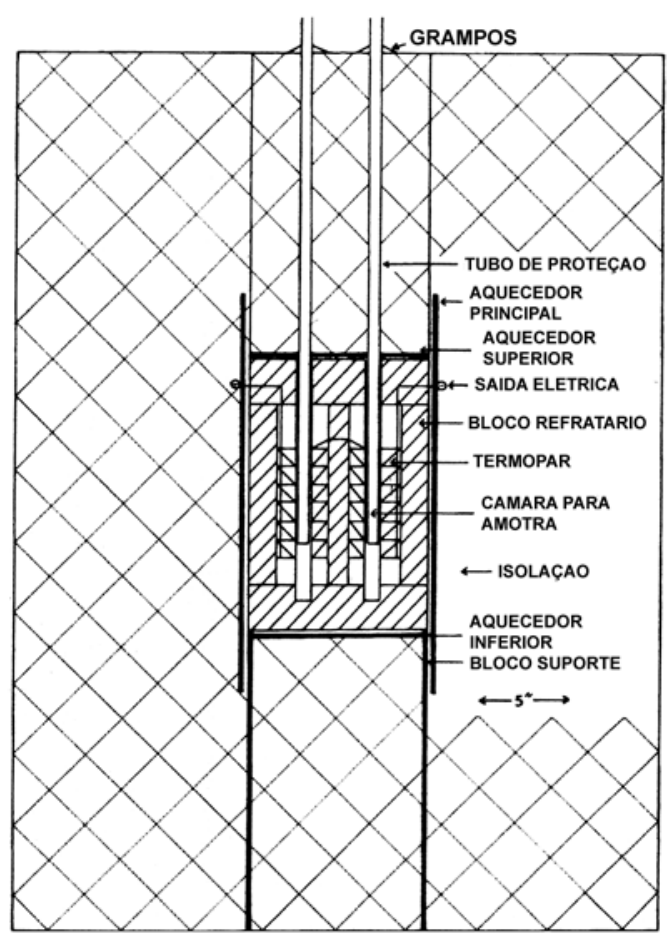

Figura 3.2 - Representação esquemática do calorímetro de solução de alta temperatura [1-2] . 
A baixa voltagem d.c. dos termopares é enviada para um amplificador e assim para um computador onde é feita a integração do sinal para obtenção do gráfico como os valores numéricos sob o pico calorimétrico.

Antes do início do experimento as amostras são deixadas no ambiente do ensaio para atingir equilíbrio térmico até que um sinal estável dos termopares seja obtido (linha base estável). Uma reação é assim iniciada em uma das câmaras de amostra e a outra age como um controle. O termopar registra a mudança na temperatura entre a câmara da amostra e o bloco ao passo que o calor é liberado ou absorvido pela reação. O calor é gradualmente transferido para o bloco e o pico calorimétrico decai aproximadamente exponencialmente para a linha base original. Como o gradiente de temperatura gerado pela reação é pequeno, a taxa de fluxo de calor para fora do calorímetro é proporcional à diferença de temperatura entre o bloco e a câmara. $\mathrm{O}$ efeito calorimétrico total é então proporcional à área sob o pico calorimétrico. Uma vez que um fator de calibração é determinado pode-se calcular o efeito calorimétrico.

Para o experimento de calorimetria foi usado borato de chumbo como solvente que foi mantido a uma temperatura constante de $700{ }^{\circ} \mathrm{C}$. Um fluxo de $\mathrm{O}_{2}$ a aproximadamente $40 \mathrm{~mL} \mathrm{~min}^{-1}$ foi mantido através da câmara de análise durante o experimento para evitar acúmulo de vapor de $\mathrm{H}_{2} \mathrm{O}$ liberado pela amostra quando esta é dissolvida pelo sistema [11-12] .

As amostras foram armazenadas no laboratório de calorimetria onde há controle de temperatura e umidade $\left(25{ }^{\circ} \mathrm{C}\right.$ e $45 \%$ de umidade relativa) para alcançar equilíbrio térmico e de conteúdo de $\mathrm{H}_{2} \mathrm{O}$. As amostras foram levemente prensadas em pastilhas de $5 \mathrm{mg}$ e mergulhadas nas câmaras de ensaio da temperatura ambiente até zona isotérmica do equipamento a $700{ }^{\circ} \mathrm{C}$.

Como visto anteriormente, um ciclo termodinâmico deve ser considerado para se levar em conta todas as componentes envolvidas nos resultados computados. Em particular, o efeito da desorção de $\mathrm{H}_{2} \mathrm{O}$ da superfície deve ser considerado principalmente porque se tratam de nanopartículas com elevadas áreas de superfície específica. Deste modo, o conteúdo total de $\mathrm{H}_{2} \mathrm{O}$ foi determinado pesando as amostras após o equilíbrio ser atingido e submetendo-as a calcinação a $1550{ }^{\circ} \mathrm{C}$ por 12 horas. Este procedimento leva a um considerável 
coalescimento das partículas devido à sinterização e uma diminuição da superfície livre para adsorção de água, permitindo considerar-se que desde a retirada das amostras do forno a $825^{\circ} \mathrm{C}$ até a pesagem não há adsorção significativa de $\mathrm{H}_{2} \mathrm{O}$ no material a ser analisado, incluindo o transporte destas utilizando dissecador até a balança.

Para se determinar a quantidade de $\mathrm{H}_{2} \mathrm{O}$ quimicamente adsorvido considerou-se, por definição, que esta é aquela remanescente após tratamento a $125^{\circ} \mathrm{C}$ por $12 \mathrm{~h}$ [5327]. Deste modo, determinou-se a quantidade de $\mathrm{H}_{2} \mathrm{O}$ relativa a cada amostra calcinando os pós nessas condições e determinando a perda de massa. A diferença entre a perda total $\left(\right.$ a $1550{ }^{\circ} \mathrm{C}$ ) e a perda a $125^{\circ} \mathrm{C}$ foi atribuída a $\mathrm{H}_{2} \mathrm{O}$ quimissorvida.

Uma vez determinadas as quantidades de água adsorvidas quimicamente e fisicamente nas partículas, a próxima etapa consistiu na determinação dos calores de adsorção destas moléculas na superfície da alumina a fim de se conhecer a parcela de entalpia referente a esta adsorção no calor total medido no experimento de calorimetria de dissolução. $\mathrm{O}$ calor de adsorção física de $\mathrm{H}_{2} \mathrm{O}$ na alumina foi determinado preparando-se amostras com diferentes frações molares de $\mathrm{H}_{2} \mathrm{O}$ para diferentes áreas de superfície específica. A partir das inclinações dos gráficos de entalpia de dissolução em borato de chumbo fundido a $700{ }^{\circ} \mathrm{C}$ e da fração molar de $\mathrm{H}_{2} \mathrm{O}$ foi determinado um valor médio de $70,09 \mathrm{~kJ} \mathrm{~mol}^{-1}$ e aplicado para a correção dos valores de calorimetria das amostras [4]. O calor de adsorção química, no entanto, é mais específico para cada amostra, sendo fundamental na correção dos resultados [5327]. Essas moléculas são mais fortemente ligadas à superfície e são proporcionais às energias de superfície [5327]. Deste modo, a determinação desta energia de quimissorção será feita a partir de ensaio de microcalorimetria de adsorção de $\mathrm{H}_{2} \mathrm{O}$ como descrito a seguir.

\subsection{Microcalorimetria de adsorção de $\mathrm{H}_{2} \mathrm{O}$}

Os calores de quimissorção de $\mathrm{H}_{2} \mathrm{O}$ em amostra de $\gamma-\mathrm{Al}_{2} \mathrm{O}_{3}$ e $\gamma-\mathrm{Al}_{2} \mathrm{O}_{3}$ contendo $\mathrm{Mn}, \mathrm{Mg}$ e $\mathrm{Zr}$ como aditivos foram medidos usando um microcalorímetro do tipo Calvet Setaram DSC-111 acoplado ao sistema de adsorção de gás do equipamento de análise de área de superfície específica Micromeritics ASAP 
2020 [2,5327] . A Figura 3.2 ilustra de forma esquemática o equipamento com legendas sobre seus componentes. As amostras foram previamente calcinadas a partir da temperatura ambiente até $150{ }^{\circ} \mathrm{C}$ da temperatura de transformação. Cerca de $50 \mathrm{mg}$ de cada amostra foi termicamente ativada a $750{ }^{\circ} \mathrm{C}$ por 2 horas sob vácuo e resfriada até a temperatura de adsorção, ou seja, $25{ }^{\circ} \mathrm{C}$. As amostras foram então expostas a doses sucessivas de vapor de $\mathrm{H}_{2} \mathrm{O}\left(1 \mathrm{~cm}^{3} \mathrm{~g}^{-1}\right.$ de $\left.\mathrm{Al}_{2} \mathrm{O}_{3}\right)$. O calor liberado e os volumes de $\mathrm{H}_{2} \mathrm{O}$ adsorvidos foram medidos em cada passo. As áreas específicas dos pós foram medidas após o tratamento por adsorção de $\mathrm{N}_{2}$ (BET) e anteriormente ao experimento de adsorção. O mesmo foi utilizado para uma amostra referência de $\gamma-\mathrm{Al}_{2} \mathrm{O}_{3}$, cujos valores são reportados na literatura [5327], e assim avaliar a sua confiabilidade.

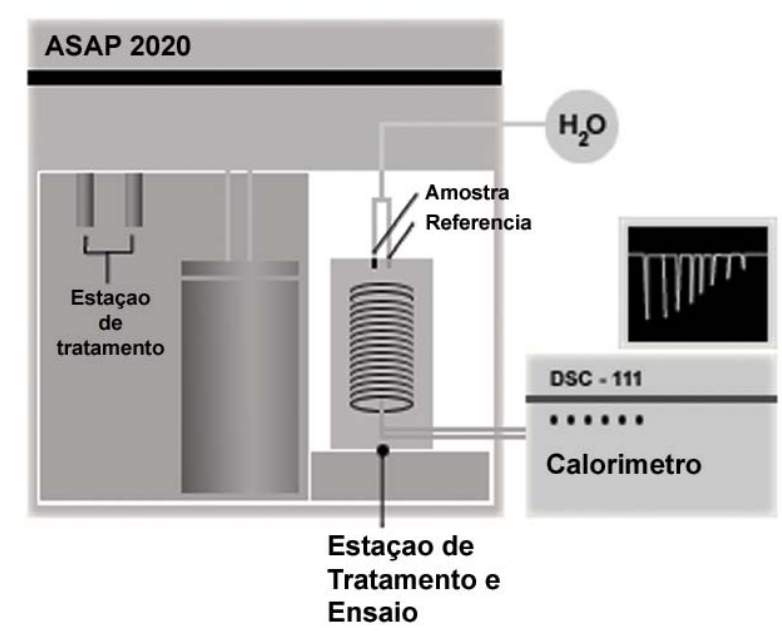

Figura 3.3 - Representação esquemática do equipamento de medida de entalpia de adsorção de $\mathrm{H}_{2} \mathrm{O}$.

\subsection{XPS (X-ray Photoelectron Spectroscopy)}

Os ensaios de espectroscopia de fotoelétrons excitados por raios $\mathrm{X}$ foram realizados num espectrofotômetro VG ESCALAB 220XL para detecção dos elementos segregados na superfície dos pós de $\mathrm{Al}_{2} \mathrm{O}_{3}$. Uma linha nãomonocromatizada de $1486,6 \mathrm{eV}$ foi utilizada para excitação com potência aplicada de $300 \mathrm{~W}$. Os analisadores operaram no modo de energia passante constante de 40 eV. O nível de vácuo durante o experimento foi menor que $10^{-7} \mathrm{~Pa}$. Os pós de 
amostra foram prensados em finas pastilhas dentro de folhas de índio. As quantificações experimentais foram obtidas utilizando o software Eclipse provido pela ThermoVG Scientific. Os ensaios foram realizados no Laboratoire de Catalyse de Lille - École Nationale Supérieure de Chimie de Lille. 


\section{RESULTADOS E DISCUSSÃO}

\subsection{Estudo do efeito da $\mathrm{H}_{2} \mathrm{O}$ na síntese da alumina}

Este trabalho foi organizado de modo a investigar a influência dos aditivos nas energias do sistema e, por conseqüência, na temperatura de transformação de fase da alumina, desde que estabelecida a presença de um tamanho crítico de partícula e sua relação com as energias de superfície e de rede. No entanto, para fazer uma avaliação confiável da ação dos aditivos, deve-se estudar primeiramente o efeito da presença de vapor de $\mathrm{H}_{2} \mathrm{O}$ no sistema, tanto na síntese como na transformação de fase. Isto porque a presença de vapor de $\mathrm{H}_{2} \mathrm{O}$ mostrou ter efeito catalítico em processos semelhantes [1,2,1-2,4] , e quantidades variáveis de vapor de $\mathrm{H}_{2} \mathrm{O}$ nas atmosferas de reação durante os ensaios para estudo dos aditivos podem levar a conclusões errôneas. $\mathrm{O}$ efeito da presença de vapor de $\mathrm{H}_{2} \mathrm{O}$ é tão significativo neste sistema que ensaios preliminares em atmosfera ambiente foram sensíveis às variações de umidade relativa, sendo obtidos resultados diferentes para temperatura de transformação $\gamma-\alpha$ da $\mathrm{Al}_{2} \mathrm{O}_{3}$ utilizando $\mathrm{o}$ mesmo procedimento em dias diferentes. Em atmosfera seca controlada, no entanto, os resultados foram sempre constantes e as variações dentro dos erros esperados.

$\mathrm{O}$ efeito da presença de umidade na atmosfera de síntese foi estudado inicialmente avaliando a curva de DTA (em atmosfera seca) para amostras de mesma composição sintetizadas nas duas atmosferas (seca e úmida). Não houve variação significativa entre as curvas obtidas para $\mathrm{Al}_{2} \mathrm{O}_{3}$ livre de aditivos sintetizados sob as duas atmosferas. No entanto, para os materiais contendo os aditivos, a atmosfera de síntese mostrou-se determinante no produto final e na evolução da curva de DTA. A Figura 4.1 mostra os gráficos de DTA para amostras de $\mathrm{Al}_{2} \mathrm{O}_{3}$ contendo $10 \mathrm{~mol} \% \mathrm{Mn}$ produzidas nas duas situações. 


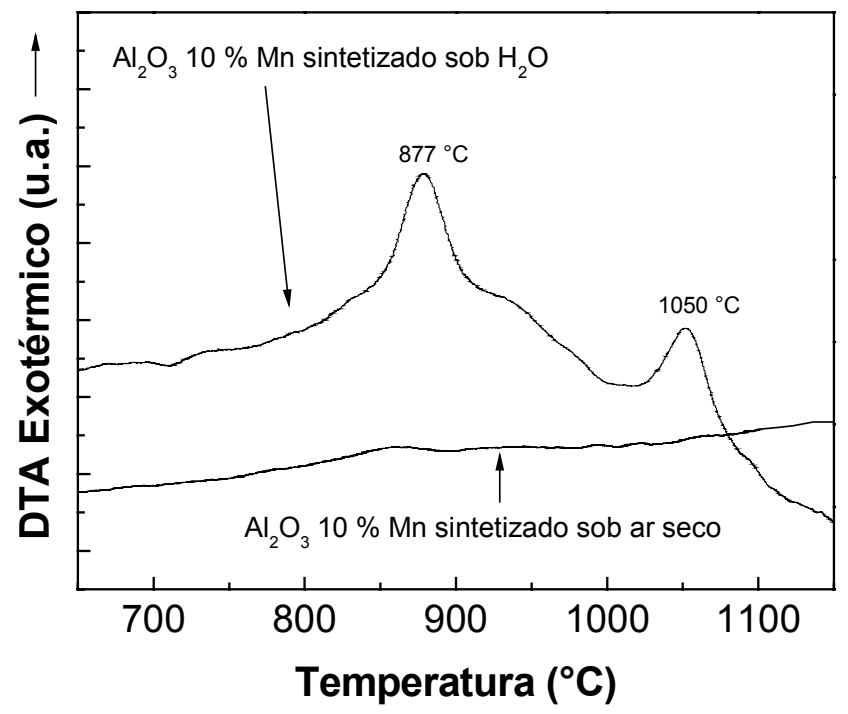

Figura 4.1 - Curva de DTA das amostras de $\mathrm{Al}_{2} \mathrm{O}_{3}$ contendo $10 \mathrm{~mol} \% \mathrm{Mn}$ sintetizadas pelo método dos precursores poliméricos em atmosfera seca e contendo $\mathrm{H}_{2} \mathrm{O}$.

Para $\mathrm{Al}_{2} \mathrm{O}_{3}$ sintetizada sob atmosfera com vapor de $\mathrm{H}_{2} \mathrm{O}$ há a presença dos dois picos exotérmicos característicos atribuídos à transformação de fase de amorfa para $\gamma-\mathrm{Al}_{2} \mathrm{O}_{3} \mathrm{a} \sim 877{ }^{\circ} \mathrm{C}$ e de $\gamma-\mathrm{Al}_{2} \mathrm{O}_{3}$ para $\alpha-\mathrm{Al}_{2} \mathrm{O}_{3} \mathrm{a} \sim 1050{ }^{\circ} \mathrm{C}$. Quando há ausência de $\mathrm{H}_{2} \mathrm{O}$ na atmosfera de síntese, os picos referentes à estas duas fases não estão presentes. Este fato é incoerente com uma atribuição apenas difusional da presença da água no sistema. Isto é, a ação da água na cristalização e transformação de fase é sempre descrita como relacionada apenas ao incremento no processo de difusão e diminuição das energias de ativação [4] . Entretanto, a Figura 4.2 mostra a difração de raios $\mathrm{X}$ dos pós obtidos após o DTA e indica fases diferentes para as duas atmosferas de síntese. 


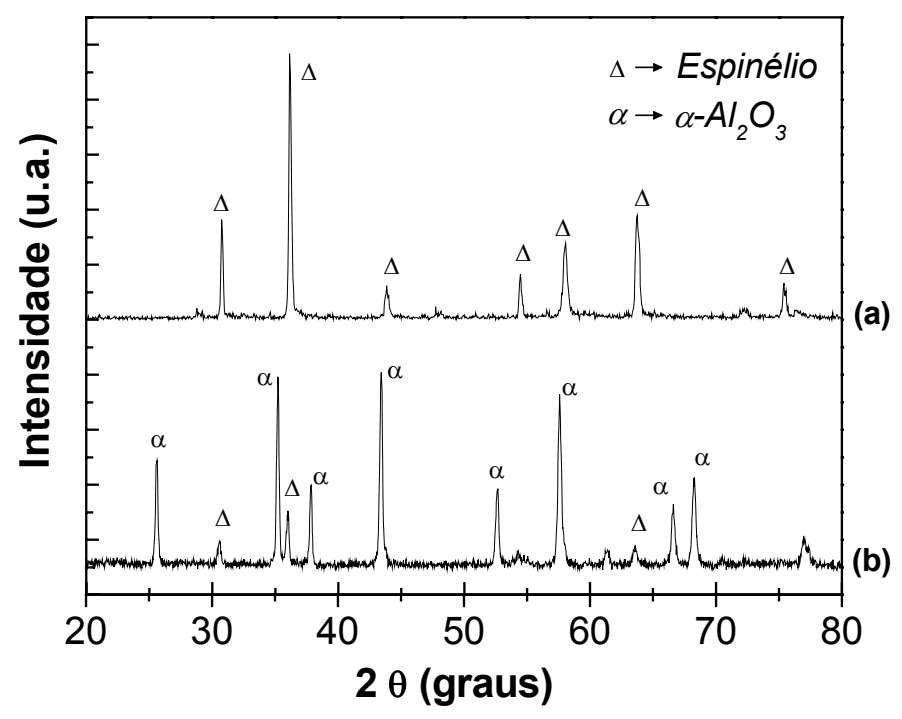

Figura 4.2 - Difração de raios X das amostras contendo 10 mol\% Mn sintetizadas em ar seco (a) e contendo $\mathrm{H}_{2} \mathrm{O}$ (b) após ensaio de DTA em atmosfera seca. A legenda das fases presentes é mostrada no gráfico.

A presença de $\alpha-\mathrm{Al}_{2} \mathrm{O}_{3}$ é observada para o material sintetizado em atmosfera úmida com uma segunda fase identificada como uma aluminato de manganês. A presença desta segunda fase está relacionada à diferença de solubilidade do $\mathrm{Mn}$ dentro a rede do $\gamma-\mathrm{Al}_{2} \mathrm{O}_{3}$ (como será apresentado em detalhes numa seção posterior) e do $\alpha-\mathrm{Al}_{2} \mathrm{O}_{3}$ após a transformação. No entanto, para $\mathrm{Al}_{2} \mathrm{O}_{3}$ $10 \mathrm{~mol} \% \mathrm{Mn}$ sintetizado sob atmosfera seca não é observada a presença de fase $\alpha$ $\mathrm{Al}_{2} \mathrm{O}_{3}$ após o DTA. Apenas um aluminato de manganês com estrutura semelhante à fase espinélio galaxita pôde ser observado. A ausência dos picos de cristalização de $\gamma-\mathrm{Al}_{2} \mathrm{O}_{3}$ e transformação para $\alpha-\mathrm{Al}_{2} \mathrm{O}_{3}$ no DTA é coerente com os dados de DRX e indica a cristalização do espinélio em temperaturas mais baixas, assim como para a formação de $\beta$-aluminas [7] . Para a $\mathrm{Al}_{2} \mathrm{O}_{3}$ contendo $5 \mathrm{~mol} \% \mathrm{Mn}$ é observado efeito semelhante, mas mesmo para atmosfera seca observa-se a presença de $\alpha-\mathrm{Al}_{2} \mathrm{O}_{3}$, mas em uma proporção muito menor que a observada na síntese em atmosfera úmida. 
A partir dos diferentes estados de oxidação possíveis para o íon $\mathrm{Mn}$, poder-se-ia supor que a presença ou não de $\mathrm{H}_{2} \mathrm{O}$ induz diferentes estados que seriam responsáveis pelas diferentes fases presentes em cada atmosfera. No entanto, o gráfico da Figura 4.3 mostra que um efeito similar ao observado para os pós contendo Mn está presente nos pós de alumina contendo $\mathrm{Mg}$ como aditivo. $\mathrm{Na}$ Figura 4.3 são mostrados os gráficos de DTA (em atmosfera seca) das amostras de $\mathrm{Al}_{2} \mathrm{O}_{3}$ contendo $5 \mathrm{~mol} \% \mathrm{Mg}$ sintetizadas sob atmosfera úmida e seca. Assim como para o caso do Mn, há omissão dos picos exotérmicos de cristalização de gama e transformação para alfa, indicando um fenômeno semelhante.

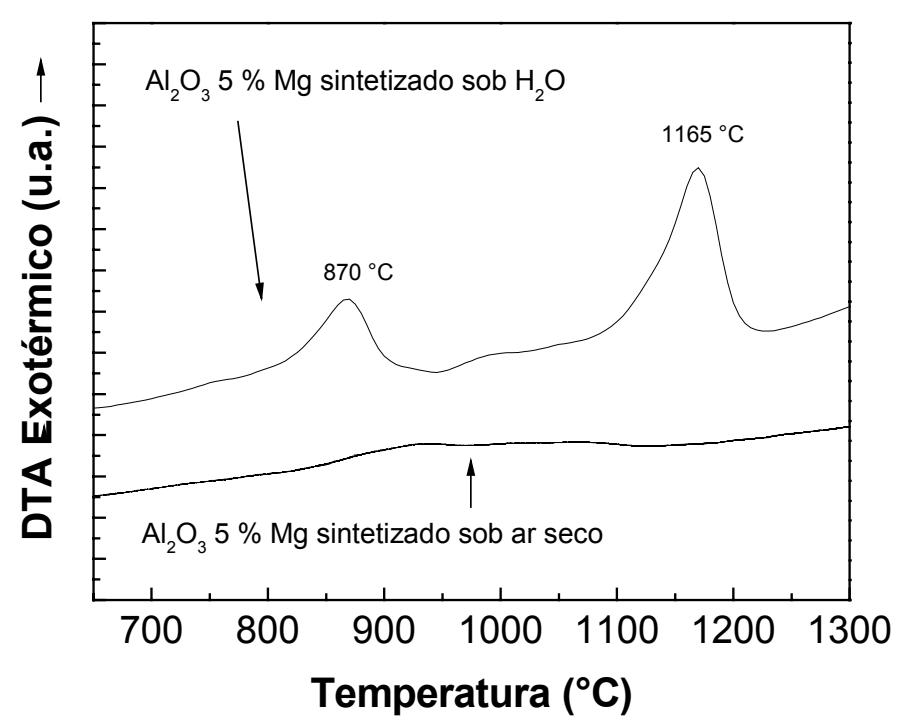

Figura 4.3 - Curva de DTA das amostras de $\mathrm{Al}_{2} \mathrm{O}_{3}$ contendo $5 \mathrm{~mol} \% \mathrm{Mg}$ sintetizadas pelo método dos precursores poliméricos em atmosfera seca e contendo $\mathrm{H}_{2} \mathrm{O}$. 


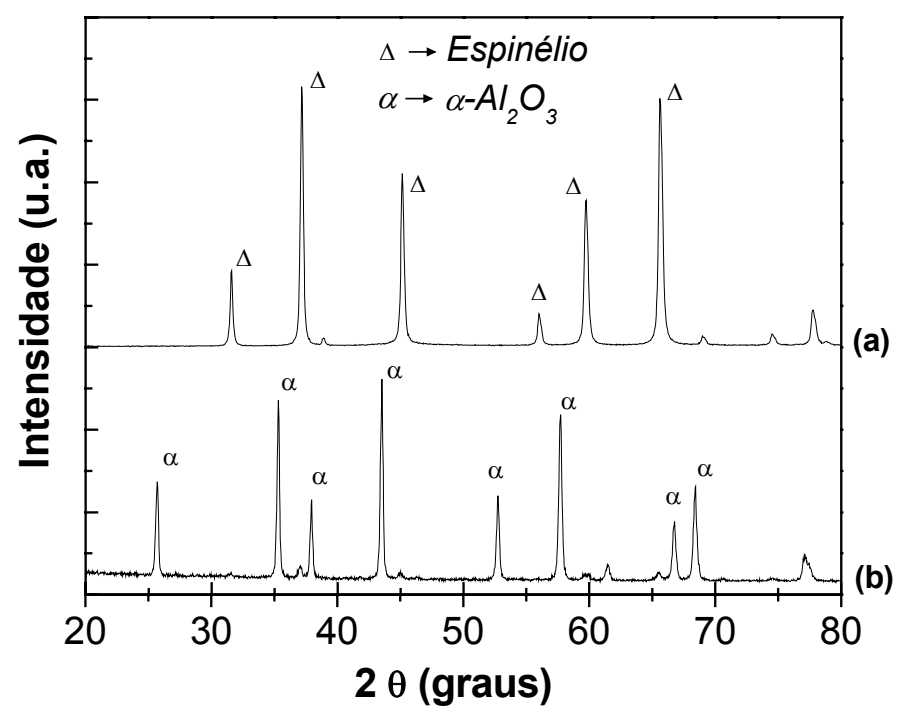

Figura 4.4 - Difração de raios X das amostras contendo 5 mol\% $\mathrm{Mg}$ sintetizadas em ar seco (a) e contendo $\mathrm{H}_{2} \mathrm{O}$ (b) após ensaio de DTA em atmosfera seca. A legenda das fases presentes é mostrada no gráfico.

Os gráficos de difração de raios $\mathrm{X}$ das amostras mostrados na Figura 4.4 mostram a formação de uma fase espinélio também para $5 \mathrm{~mol} \% \mathrm{Mg}$ sintetizado sob atmosfera seca após o DTA. Para a amostra sintetizada na presença de $\mathrm{H}_{2} \mathrm{O}$ há apenas pequenos traços da formação do espinélio e a fase dominante é $\alpha-\mathrm{Al}_{2} \mathrm{O}_{3}$. Para $\mathrm{Al}_{2} \mathrm{O}_{3}$ contendo $3 \mathrm{~mol} \%$ de $\mathrm{Mg}$ comportamento similar foi observado, mas em ambas as atmosferas $\alpha-\mathrm{Al}_{2} \mathrm{O}_{3}$ foi detectado, mas para atmosfera seca a fase espinélio é preponderante.

$\mathrm{O}$ efeito semelhante tanto para as amostras contendo $\mathrm{Mn}$ e $\mathrm{Mg}$ desacredita uma teoria baseada no número de oxidação desde que a valência do íon Mg é usualmente 2+. Desta forma, indroduz-se aqui uma hipótese de ação da $\mathrm{H}_{2} \mathrm{O}$ nas energias de superfície das fases envolvidas. Como descrito na literatura e discutido em detalhes ao longo deste trabalho, exite uma ação significativa da energia de superfície na temperatura de transformação e também na estabilidade de fases. Sabendo que a presença de $\mathrm{H}_{2} \mathrm{O}$ sobre uma superfície muda diferentemente as energias de estruturas e composições [5327,23,24] e que 
espinélios de $\mathrm{Mn}$ e $\mathrm{Mg}$ têm grande afinidade por moléculas de $\mathrm{H}_{2} \mathrm{O}$ [7-8], como resultado de uma elevada energia de adsorção, é coerente pensar que as moléculas de $\mathrm{H}_{2} \mathrm{O}$ podem estabilizar a superfície dos espinélio, promovendo sua formação em detrimento à formação de $\gamma-\mathrm{Al}_{2} \mathrm{O}_{3}$.

No entanto, não sendo foco principal deste trabalho um estudo detalhado com provas substanciais sobre a razão da formação destas sob atmosfera seca, fica este a título de perspectivas futuras. Como o objetivo fundamental deste trabalho é o estudo da transformação de fase $\alpha-\gamma$ da alumina e sua relação com os aditivos, os pós dos ensaios realizados no restante deste documento foram todos sintetizados sob atmosfera úmida.

\subsection{Estudo do efeito da $\mathrm{H}_{2} \mathrm{O}$ na transformação de fase $\gamma-\alpha$ da alumina}

Tendo sido verificado o efeito da umidade na atmosfera de síntese da alumina com aditivos, cabe agora um estudo do efeito do $\mathrm{H}_{2} \mathrm{O}$ na temperatura de transformação $\gamma-\alpha$ da $\mathrm{Al}_{2} \mathrm{O}_{3}$ produzida sob atmosfera úmida e sem aditivos. $\mathrm{A}$ Figura 4.5 mostra o gráfido de DTA sob atmosfera úmida e seca das amostras de $\mathrm{Al}_{2} \mathrm{O}_{3}$ produzida em atmosfera com $\mathrm{H}_{2} \mathrm{O}$. 


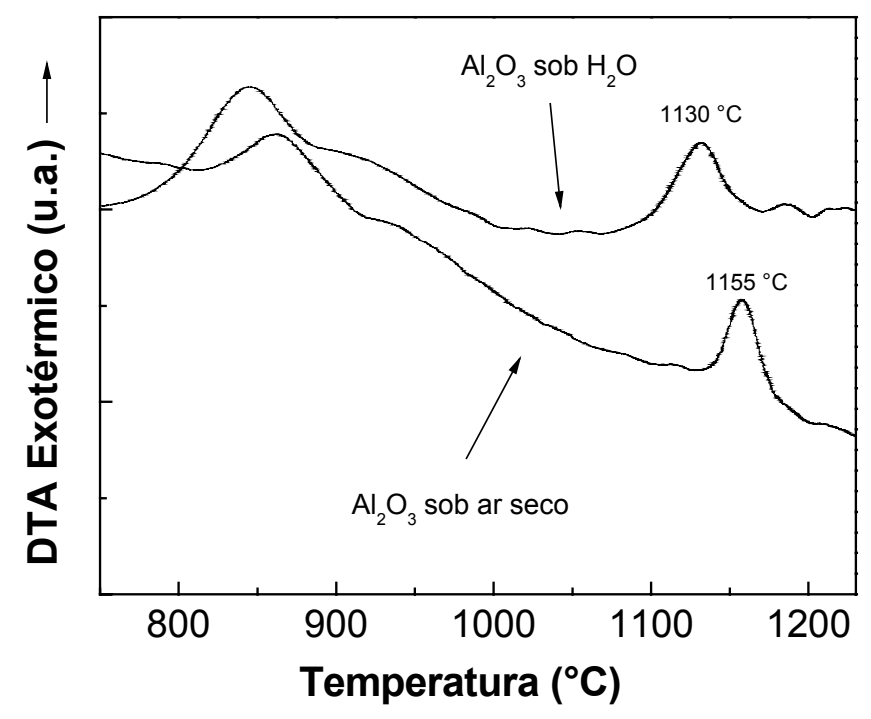

Figura 4.5 - Curva de DTA sob atmosfera seca e úmida das amostras de $\mathrm{Al}_{2} \mathrm{O}_{3}$ sem aditivos, sintetizadas pelo método dos precursores poliméricos em atmosfera contendo $\mathrm{H}_{2} \mathrm{O}$.

Nota-se a presença de dois picos, sendo um de cristalização da fase $\gamma$ $\mathrm{Al}_{2} \mathrm{O}_{3}$ e outro referente à transformação $\gamma-\alpha \mathrm{Al}_{2} \mathrm{O}_{3}$ para ambas as atmosferas de ensaio. No entanto, a temperatura de transformação no ensaio sob umidade é cerca de $25{ }^{\circ} \mathrm{C}$ mais baixa que aquela realizada sob ar seco. Este resultado é observado tanto na cristalização da fase de transição quanto na temperatura de transformação. Para garantir que este resultado não é uma simples conseqüência de uma menor taxa de aquecimento do forno devido à presença de $\mathrm{H}_{2} \mathrm{O}$ a Figura 4.6 mostra as taxas de aquecimento medidas para ambos ensaios. Note que as curvas são praticamente idênticas e a variação de temperatura pode ser atribuída a ação da $\mathrm{H}_{2} \mathrm{O}$ nas amostras. 


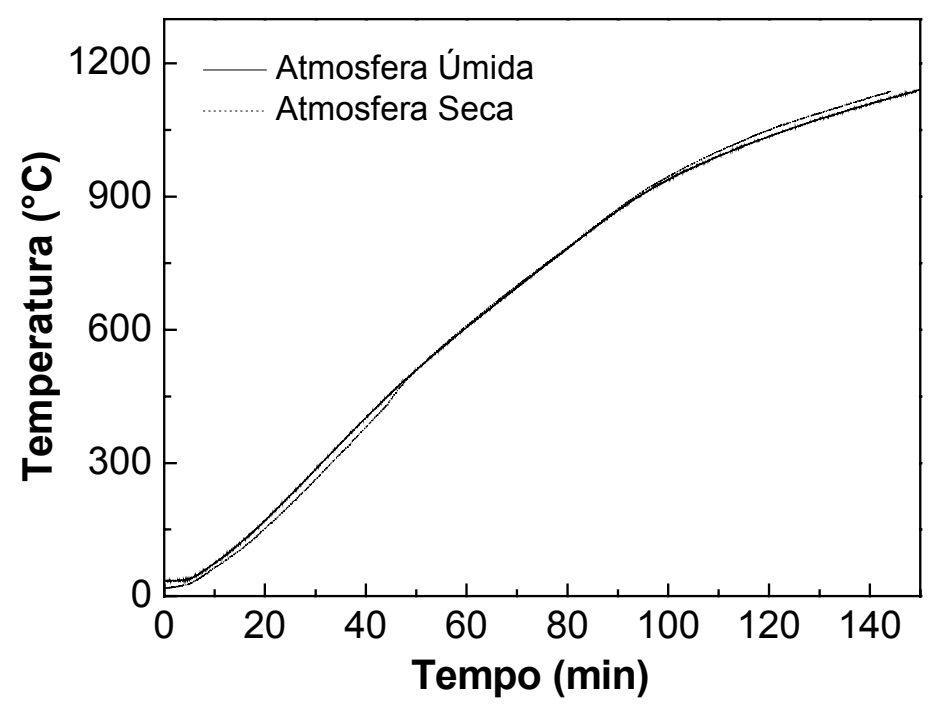

Figura 4.6 - Temperatura em função do tempo mostrando a taxa de subida de temperatura do forno utilizado para os ensaios de DTA.

Este resultado de diminuição da temperatura de transformação já havia sido tratado anteriormente por Bagwell e Messing [4] que atribuíram a diminuição da temperatura de transformação a um aumento no coeficiente de difusão superficial devido a presença de vapor de água no ambiente, diminuindo a energia de ativação da reação. Outros autores, sobre o mesmo tema, sugeriram ainda que a moléculas podem diminuir localmente a temperatura na superfície da partículas, diminuindo a velocidade de cristalização e também modificar fluxos difusionais $[1,2,1-2]$.

Entretanto, nota-se que a discussão considera sempre que os parâmetros cinéticos do processo são preponderantes sobre os termodinâmicos. Certamente a presença de $\mathrm{H}_{2} \mathrm{O}$ no sistema tende a diminuir as energias de superfície dos polimorfos de alumina presentes [4] . O que deve ser considerado, no entanto, é a energia envolvida nesta redução, i.e., para cada polimorfo a adsorção de uma molécula de $\mathrm{H}_{2} \mathrm{O}$ diminui de um certo valor a energia total de superfície e que a quantidade adsorvida depende da pressão parcial de água na atmosfera durante a transformação. Neste ponto vale comentar sobre os processos de síntese de alumina realizados através de métodos de precipitação de hidróxidos a partir 
soluções aquosas. Nestes casos, a presença de água na atmosfera de calcinação também deve ser determinante para a temperatura na qual as fases são estáveis, pois a decomposição dos hidratos leva a formaçào de vapor de água nos fornos de síntese.

Diversos estudos têm se dedicado a determinação das energias de adsorção de $\mathrm{H}_{2} \mathrm{O}$ nos polimorfos da alumina $[23,5387,11,36,24]$. Nestes estudos, um valor médio para adsorção de $\mathrm{H}_{2} \mathrm{O}$ nas diferentes superfícies de $\gamma$-alumina foi obtido de aproximadamente $-190 \mathrm{~kJ} \mathrm{~mol}^{-1}$. Para $\alpha$-alumina este valor está próximo de $-800 \mathrm{~kJ} \mathrm{~mol}^{-1}$. Sendo a transformação dependente de um balanço de energia entre a energia de superfície da alumina de transição gama e de sua rede e a da superfície da alumina alfa e de sua rede, pode-se notar que a presença de água modificará a termodinâmica do processo. Isto é, a presença de moléculas de $\mathrm{H}_{2} \mathrm{O}$ diminui as energias de superfície de ambas as fases. No entanto, como este efeito é mais pronunciado para alumina alfa, esta tem um efeito de estabilização mais pronunciado, levando a transformação a ocorrer em temperaturas mais baixas.

Não é o intuito deste trabalho a prova desta hipótese de mecanismo de ação das moléculas de $\mathrm{H}_{2} \mathrm{O}$ na transformação de fase $\gamma-\alpha$ da $\mathrm{Al}_{2} \mathrm{O}_{3}$. Estas idéias, no entanto, surgiram da dependência da transformação de fase das energias do sistema, particularmente na energia de superfície, que é comprovada nas próximas seções que consistem do foco principal deste trabalho, isto é, o efeito dos aditivos na transformação.

\subsection{Estudo da transformação de fase da alumina sem aditivos}

Nas próximas seções serão estudados os efeitos dos aditivos nas energias de superfície e de rede da $\mathrm{Al}_{2} \mathrm{O}_{3}$, avaliando-se a presença de tamanhos críticos de transformação e tentando estabelecer uma relação entre os resultados. Inicialmente apresenta-se um estudo na transformação de fase da alumina preparada pelo método Pechini sem aditivos. Os valores obtidos são comparados com os reportados na literatura, em particular para as medidas de adsorção de $\mathrm{H}_{2} \mathrm{O}$ em amostras similares a fim de avaliar o procedimento experimental adotado neste trabalho. 
Na Figura 4.7 observam-se os dados de DTA para $\mathrm{Al}_{2} \mathrm{O}_{3}$ preparado pelo método do precursor polimérico e tratado a $650{ }^{\circ} \mathrm{C}$ por $15 \mathrm{~h}$. A análise foi realizada a uma taxa de $10{ }^{\circ} \mathrm{C}$ por minutos sob atmosfera de ar sintético seco e mostra o pico exotérmico atribuído à transformação $\gamma-\alpha$ da alumina. No detalhe da Figura 4.7 é mostrada a derivada do gráfico de DTA que indica a temperatura de início da reação determinada em $\sim 1025{ }^{\circ} \mathrm{C}$, coerentemente com dados da literatura para esta transformação [5327] . Ainda na Figura 4.7 são mostradas as áreas de superfície específica das amostras calcinadas e resfriadas nas temperaturas ao longo da transformação, de acordo com o procedimento experimental descrito, de modo a avaliar a presença de um tamanho crítico para a reação. A Figura 4.8 mostra a difração de raios $\mathrm{X}$ de uma das amostras anteriores à temperatura de início da reação indicada pelo DTA e uma imediatamente posterior a esta, mostrando tratar-se da reação em questão e reforçando a coerência da determinação da temperatura de início feita pela derivada da curva de DTA (Figura 4.7). Os difratogramas estão de acordo com os descritos na literatura para fase espinélio $\gamma-\mathrm{Al}_{2} \mathrm{O}_{3}$ anteriormente a transformação e presença de $\alpha-\mathrm{Al}_{2} \mathrm{O}_{3}$ após o início da transformação . 


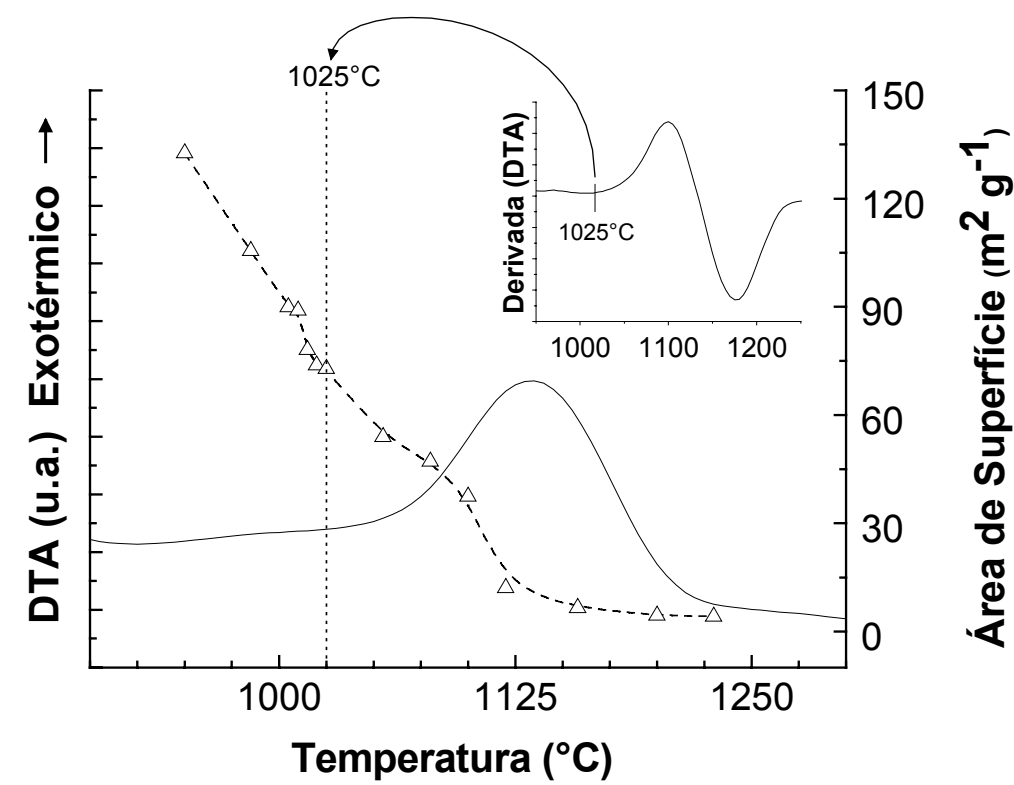

Figura 4.7 - Análise térmica diferencial (DTA) e áreas de superfície específica de amostras de $\mathrm{Al}_{2} \mathrm{O}_{3}$ sem aditivos $(\Delta)$ sintetizadas pelo método dos precursores poliméricos e calcinadas em diferentes temperaturas a uma taxa de $10^{\circ} \mathrm{C} \min ^{-1}$. No detalhe a derivada da curva de DTA mostrando a temperatura de início da transformação.

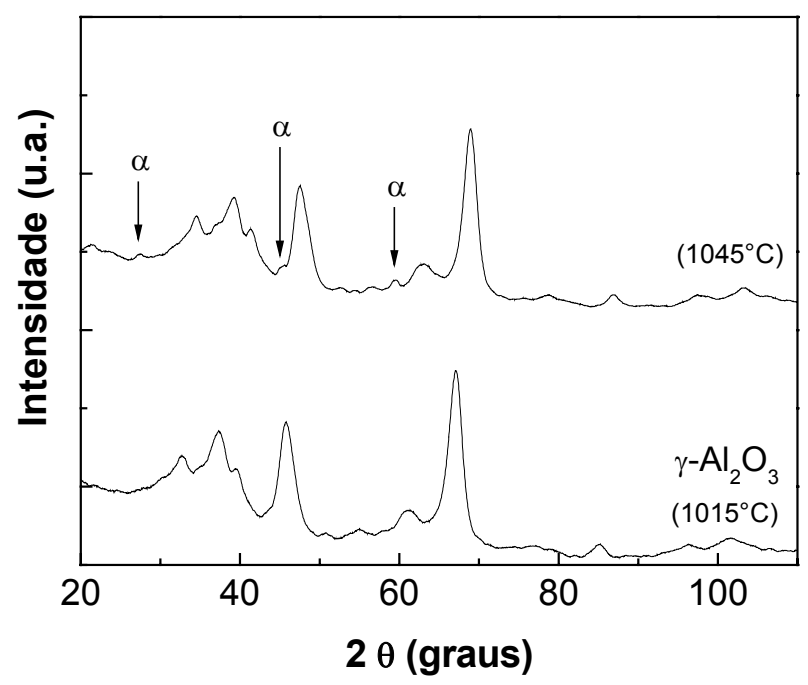

Figura 4.8 - Difração de raios $\mathrm{X}$ de amostras de $\mathrm{Al}_{2} \mathrm{O}_{3}$ sem aditivos calcinada em uma temperatura anterior $\left(1015^{\circ} \mathrm{C}\right)$ e imediatamente posterior $\left(1045^{\circ} \mathrm{C}\right)$ à transformação de fase. 
Analisando o conjunto de dados nota-se que a transformação tem início quando $\gamma-\mathrm{Al}_{2} \mathrm{O}_{3}$ atinge um área de superfície específica de aproximadamente 75 $\mathrm{m}^{2} \mathrm{~g}^{-1}$. Este resultado é interpretado como sendo o tamanho crítico de partícula para a transformação [5327]. Nota-se no entanto, que existe uma incoerência deste valor com o valor reportado na literatura de $125 \mathrm{~m}^{2} \mathrm{~g}^{-1}$ [1-2,5327], obtido considerando a energia livre total das fases composta pela entalpia das fases e a energia das superfícies $\left(1,67 \mathrm{~J} \mathrm{~m}^{-2}\right.$ para $\gamma-\mathrm{Al}_{2} \mathrm{O}_{3}$ e $2,64 \mathrm{~J} \mathrm{~m}^{-2}$ para $\left.\alpha-\mathrm{Al}_{2} \mathrm{O}_{3}\right)$. A determinação deste último, no entanto, desconsidera a variável entrópica do sistema na transformação. Isto é, durante um processo real de transformação a temperaturas elevadas, o elemento entrópico é bastante significativo e o termo $T \Delta S$ deve torna-se relevante na energia livre. Para um cálculo aproximado deste efeito pode-se considerar que em temperaturas suficientemente elevadas o termo $T \Delta S$ pode ser o fator predominante na energia livre total e, assim, $\gamma-\mathrm{Al}_{2} \mathrm{O}_{3}$ (que possui maior entropia devido a estrutura de vacâncias) poderia ser mais estável que $\alpha-\mathrm{Al}_{2} \mathrm{O}_{3}$. Experimentalmente tal transição não pôde ser detectada até o ponto de fusão da $\alpha-\mathrm{Al}_{2} \mathrm{O}_{3}, 2054{ }^{\circ} \mathrm{C}(2327 \mathrm{~K})$, mas a estrutura da alumina líquida mostra-se com características de $\gamma-\mathrm{Al}_{2} \mathrm{O}_{3}$ (isto é, $\mathrm{Al}^{3+}$ com coordenação tetraédrica [3] ). Deste modo, pode-se supor que a menor temperatura na qual ocorre a transformação de $\alpha-\mathrm{Al}_{2} \mathrm{O}_{3}$ para $\gamma-\mathrm{Al}_{2} \mathrm{O}_{3}$ será o ponto de fusão. Assim, a energia livre $\Delta G$ de transformação de $\alpha-\mathrm{Al}_{2} \mathrm{O}_{3}$ para $\gamma-\mathrm{Al}_{2} \mathrm{O}_{3}$ será zero para $2054{ }^{\circ} \mathrm{C}(2327$ K). Assumindo a entalpia de transformação como sendo $13,4 \mathrm{~kJ} \mathrm{~mol}^{-1}[4], \Delta S_{\alpha-\gamma}$ é $5,7 \mathrm{~J} \mathrm{~K}^{-1} \mathrm{~mol}^{-1}$. Considerando a temperatura de preparação média das amostras como $1000^{\circ} \mathrm{C}$, pode-se calcular o termo entrópico na estrutura, que representaria uma queda na área de superfície específica crítica de transformação para aproximadamente $60 \mathrm{~m}^{2} \mathrm{~g}^{-1}$ utilizando como dados para o cálculo os resultados de energia de superfície de McHale e colaboradores [5327] .

Este resultado é mais próximo da área crítica determinada na Figura 4.7 mostrando que, apesar das aproximações, um efeito entrópico age no sistema. Quando a amostra é resfriada imediatamente durante o tratamento térmico, como na preparação das amostras deste trabalho, a estrutura e microestrutura das partículas durante o processo é mantida não havendo tempo e condições para relaxação. O efeito da entropia é assim indiretamente incorporado e observado na 
área crítica de superfície. Uma maior desordem na rede cristalina deve também ser observada, o que gera uma conseqüente energia de volume menor que das estruturas em equilíbrio reportadas na literatura [5327]. A seguir apresentamos os resultados da calorimetria de dissolução de alta temperatura comprovando tais hipóteses.

Sete amostras de alumina sem aditivos foram submetidas aos ensaios de calorimetria de dissolução utilizando borato de chumbo como solvente a $700{ }^{\circ} \mathrm{C}$. A Tabela 4.1A compila as medidas calorimétricas obtidas. A área de superfície específica de cada amostra e as temperaturas de transformação são mostradas na Tabela 4.1B. Os resultados, no entanto, devem ser corrigidos para a presença de $\mathrm{H}_{2} \mathrm{O}$ adsorvido na superfície. Calculando o conteúdo de $\mathrm{H}_{2} \mathrm{O}$ das amostras conforme detalhado nos procedimentos experimentais, determinou-se uma média de $35 \%$ em massa de $\mathrm{H}_{2} \mathrm{O}$ quimissorvido, coerente com o reportado na literatura para amostras preparadas por calcinação de hidróxidos [5327] .

$\mathrm{O}$ calor de quimissorção da $\mathrm{H}_{2} \mathrm{O}$ na alumina foi determinado por microcalorimetria de adsorção. A amostra foi termicamente ativada a $750{ }^{\circ} \mathrm{C}$ sob vácuo e então resfriada até $25{ }^{\circ} \mathrm{C}$ sendo sucessivamente exposta a diferentes quantidades de vapor de água. A energia liberada na adsorção foi computada pelo microcalorímetro. Comparando as perdas de massa após o tratamento a $750{ }^{\circ} \mathrm{C} \mathrm{e}$ aquela a $1550{ }^{\circ} \mathrm{C}$ pôde-se determinar a quantidade de $\mathrm{H}_{2} \mathrm{O}$ remanescente na superfície anterior a exposição ao vapor de $\mathrm{H}_{2} \mathrm{O}$. Um total de $6 \mathrm{mg}$ de $\mathrm{H}_{2} \mathrm{O}$ por grama de $\mathrm{Al}_{2} \mathrm{O}_{3}$ foi determinado. Este valor corresponde a 2,86 $\mathrm{OH}$ levando em consideração a área de superfície específica da amostra de alumina submetida ao ensaio. 
Tabela 4.1A. Sumário dos resultados obtidos para as amostras de $\gamma-\mathrm{Al}_{2} \mathrm{O}_{3}$ sem aditivos com seus respectivos conteúdos de $\mathrm{H}_{2} \mathrm{O}$ e dados de calorimetria de dissolução de alta temperatura. Os erros relatados são desvios padrões. $\Delta H_{s o l}$ é o valor não corrigido do calor de dissolução. $\Delta H_{c l}$ é $\Delta H_{s o l}$ corrigido usando os dados de calor de adsorção de $\mathrm{H}_{2} \mathrm{O}$ reportado por McHale et al [5327]. $\Delta H_{c 2}$ é $\Delta H_{\text {sol }}$ corrigido usando os dados de calor de adsorção de $\mathrm{H}_{2} \mathrm{O}$ obtidos neste trabalho. * $\mathrm{O}$ conteúdo de $\mathrm{H}_{2} \mathrm{O}$ adsorvido foi medido por perda de massa (gramas de $\mathrm{H}_{2} \mathrm{O}$ por grama de $\mathrm{Al}_{2} \mathrm{O}_{3}$ ) e transformado calculando o número de moléculas de $\mathrm{H}_{2} \mathrm{O}$ dividido pela área de superfície específica de cada amostra em $\mathrm{nm}^{2}$.

\begin{tabular}{|c|c|c|c|c|c|c|c|}
\hline Amostra & $\begin{array}{c}\mathrm{x} \mathrm{em} \\
\mathrm{Al}_{2} \mathrm{O}_{3} \cdot \mathrm{x} \mathrm{H}_{2} \mathrm{O} \\
\text { (equilíbrio) }\end{array}$ & $\begin{array}{c}\mathrm{H}_{2} \mathrm{O} \text { Quimissorvida } \\
\left.(\mathrm{OH} \mathrm{nm})^{-2}\right)^{*}\end{array}$ & $\begin{array}{c}\Delta H_{\text {sol }} \\
\left(\mathrm{J} \mathrm{g}^{-1} \mathrm{Al}_{2} \mathrm{O}_{3} \cdot \mathrm{xH}_{2} \mathrm{O}\right)\end{array}$ & $\begin{array}{c}\Delta H_{\text {sol }} \\
\left(\mathrm{kJ} \mathrm{mol}^{-1} \mathrm{Al}_{2} \mathrm{O}_{3} \cdot \mathrm{xH}_{2} \mathrm{O}\right)\end{array}$ & $\begin{array}{l}\text { Número de } \\
\text { ensaios }\end{array}$ & $\begin{array}{c}\Delta H_{c l}\left(\mathrm{~kJ} \mathrm{~mol}^{-1}\right. \\
\left.\mathrm{Al}_{2} \mathrm{O}_{3}\right)\end{array}$ & $\begin{array}{c}\Delta H_{c 2}\left(\mathrm{~kJ} \mathrm{~mol}^{-1}\right. \\
\left.\mathrm{Al}_{2} \mathrm{O}_{3}\right)\end{array}$ \\
\hline AP1 & 0,580 & 18,0 & $1037,1 \pm 18,1$ & $105.8 \pm 1,2$ & 9 & $52,3 \pm 1,4$ & $56,3 \pm 1,4$ \\
\hline AP2 & 0,501 & 19,5 & $981,9 \pm 9,4$ & $100.1 \pm 0,6$ & 4 & $53,7 \pm 1,0$ & $56.9 \pm 1,0$ \\
\hline AP3 & 0,548 & 25,3 & $1004,4 \pm 16,1$ & $112.3 \pm 1,8$ & 8 & $54,8 \pm 1,6$ & $57.6 \pm 1,6$ \\
\hline AP4 & 0,455 & 21,1 & $978,4 \pm 13,8$ & $107.8 \pm 1,5$ & 6 & $58,3 \pm 1,4$ & $61.1 \pm 1,4$ \\
\hline AP5 & 0,431 & 22,8 & $982,8 \pm 10,8$ & $107.7 \pm 1,2$ & 7 & $61,7 \pm 1,1$ & $64.1 \pm 1,0$ \\
\hline AP6 & 0,373 & 20,9 & $957,5 \pm 11,8$ & $104.1 \pm 1,2$ & 8 & $63,8 \pm 1,2$ & $66.1 \pm 1,2$ \\
\hline AP7 & 0,397 & 22,6 & $963,6 \pm 22,7$ & $105.1 \pm 2,3$ & 7 & $62.8 \pm 2,2$ & $65.0 \pm 2,2$ \\
\hline
\end{tabular}


Tabela 4.1B. Caracterização das amostras preparadas nas temperaturas indicadas na tabela. As fases foram identificadas como exclusivamente de $\gamma-\mathrm{Al}_{2} \mathrm{O}_{3}$ por difração de raios $\mathrm{X}$ e a área de superfície específica foi medida por adsorção de $\mathrm{N}_{2}$ (BET).

\begin{tabular}{|c|c|c|}
\hline Amostra & Temperatura $\left({ }^{\circ} \mathrm{C}\right)$ & $\begin{array}{c}\text { Área de superfície } \\
\text { específica }\left(\mathrm{m}^{2} \mathrm{~g}^{-1}\right)\end{array}$ \\
\hline AP1 & 950 & 132,6 \\
\hline AP2 & 985 & 105,5 \\
\hline AP3 & 1005 & 89,9 \\
\hline AP4 & 1010 & 89,0 \\
\hline AP5 & 1015 & 78,1 \\
\hline AP6 & 1020 & 73,8 \\
\hline AP7 & 1025 & 72,8 \\
\hline
\end{tabular}

A Figura 4.9A mostra a entalpia de adsorção de $\mathrm{H}_{2} \mathrm{O}$ no $\gamma-\mathrm{Al}_{2} \mathrm{O}_{3}$ em função da cobertura de $\mathrm{OH}$ na superfície. A curva tem um decaimento exponencial que é coerente com um comportamento de Freundlich [5327] . Na Figura 4.9B a integral dos dados é apresentada mostrando que para uma cobertura de $15 \mathrm{OH} \mathrm{nm}^{-2}$ há uma energia associada de aproximadamente $1,30 \mathrm{~J} \mathrm{~m}^{-2}$. Note que os resultados integrados foram corrigidos para a quantidade de $\mathrm{OH}$ pré-adsorvida $\left(2,86 \mathrm{OH} \mathrm{nm}^{-}\right.$ ${ }^{2}$ ), sendo a energia relativa a estas moléculas determinada através de uma extrapolação linear dos dados de coberturas menores que $6 \mathrm{OH} \mathrm{nm}^{-2}$ até zero e assim adicionando $0,346 \mathrm{~J} \mathrm{~m}^{-2}$ a cada ponto medido. Este resultado $\left(\sim 1,30 \mathrm{~J} \mathrm{~m}^{-2}\right)$ é menor que aquele apresentado na literatura para $\gamma-\mathrm{Al}_{2} \mathrm{O}_{3}$ com a mesma fração de $\mathrm{OH}$ produzida por calcinação de hidróxidos $\left(\sim 1,54 \mathrm{~J} \mathrm{~m}^{-2}\right)$ [5327]. Para avaliar esta diferença nos resultados, que pode estar relacionada com o processo de síntese dos materiais ou a impurezas, testou-se o mesmo procedimento adotado neste ensaio na mesma amostra utilizada nos relatos da literatura fornecida pelos autores destes, denominada a partir daqui como $\gamma-\mathrm{Al}_{2} \mathrm{O}_{3}$ referência $\left(167,1 \mathrm{~m}^{2} \mathrm{~g}^{-1}\right)$. 

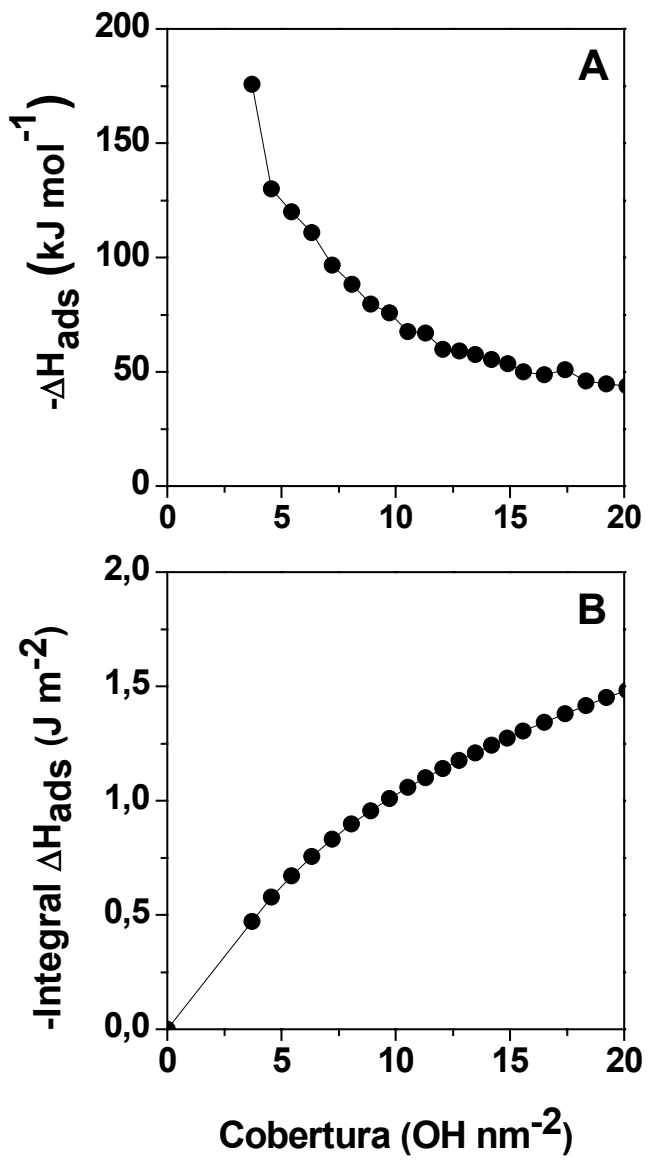

Figura 4.9 - Entalpia de adsorção de $\mathrm{H}_{2} \mathrm{O}$ na superfície de $\gamma-\mathrm{Al}_{2} \mathrm{O}_{3}$ sem aditivos em função da cobertura de OH. (A) Entalpia de adsorção medida para cada adsorção. (B) Integral das medidas de calor de adsorção.

$\mathrm{Na}$ Figura 4.10A são apresentados os resultados obtidos para $\gamma-\mathrm{Al}_{2} \mathrm{O}_{3}$ referência utilizando o procedimento descrito neste trabalho e o reportado na literatura [5327]. 

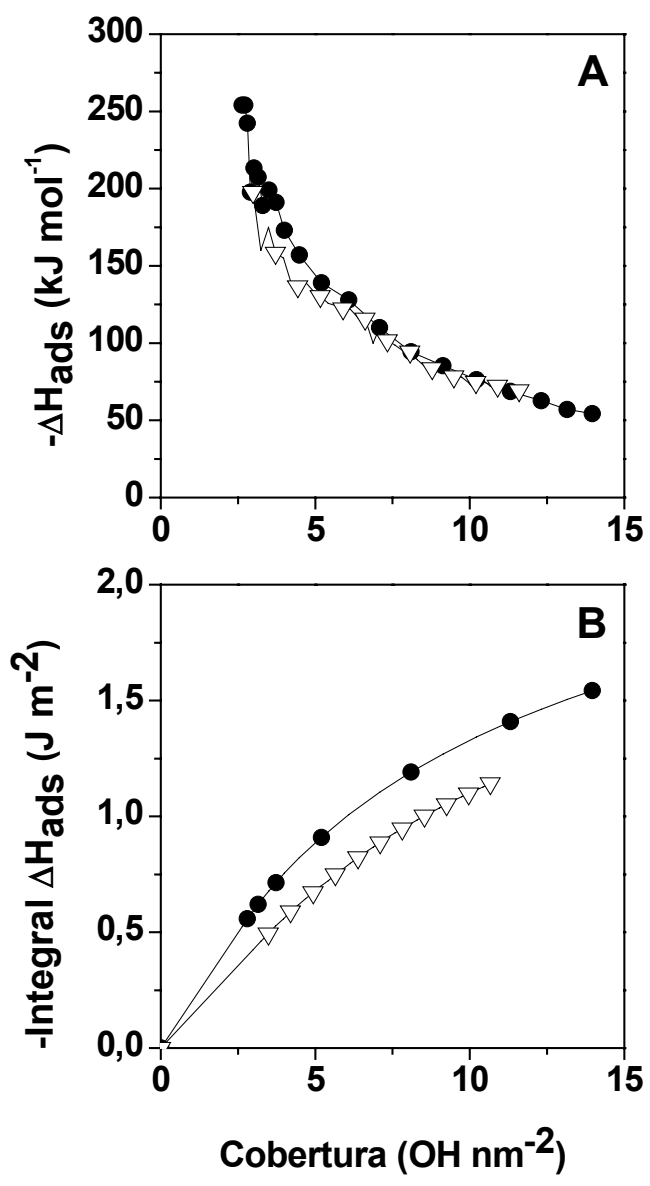

Figura 4.10 - Entalpia de adsorção de $\mathrm{H}_{2} \mathrm{O}$ na superfície do $\gamma-\mathrm{Al}_{2} \mathrm{O}_{3}$ referência em função da cobertura de $\mathrm{OH}$. (A) Entalpia de adsorção medida para cada adsorção reportado na literatura $(\bullet)$ e medido neste trabalho $(\nabla)$. (B) Integral das medidas de calor de adsorção reportado na literatura $(\bullet)$ e medido neste trabalho $(\nabla)$.

Os resultados obtidos neste trabalho são inferiores ao da literatura. Isto é claramente observado na Figura 4.10B onde a integral dos dados mostra uma diferença média de $0,2 \mathrm{~J} \mathrm{~m}^{-2}$. Os resultados obtidos neste trabalho para a $\gamma-\mathrm{Al}_{2} \mathrm{O}_{3}$ referência são, no entanto, bastante similares àqueles apresentados na Figura 4.9, sugerindo que a causa dos valores inferiores não devem estar relacionada ao processo de síntese ou preparação dos materiais mas sim a uma diferença no procedimento. Esta discrepância deve estar principalmente relacionada ao vácuo menos intenso imposto nas amostras antes do experimento. Nota-se que a entalpia 
de adsorção das primeiras moléculas na alumina referência relatada na literatura é de cerca de $254 \mathrm{~kJ} \mathrm{~mol}^{-1}$. A maior energia associada foi de $198 \mathrm{~kJ} \mathrm{~mol}^{-1}$ para a alumina referência sob as condições deste trabalho. Isto pode ser uma evidência de que o tratamento não foi suficiente para remover as moléculas de $\mathrm{H}_{2} \mathrm{O}$ mais energeticamente adsorvidas na superfície. No entanto, mesmo utilizando comparativamente as duas correções para $\mathrm{H}_{2} \mathrm{O}$ quimissorvido nos dados de calorimetria de dissolução, somente uma pequena diferença é observada e os resultados obtidos são semelhantes. Isto demonstra a confiabilidade dos resultados deste trabalho e principalmente das análises comparativas para estudo da ação dos íons aditivos que serão executadas na seqüência do trabalho.

Os dados de calorimetria de dissolução foram então corrigidos a partir dos dados de conteúdos de $\mathrm{H}_{2} \mathrm{O}$ determinados por perda de massa e de entalpia de adsorção. A Tabela 4.1A mostra a fração molar de $\mathrm{H}_{2} \mathrm{O}$ inicial presente nas amostras assim como o conteúdo $\mathrm{H}_{2} \mathrm{O}$ quimicamente adsorvido indicado por $\mathrm{OH}$ $\mathrm{nm}^{-2}$. O fato da fração de $\mathrm{OH}$ não aumentar progressivamente com a área de superfície específica das amostras está relacionado ao estado de aglomeração (aglomerados fracos) e variações internas de umidade no laboratório de ensaio, ambos não afetando os estudos em questão. Baseado nos gráficos das integrais das entalpias de adsorção nas Figuras 4.9B e 4.10B determinaram-se as energias totais relativas às moléculas de $\mathrm{H}_{2} \mathrm{O}$ quimicamente adsorvidas, considerando o ensaio realizado neste trabalho e aquele reportado na literatura. A correção foi feita utilizando ambos os dados para comparação e os resultados finais são mostrados na Figura 4.11. 


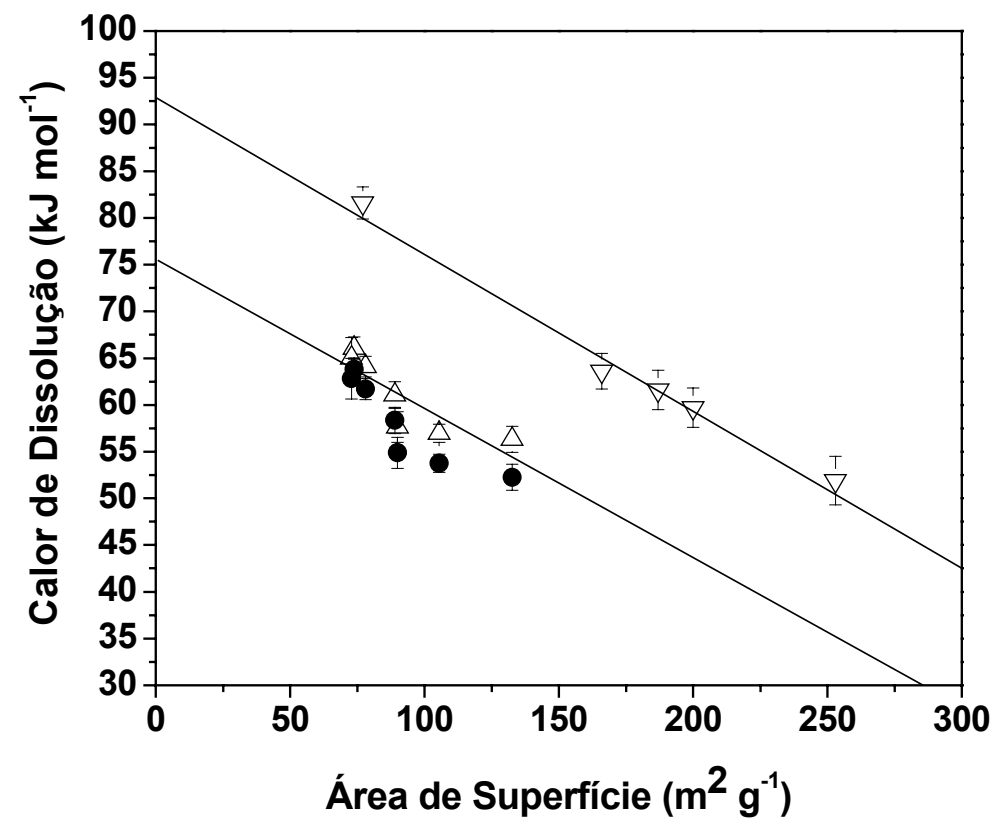

Figura 4.11 - Calor de dissolução em função da área de superfície específica do $\gamma$ $\mathrm{Al}_{2} \mathrm{O}_{3}$. Resultados corrigidos com os valores de entalpia de quimissorção de $\mathrm{H}_{2} \mathrm{O}$ reportados na literatura $(\bullet)$, valores corrigidos utilizando as medidas deste trabalho $(\Delta)$ e valores comparativos da literatura $(\nabla)[5327]$.

A Figura 4.11 mostra que os resultados de calorimetria são próximos, tanto utilizando as correções apresentadas na literatura para $\mathrm{H}_{2} \mathrm{O}$ quimissorvido [5327] como utilizando os deste trabalho mostrando a confiabilidade do procedimento experimental. No entanto, nota-se que os resultados de calorimetria de dissolução de mergulho (drop solution) são consideravelmente menores que aqueles descritos na literatura para $\gamma-\mathrm{Al}_{2} \mathrm{O}_{3}$ referência [5327]. As energias de superfície determinadas pela inclinação destes gráficos são bastante semelhantes, sendo 1,67 $\mathrm{J} \mathrm{m}^{-2}$ para $\gamma-\mathrm{Al}_{2} \mathrm{O}_{3}$ referência e $1,61 \mathrm{~J} \mathrm{~m}^{-2}$ para $\gamma-\mathrm{Al}_{2} \mathrm{O}_{3}$ deste trabalho. Isto está de acordo com a hipótese de ação da entropia na estrutura da alumina durante a transformação. Havendo um resfriamento brusco das amostras durante a transformação, a estrutura é mantida, assim como a ação da entropia. Neste caso, a entropia estaria relacionada a um aumento da desordem da rede, diminuindo o calor de dissolução. Este efeito é menos intensos na superfície das partículas [2] , 
o que é coerente com os resultados similares de energia de superfície. A entropia associada ao método de síntese seria então responsável pelo tamanho crítico mais elevado observado para a alumina neste trabalho. Isto considerando o produto final com energias semelhantes após a reação de transformação de ambas as amostras, hipótese esta razoável levando em conta a estrutura compacta e coalescida do $\alpha-\mathrm{Al}_{2} \mathrm{O}_{3}$.

A influência dos aditivos foi então verificada e comparada com os dados obtidos para $\gamma-\mathrm{Al}_{2} \mathrm{O}_{3}$ preparada pelo método Pechini utilizando o mesmo procedimento experimental como descrito nas próximas seções.

\subsection{Efeito do íon Mg na transformação de fase $\gamma-\alpha \mathrm{da} \mathrm{Al}_{2} \mathrm{O}_{3}$}

A Figura 4.12 mostra o efeito do íon $\mathrm{Mg}$ na temperatura de transformação de fase $\gamma-\alpha$ do $\mathrm{Al}_{2} \mathrm{O}_{3}$ através do pico exotérmico característico. Utilizando a derivada da curva de DTA apresentada no detalhe da figura observou-se a temperatura de início da transformação para cada amostra. Comparativamente com o pico relativo à $\mathrm{Al}_{2} \mathrm{O}_{3}$ sem aditivos, nota-se um aumento na temperatura de transformação de $50{ }^{\circ} \mathrm{C}$ para $\mathrm{Al}_{2} \mathrm{O}_{3} 3 \mathrm{~mol} \% \mathrm{Mg}\left(1070{ }^{\circ} \mathrm{C}\right)$ e $55^{\circ} \mathrm{C}$ para $5 \% \mathrm{Mg}$ $\left(1075^{\circ} \mathrm{C}\right)$. Na mesma figura são apresentadas as medidas de área de superfície específica das amostras tratadas em temperaturas anteriores a transformação para avaliação da presença de um tamanho crítico e comparação com aquele da $\mathrm{Al}_{2} \mathrm{O}_{3}$ sem aditivos. Correlacionando os dados de DTA com os dados de área de superfície específica apresentados na Figura 4.12 nota-se uma área crítica de transformação de aproximadamente $75 \mathrm{~m}^{2} \mathrm{~g}^{-1}$, semelhante à determinada para $\mathrm{Al}_{2} \mathrm{O}_{3}$. A Figura 4.13 mostra a difração de raios $\mathrm{X}$ de duas amostras de $\gamma-\mathrm{Al}_{2} \mathrm{O}_{3}$ contendo 3 e $5 \mathrm{~mol} \%$ de $\mathrm{Mg}$ comprovando a presença apenas da fase espinélio sem a formação de fases secundárias que poderiam colocar dúvidas no estudo comparativo dos tamanhos de partícula. 


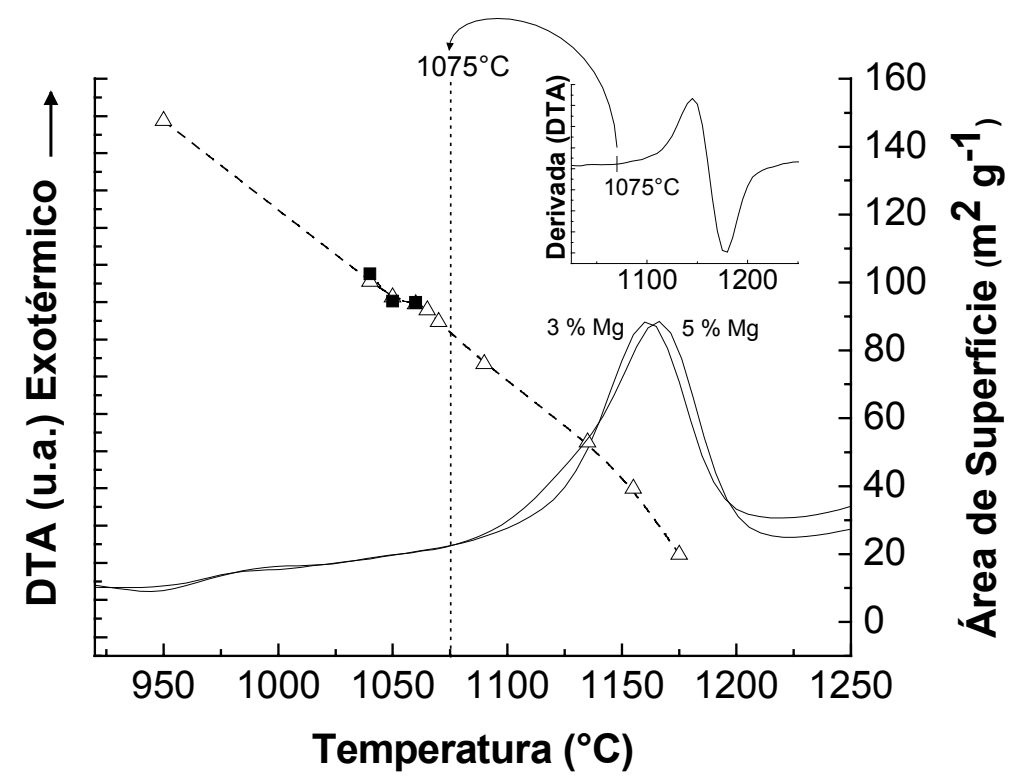

Figura 4.12 - Análise térmica diferencial (DTA) e áreas de superfície específicas das amostras de $\gamma-\mathrm{Al}_{2} \mathrm{O}_{3}$ contendo $\mathrm{Mg}$ como aditivo. As áreas de superfície específicas são referentes às amostras contendo $5 \mathrm{~mol} \%$ de $\mathrm{Mg}(\Delta)$ e $3 \mathrm{~mol} \% \mathrm{Mg}$ (匹). No detalhe a derivada da curva de DTA para a amostra $\mathrm{Al}_{2} \mathrm{O}_{3} 5 \mathrm{~mol} \% \mathrm{Mg}$.

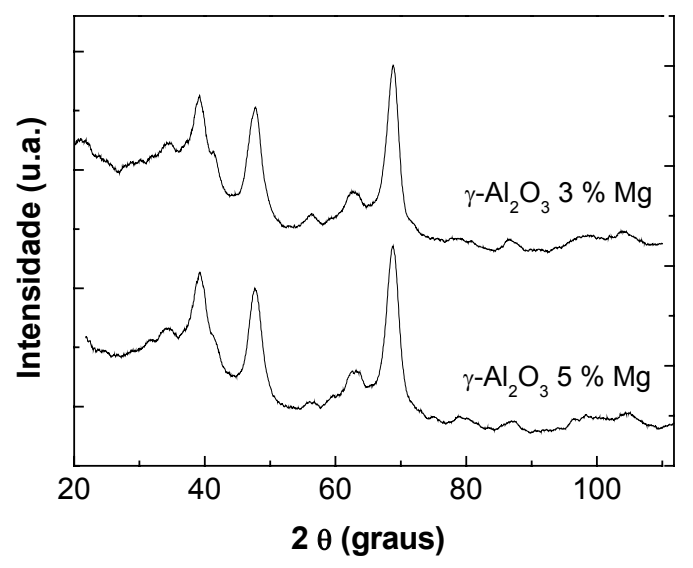

Figura 4.13 - Difração de raios $\mathrm{X}$ de amostras de $\gamma-\mathrm{Al}_{2} \mathrm{O}_{3}$ contendo $\mathrm{Mg}$ como aditivo e tratadas em temperaturas à $10{ }^{\circ} \mathrm{C}$ do início da transformação de fase. 
Baseado nos fundamentos termodinâmicos da transformação pode-se supor, numa primeira análise dos resultados, que o aditivo não influencia de forma determinante a resultante das energias do sistema, não alterando a relação entre a energia de volume e energia de superfície que determinam o tamanho crítico. No entanto, a precisão na determinação destes valores de tamanho não permite uma conclusão definitiva a este respeito. Isto é, o desvio padrão médio na determinação da área de superfície específica das amostras $\left(\sim 1,5 \mathrm{~m}^{2} \mathrm{~g}^{-1}\right)$ torna importante uma avaliação cuidadosa de todo o fenômeno para obterem-se conclusões realistas.

Desta maneira, torna-se interessante uma análise das energias dos sistemas por calorimetria de dissolução de alta temperatura para avaliação da ação do aditivo. As medidas de calor de dissolução das amostras de $\mathrm{Al}_{2} \mathrm{O}_{3}$ contendo 3 e 5 mol \% Mg obtidas em diversas temperaturas anteriores a transformação são relacionadas na Tabela 4.2A. As áreas de superfície específica para as respectivas temperaturas de calcinação das amostras são mostradas na Tabela 4.2B. As condições dos ensaios foram semelhantes àquelas descritas para $\mathrm{Al}_{2} \mathrm{O}_{3}$ sem aditivos. Da mesma maneira há necessidade de correção das medidas devido à presença de $\mathrm{H}_{2} \mathrm{O}$ adsorvida na superfície das amostras. $\mathrm{O}$ conteúdo total de $\mathrm{H}_{2} \mathrm{O}$ foi determinado pela perda de massa total a $1550{ }^{\circ} \mathrm{C}$ e a quantidade quimissorvida de $\mathrm{H}_{2} \mathrm{O}$ foi determinada pela perda de massa a $125^{\circ} \mathrm{C}$ como descrito na seção experimental. $\mathrm{O}$ conteúdo de $\mathrm{H}_{2} \mathrm{O}$ quimissorvida para cada amostra é mostrado na Tabela 4.2A. O calor de quimissorção de $\mathrm{H}_{2} \mathrm{O}$ na $\gamma-\mathrm{Al}_{2} \mathrm{O}_{3} 5 \% \mathrm{Mg}$ foi medido utilizando técnica de microcalorimetria de adsorção de gases. A Figura 4.14A mostra os resultados de calor de adsorção de $\mathrm{H}_{2} \mathrm{O}$ em $\gamma-\mathrm{Al}_{2} \mathrm{O}_{3} 5 \% \mathrm{Mg}$ em função da cobertura de $\mathrm{OH}$ nas partículas. A título de comparação são colocados no gráfico os dados referentes à alumina sem aditivos obtidos neste trabalho. 
Tabela 4.2A. Sumário dos resultados das análises de calorimetria de dissolução de alta temperatura e os conteúdos de $\mathrm{H}_{2} \mathrm{O}$ das amostras de $\mathrm{Al}_{2} \mathrm{O}_{3}$ contendo $\mathrm{Mg}$. As amostras de $5 \mathrm{M} 1$ a $5 \mathrm{M} 6$ são $\gamma-\mathrm{Al}_{2} \mathrm{O}_{3} 5 \mathrm{~mol} \% \mathrm{Mg}$, e $3 \mathrm{M} 1$ a $3 \mathrm{M} 3$ são $\gamma-\mathrm{Al}_{2} \mathrm{O}_{3} 3 \mathrm{~mol} \% \mathrm{Mg}$. $\Delta H_{\text {sol }}$ é o calor de dissolução e $\Delta H_{c 2}$ é o valor corrigido para o conteúdo $\mathrm{H}_{2} \mathrm{O}$. Os erros apresentados são desvios padrões. * $\mathrm{O}$ conteúdo de $\mathrm{H}_{2} \mathrm{O}$ adsorvido foi medido por perda de massa (gramas de $\mathrm{H}_{2} \mathrm{O}$ por grama de $\mathrm{Al}_{2} \mathrm{O}_{3}$ ) e transformado calculando o número de moléculas de $\mathrm{H}_{2} \mathrm{O}$ dividido pela área de superfície específica de cada amostra em $\mathrm{nm}^{2}$.

\begin{tabular}{|c|c|c|c|c|c|c|}
\hline Amostra & $\begin{array}{c}x \text { in } \\
\mathrm{Mg}_{\mathrm{n}} \mathrm{Al}_{2-\mathrm{n}} \mathrm{O}_{3-\mathrm{n}} x \mathrm{H}_{2} \mathrm{O} \\
\text { (equilíbrio) }\end{array}$ & $\begin{array}{c}\mathrm{H}_{2} \mathrm{O} \\
\text { Quimissorvida } \\
(\mathrm{OH} \mathrm{nm})^{-2} *\end{array}$ & $\begin{array}{c}\Delta H_{\text {sol }} \\
\left(\mathrm{kJ} \mathrm{g}^{-1}\right. \\
\left.\mathrm{Mg}_{\mathrm{n}} \mathrm{Al}_{2-\mathrm{n}} \mathrm{O}_{3-\mathrm{n}} \cdot x \mathrm{H}_{2} \mathrm{O}\right)\end{array}$ & $\begin{array}{c}\Delta H_{\text {sol }} \\
\left(\mathrm{kJ} \mathrm{mol}^{-1}\right. \\
\left.\mathrm{Mg}_{\mathrm{n}} \mathrm{Al}_{2-\mathrm{n}} \mathrm{O}_{3-\mathrm{n}} \cdot x \mathrm{H}_{2} \mathrm{O}\right)\end{array}$ & $\begin{array}{l}\text { Número de } \\
\text { ensaios }\end{array}$ & $\begin{array}{c}\Delta H_{c} \\
\left(\mathrm{~kJ} \mathrm{~mol}^{-1}\right. \\
\left.\mathrm{Mg}_{\mathrm{n}} \mathrm{Al}_{2-\mathrm{n}} \mathrm{O}_{3-\mathrm{n}}\right)\end{array}$ \\
\hline $5 \mathrm{M} 1$ & 0,659 & 18,5 & 1122,79 & $158,8 \pm 1,2$ & 4 & $79,9 \pm 1,2$ \\
\hline $5 \mathrm{M} 2$ & 0,439 & 18,0 & $1003,2 \pm 15,6$ & $106,7 \pm 1,2$ & 6 & $89,8 \pm 1,2$ \\
\hline $5 \mathrm{M} 3$ & 0,392 & 16,9 & $978,8 \pm 22,6$ & $105,3 \pm 1,4$ & 12 & $86,1 \pm 0,8$ \\
\hline $5 \mathrm{M} 4$ & 0,490 & 21,6 & $1005,2 \pm 8,0$ & $105,2 \pm 2,1$ & 8 & $92,1 \pm 1,3$ \\
\hline 5M5 & 0,438 & 19,7 & $994,1 \pm 13,4$ & $106,7 \pm 1,2$ & 8 & $89,0 \pm 1,0$ \\
\hline 5M6 & 0,326 & 17,6 & $976,5 \pm 7,7$ & $102,3 \pm 0,8$ & 9 & $99,0 \pm 1,4$ \\
\hline 3M1 & 0,507 & 20,4 & $1011,7 \pm 16,7$ & $110,6 \pm 1,6$ & 8 & $81,3 \pm 1,7$ \\
\hline $3 \mathrm{M} 2$ & 0,443 & 19,4 & $981,1 \pm 11,1$ & $106,5 \pm 1,3$ & 7 & $83,8 \pm 1,1$ \\
\hline $3 \mathrm{M} 3$ & 0,380 & 16,6 & $1016,9 \pm 15,1$ & $108,7 \pm 1,6$ & 6 & $94,7 \pm 1,5$ \\
\hline
\end{tabular}


Tabela 4.2B. Caracterização das amostras preparadas nas temperaturas indicadas na tabela. As fases foram identificadas como exclusivamente de $\gamma-\mathrm{Al}_{2} \mathrm{O}_{3}$ por difração de raios X e a área específica foi medida por adsorção de $\mathrm{N}_{2}$ (BET).

\begin{tabular}{|c|c|c|}
\hline Amostra & Temperatura $\left({ }^{\circ} \mathrm{C}\right)$ & $\begin{array}{c}\text { Área de Superfície } \\
\text { Específica }\left(\mathrm{m}^{2} \mathrm{~g}^{-1}\right)\end{array}$ \\
\hline 5M1 & 950 & 147,6 \\
\hline $5 \mathrm{M} 2$ & 1040 & 100,3 \\
\hline 5M3 & 1050 & 95,7 \\
\hline 5M4 & 1060 & 93,6 \\
\hline 5M5 & 1065 & 91,8 \\
\hline 5M6 & 1075 & 76,2 \\
\hline 3M1 & 1040 & 102,5 \\
\hline 3M2 & 1050 & 94,5 \\
\hline 3M3 & 1060 & 94,1 \\
\hline
\end{tabular}



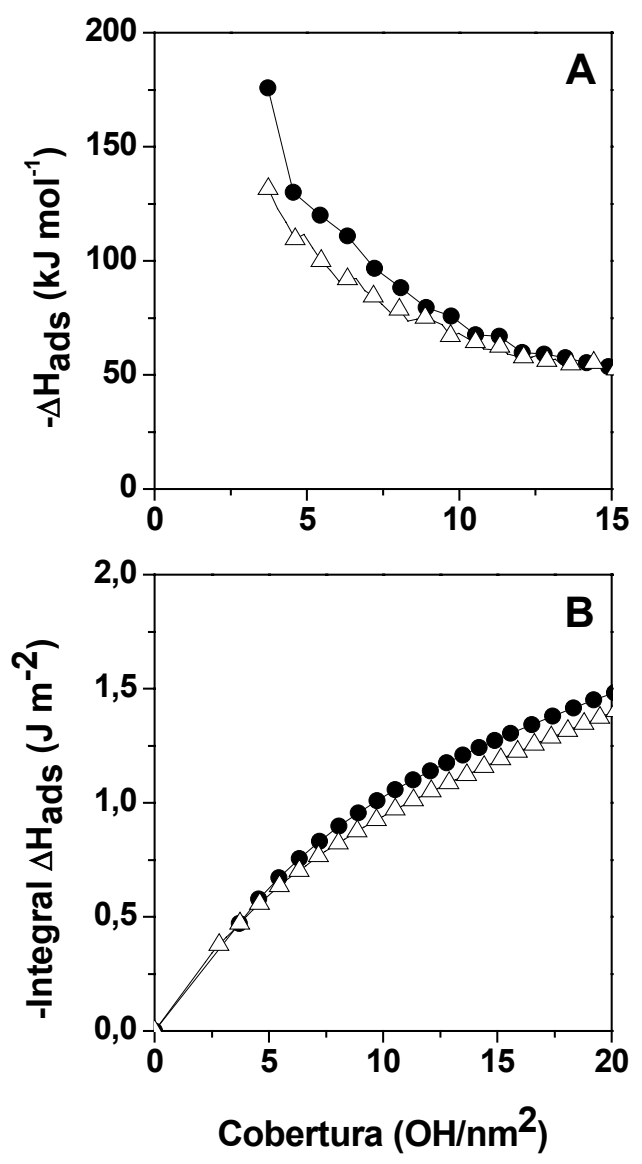

Figura 4.14 - Entalpia de adsorção de $\mathrm{H}_{2} \mathrm{O}$ na superfície do $\gamma-\mathrm{Al}_{2} \mathrm{O}_{3}$ em função da cobertura de $\mathrm{OH}$. (A) Entalpia de adsorção medida para $\gamma-\mathrm{Al}_{2} \mathrm{O}_{3}(\bullet)$ e $\gamma-\mathrm{Al}_{2} \mathrm{O}_{3}$ contendo $5 \mathrm{~mol} \% \mathrm{Mg}(\Delta)$. (B) Integral das medidas de calor de adsorção para (•) $\gamma-\mathrm{Al}_{2} \mathrm{O}_{3}$ e $(\Delta) \gamma-\mathrm{Al}_{2} \mathrm{O}_{3}$ contendo $5 \mathrm{~mol} \% \mathrm{Mg}$.

Nota-se uma variação de apenas $\sim 0,1 \mathrm{~J} \mathrm{~m}^{-2}$ entre as energias integradas de adsorção de $\mathrm{H}_{2} \mathrm{O}$ em $\gamma-\mathrm{Al}_{2} \mathrm{O}_{3}$ e $\gamma-\mathrm{Al}_{2} \mathrm{O}_{3}$ contendo $\mathrm{Mg}$ (Figura 4.14B). Este valor está pouco acima dos erros experimentais, não podendo assim ser diretamente relacionado à presença de sítios de menor energia na superfície do sistema contendo aditivo. Há índicos, portanto, de que as energias de superfície são similares para ambas amostras, sugerindo uma distribuição homogênea do aditivo na estrutura da partícula, desde que havendo segregação superficial preferencial esta diminuiria a energia de superfície $[5,1]$. 
A formação de solução sólida é assim reforçada analisando a curva de difração de raios $\mathrm{X}$ do $\gamma-\mathrm{Al}_{2} \mathrm{O}_{3}$ contendo $5 \mathrm{~mol} \% \mathrm{Mg}$ apresentada na Figura $4.13 \mathrm{e}$ o detalhe na Figura 4.15. Nestes gráficos, apesar da ausência de picos de fases secundárias, observa-se uma variação na intensidade e um pequeno deslocamento dos picos relacionados aos planos (220) - associado à alumínios tetraédricos na estrutura - e (222) - associados a alumínios tetraédricos e octaédricos da estrutura da $\gamma-\mathrm{Al}_{2} \mathrm{O}_{3}$ - sugerindo uma substituição do íon $\mathrm{Mg}^{2+}$ na rede cristalina, seguindo uma diminuição na ordenação da sub-rede .

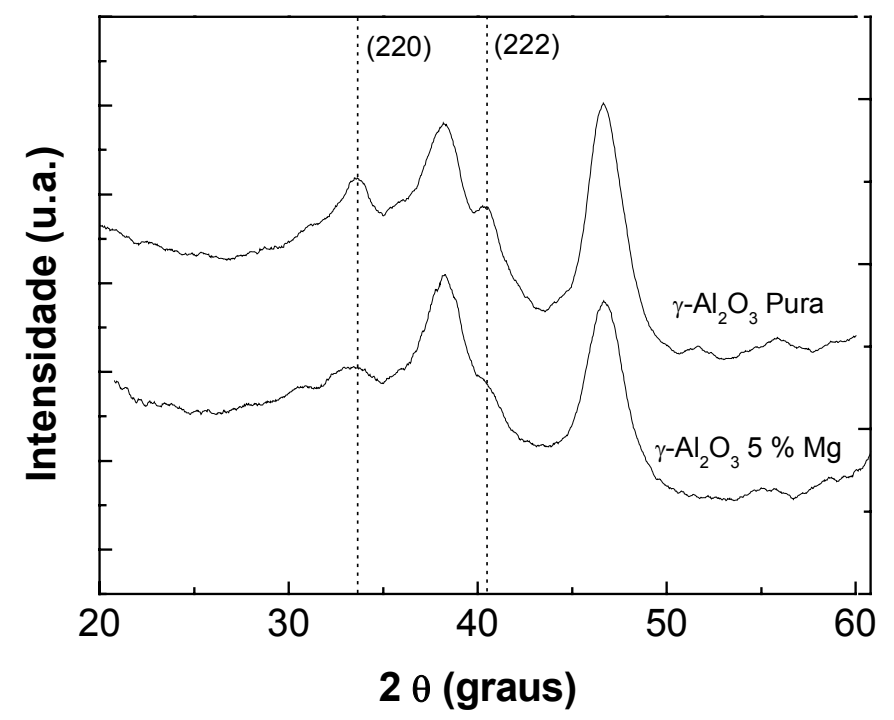

Figura 4.15 - Difração de raios $\mathrm{X}$ da $\gamma-\mathrm{Al}_{2} \mathrm{O}_{3}$ e $\gamma-\mathrm{Al}_{2} \mathrm{O}_{3}$ contendo $\mathrm{Mg}$. No detalhe os picos referentes aos planos (220) e (222) são alterados com a introdução do aditivo.

A presença do aditivo formando solução sólida pode alterar o processo de difusão na rede. Para avaliação do efeito desta distribuição do aditivo na entalpia de rede e de superfície, no entanto, recorre-se aos dados de calorimetria de dissolução. Utilizando os dados de adsorção para correção das medidas de calorimetria são obtidos os resultados apresentados na Figura 4.16 e na Tabela 4.2A. Para efeito comparativo, apresentam-se no gráfico os resultados obtidos para $\gamma-\mathrm{Al}_{2} \mathrm{O}_{3}$ sem aditivos descritos na seção anterior. Vale comentar que neste 
estudo comparativo a fórmula molecular utilizada nos cálculos das entalpias é $\mathrm{Al}_{8 / 3} \mathrm{O}_{4}$. Apesar da fórmula mais precisa para a estrutura de $\gamma-\mathrm{Al}_{2} \mathrm{O}_{3}$ ter sido reportada como $\mathrm{Al}_{8 / 3} \mathrm{O}_{4}, \mathrm{Al}_{2} \mathrm{O}_{3}$ tem sido utilizada para amostras puras sem representar discrepâncias nos calores de solução principalmente para estudos comparativos com $\alpha-\mathrm{Al}_{2} \mathrm{O}_{3}$ [5327] $\mathrm{O}$ uso de $\mathrm{Al}_{8 / 3} \mathrm{O}_{4}$ acarretaria apenas um pequeno incremento nos valores totais, mas ainda fazendo com que os resultados continuem próximos dos valores encontrados na literatura.

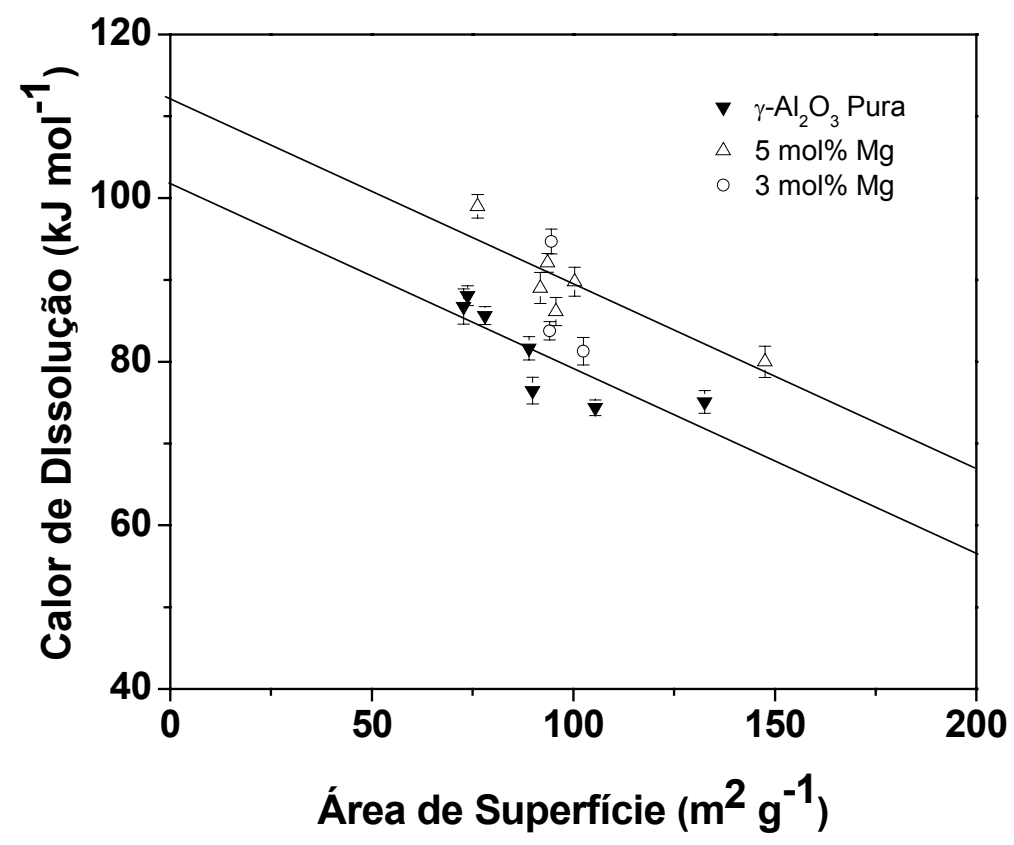

Figura 4.16 - Calor de dissolução em função da área de superfície específica da $\gamma$ $\mathrm{Al}_{2} \mathrm{O}_{3}$ e $\gamma-\mathrm{Al}_{2} \mathrm{O}_{3}$ contendo $\mathrm{Mg}$ como aditivo. Neste resultado os dados para $\gamma-$ $\mathrm{Al}_{2} \mathrm{O}_{3}$ são corrigidos para a fórmula $\mathrm{Al}_{8 / 3} \mathrm{O}_{4}$.

Para a avaliação do papel do aditivo $\mathrm{Mg}$ no calor de solução da alumina é conveniente tomar como referência a fórmula $\mathrm{Al}_{8 / 3} \mathrm{O}_{4}$, levando em consideração que há a formação da solução sólida entre $\mathrm{Al}_{8 / 3} \mathrm{O}_{4}$ e $\mathrm{MgAl}_{2} \mathrm{O}_{4}$. Isto torna viável um estudo comparativo com os valores da literatura [4] se considerando a solução ideal do ponto de vista da entalpia do sistema. Ademais, a hipótese de formação de uma solução sólida de $\mathrm{Al}_{2} \mathrm{O}_{3}$ e $\mathrm{MgAl}_{2} \mathrm{O}_{4}$ é pouco provável devido ao balanço 
de sítios nas estruturas. Assim, na Figura 4.16 são apresentados os dados de calorimetria para $\mathrm{Al}_{2} \mathrm{O}_{3}$ sem aditivos corrigidos em relação à Figura 4.11 para a fórmula $\mathrm{Al}_{8 / 3} \mathrm{O}_{4}$ e para a alumina contendo $5 \mathrm{~mol} \%$ de $\mathrm{Mg}$, sendo que a fórmula usada foi (0.069) $\mathrm{MgAl}_{2} \mathrm{O}_{4}(0.931) \mathrm{Al}_{8 / 3} \mathrm{O}_{4}$.

Uma inclinação muito semelhante das curvas de calor de adsorção em função da área de superfície específica para estrutura sem aditivos e contendo $\mathrm{Mg}$ é observada. Este dado é coerente com os obtidos na adsorção de $\mathrm{H}_{2} \mathrm{O}$ que já indicavam energias de superfície similares (Figura 4.14). Pelas inclinações das retas na Figura 4.16 determina-se uma energia de superfície de $1,62 \mathrm{~J} \mathrm{~m}^{-2}$ para $\gamma$ $\mathrm{Al}_{2} \mathrm{O}_{3}$ contendo $5 \mathrm{~mol} \% \mathrm{Mg}$ e $1,68 \mathrm{~J} \mathrm{~m}^{-2}$ para $\gamma-\mathrm{Al}_{2} \mathrm{O}_{3}$, coerente com uma solução sólida do aditivo sem segregação preferencial.

A título de comparação, uma solução sólida ideal de (0.069) $\mathrm{MgAl}_{2} \mathrm{O}_{4} \mathrm{e}$ (0.931) $\mathrm{Al}_{8 / 3} \mathrm{O}_{4}$ utilizando os calores de solução obtidos na literatura para $\mathrm{MgAl}_{2} \mathrm{O}_{4}\left(165,20 \mathrm{~kJ} \mathrm{~mol}^{-1}\right)$ [4] e $\mathrm{Al}_{8 / 3} \mathrm{O}_{4}\left(93,58 \mathrm{~kJ} \mathrm{~mol}^{-1}\right)$ [5327], leva a um calor total de $127,56 \mathrm{~kJ} \mathrm{~mol}^{-1}$. Este resultado indica que o $\mathrm{Mg}$ deve aumentar o calor de dissolução de $\gamma-\mathrm{Al}_{2} \mathrm{O}_{3}$, o que é coerente com os dados comentados abaixo. Este tipo de análise também sugere que o íon $\mathrm{Mg}$ em solução sólida no $\gamma-\mathrm{Al}_{2} \mathrm{O}_{3}$ deve alocar-se nos sítios semelhantes ao $\mathrm{Mg}$ na fase $\mathrm{MgAl}_{2} \mathrm{O}_{4}$, i.e. sítios tetraédricos [4] .

O aumento nos valores absolutos de calor de dissolução pode ser atribuído à presença de $\mathrm{Mg}$ (Figura 4.16), sendo a entalpia de solução para partículas crescidas (área de superfície específica virtualmente igual a zero) de $\gamma-\mathrm{Al}_{2} \mathrm{O}_{3}$ contendo $5 \mathrm{~mol} \%$ igual a $112,40 \mathrm{~kJ} \mathrm{~mol}^{-1}$. Esse aumento no calor de dissolução em relação a alumina sem aditivos $\left(76,08 \mathrm{~kJ} \mathrm{~mol}^{-1}\right.$ - Figura 4.11) é relacionado com um aumento na estabilidade da fase, desde que é necessária maior energia para quebra das ligações químicas da estrutura. Isso é coerente com um aumento na temperatura de transformação, como observado, atribuindo assim uma causa termodinâmica a este fenômeno em adição aos fenômenos cinéticos conhecidos [8]. Os dados para $\gamma-\mathrm{Al}_{2} \mathrm{O}_{3}$ contendo $3 \mathrm{~mol} \%$ também são apresentados na Figura 4.16 e são bastante semelhantes. Esta semelhança, em conjunto com as temperaturas de transformação bastante próximas para estas duas composições, indica que as energias do sistema são importantes no processo de transformação e 
a pequena diferença pode ser atribuída aos fatores cinéticos mais pronunciados nas amostras contendo $5 \mathrm{~mol} \% \mathrm{Mg}$. Vale notar que não se pode atribuir todo o aspecto da transformação à ação termodinâmica do aditivo. Isto é indicado pelo tamanho crítico semelhante para as amostras de 3 e $5 \mathrm{~mol} \% \mathrm{Mg}$, mostrando que o balanço de energias do sistema alcançou um limite para estas concentrações, estando os demais efeitos na temperatura de transformação associados à cinética de difusão.

Não fica evidente uma mudança no tamanho crítico de transformação em relação a alumina pura devido às imprecisões relacionadas aos ensaios utilizados para esta determinação, mas ficou demonstrada a ação do aditivo como estabilizador da fase $\gamma-\mathrm{Al}_{2} \mathrm{O}_{3}$. A mudança de tamanho crítico fica mais evidente, no entanto, para a ação do $\mathrm{Zr}$ como aditivo para a transformação como será apresentado na próxima seção. Este aditivo muda a energia de superfície da partícula e prova que uma modificação desta energia em particular tem mais importância que uma modificação na energia de volume para esta transformação.

$\mathrm{O}$ efeito do $\mathrm{Mg}$ na cinética de transformação está relacionado tanto à sua valência quanto ao seu raio iônico. Sendo um íon divalente, a presença deste na estrutura de $\gamma-\mathrm{Al}_{2} \mathrm{O}_{3}$ deveria estar relacionada à formação de vacâncias de oxigênio a fim de manter a neutralidade. No entanto, sabe-se que há a formação espontânea de vacâncias de alumínio no espinélio $\gamma-\mathrm{Al}_{2} \mathrm{O}_{3}$ para a compensação de um excesso de cargas negativas. A presença do $\mathrm{Mg}$ na estrutura deveria assim diminuir a diferença de cargas e tornando a estrutura mais compacta pela diminuição do número de vacâncias de alumínio. Esse fenômeno, associado ao maior raio iônico do $\mathrm{Mg}^{2+}(0,57 \AA)$ em relação ao $\mathrm{Al}^{3+}(0,39 \AA$ para coordenação IV), podem estar relacionados à diminuição do fluxo de massa pela rede durante a transformação e, portanto, ao aumento da temperatura de transformação.

\subsection{Efeito do íon $\mathrm{Zr}$ na transformação de fase $\gamma-\alpha$ da $\mathrm{Al}_{2} \mathrm{O}_{3}$}

A Figura 4.17 mostra os ensaios de DTA apontando a variação da temperatura do pico relativo à transformação $\alpha-\gamma$ alumina em função da presença de $\mathrm{Zr}$ como aditivo. 


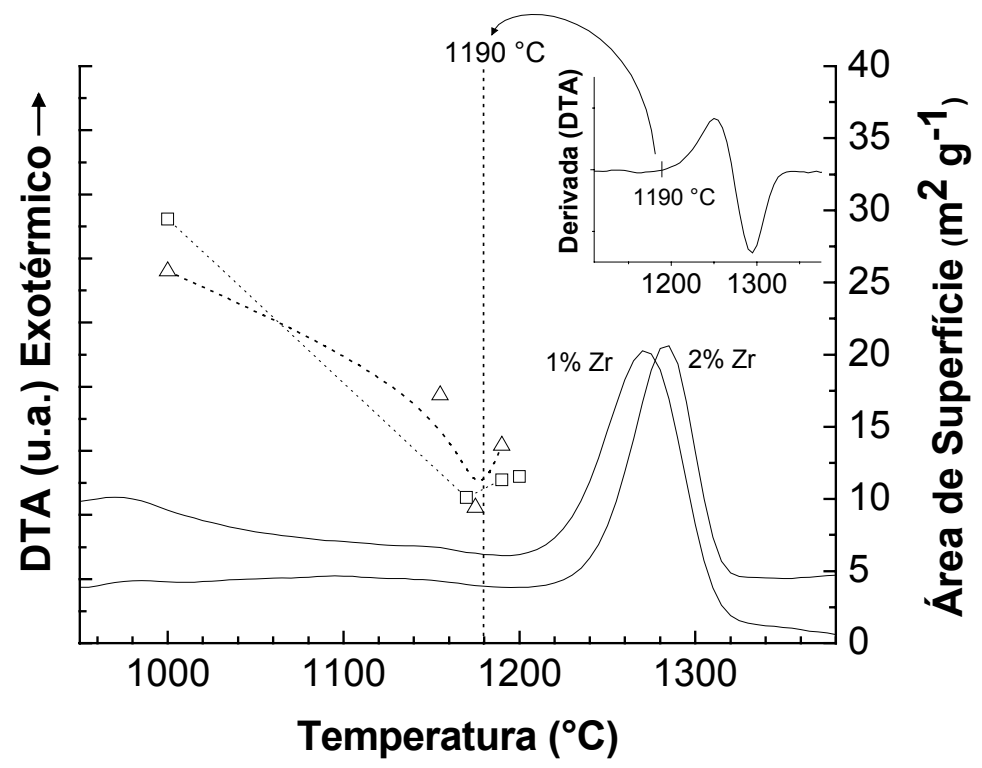

Figura 4.17 - Análise térmica diferencial (DTA) e áreas de superfície da $\mathrm{Al}_{2} \mathrm{O}_{3}$ contendo $\mathrm{Zr}$ como aditivo. As áreas de superfície específicas são referentes as amostras contendo $(\Delta) 1 \mathrm{~mol} \%$ de $\mathrm{Zr}$ e (口) $2 \mathrm{~mol} \% \mathrm{Zr}$. O pico de DTA de maior temperatura é relativo à amostra contendo $2 \% \mathrm{Zr}$. No detalhe a derivada da curva de DTA da amostra contendo $1 \mathrm{~mol} \% \mathrm{Zr}$.

Nota-se a partir da derivada da DTA que o início da transformação é modificado para $1190{ }^{\circ} \mathrm{C}$ na amostra contendo 1 mol\% de $\mathrm{Zr}$ e $1205{ }^{\circ} \mathrm{C}$ na amostra de 2 mol \% (derivada não mostrada na figura). Na mesma figura são apresentadas as áreas de superfície específica das amostras tratadas em temperaturas anteriores à transformação. O tamanho crítico da transformação é consideravelmente aumentado (diminuição da área de superfície específica) em relação aquele determinado para a alumina livre de aditivos, e valores de área de aproximadamente $10 \mathrm{~m}^{2} \mathrm{~g}^{-1}$ são observados para as amostras imediatamente anteriores à transformação.

Baseado nas considerações termodinâmicas da transformação, estes valores de área específica são coerentes com a diminuição da energia de volume e ou da energia de superfície. Para poder seguir a discussão com coerência deve-se, no entanto, examinar as fases presentes na situação anterior à transformação. A 
Figura 4.18 mostra a curva de difração de raios $\mathrm{X}$ das amostras. Apenas o espinélio $\gamma-\mathrm{Al}_{2} \mathrm{O}_{3}$ pode ser observado e uma comparação com os gráficos de difração apresentados para $\gamma-\mathrm{Al}_{2} \mathrm{O}_{3}$ sem aditivos (Figura 4.8) indicam uma maior cristalização, coerente com a menor área de superfície específica medida, não havendo indícios de solubilização do aditivo na rede.

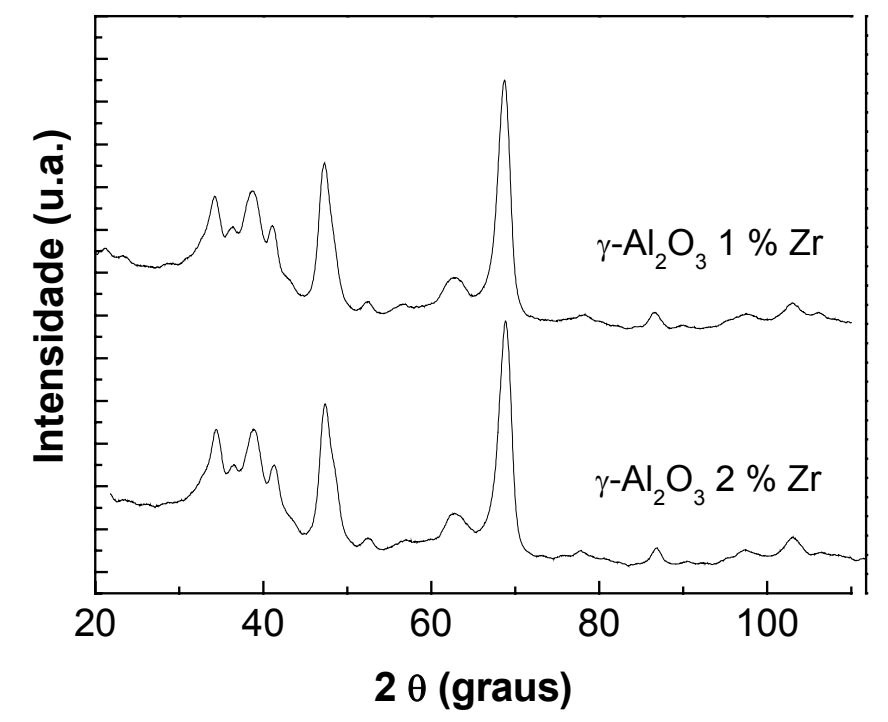

Figura 4.18 - Difração de raios $\mathrm{X}$ de amostras de $\gamma-\mathrm{Al}_{2} \mathrm{O}_{3}$ contendo $\mathrm{Zr}$ como aditivo e tratadas à $10^{\circ} \mathrm{C}$ abaixo da temperatura de início da transformação de fase.

Para se avaliar a energia total do sistema pouco antes da transformação de fase foi realizada a calorimetria de dissolução de alta temperatura utilizando borato de chumbo como solvente. Assim como para os ensaios descritos para $\mathrm{Al}_{2} \mathrm{O}_{3}$ sem aditivos e contendo $\mathrm{Mg}$ como aditivo, as medidas necessitam de correção pela presença de $\mathrm{H}_{2} \mathrm{O}$ adsorvida na superfície. A Figura 4.19A mostra a entalpia de adsorção de $\mathrm{H}_{2} \mathrm{O}$ na superfície da alumina contendo $2 \mathrm{~mol} \% \mathrm{Zr}$ para posterior utilização para a correção. 

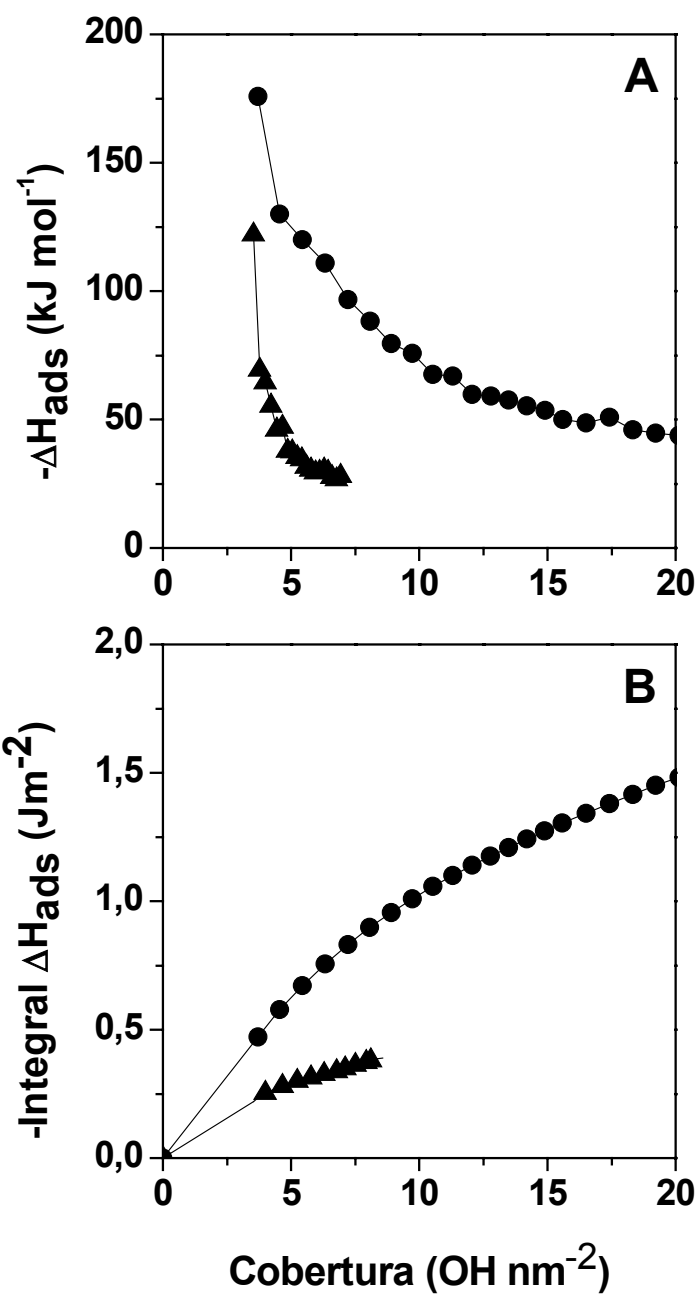

Figura 4.19 - Entalpia de adsorção de $\mathrm{H}_{2} \mathrm{O}$ na superfície do $\gamma-\mathrm{Al}_{2} \mathrm{O}_{3}$ e $\gamma-\mathrm{Al}_{2} \mathrm{O}_{3}$ contendo $\mathrm{Zr}$ em função da cobertura de $\mathrm{OH}$. (A) Entalpia de adsorção medida para $\gamma-\mathrm{Al}_{2} \mathrm{O}_{3}(\bullet)$ e $\gamma-\mathrm{Al}_{2} \mathrm{O}_{3}$ contendo $\mathrm{Zr}(\boldsymbol{\Delta})$. (B) Integral das medidas de calor de adsorção $(\bullet) \gamma-\mathrm{Al}_{2} \mathrm{O}_{3}$ e $(\boldsymbol{\Delta}) \gamma-\mathrm{Al}_{2} \mathrm{O}_{3}$ contendo $\mathrm{Zr}$.

Os gráficos mostram o calor de adsorção em função da cobertura de $\mathrm{OH}$ na superfície. Comparando os resultados com os obtidos para $\gamma-\mathrm{Al}_{2} \mathrm{O}_{3}$, também apresentados nesta figura, é possível constatar uma diminuição significativa nos calores de adsorção. Isto indica a presença de sítios de menor energia na amostra com $\mathrm{Zr}$, o que é confirmado pela integral dos valores da Figura 4.19A apresentados na Figura 4.19B e que mostrou uma diminuição média de $0,6 \mathrm{~J} \mathrm{~m}^{-2}$. 
Este resultado é um indício de diminuição da energia de superfície o que foi verificado pela análise de calorimetria de solução que será apresentada a seguir. A presença destes sítios de menor energia deve estar relacionada a um fenômeno de segregação do Zr na superfície das partículas [1] . De fato, a segregação de íons aditivos tem sido observada em alguns materiais sintetizados pelo método dos precursores poliméricos $[10,6,1-4]$. A presença destes íons segregados gera diminuição da energia de superfície e conseqüências na microestrutura e propriedades das partículas [2,1-4] .

Os resultados de calorimetria de dissolução corrigidos utilizando-se os dados de energia de adsorção de $\mathrm{H}_{2} \mathrm{O}$ são apresentados na Figura 4.20 e na Tabela 4.3A e comparados com a $\gamma-\mathrm{Al}_{2} \mathrm{O}_{3}$ sem aditivos, sendo possível se demonstrar a diminuição na energia de superfície ocasionada pela presença dos íon Zr.

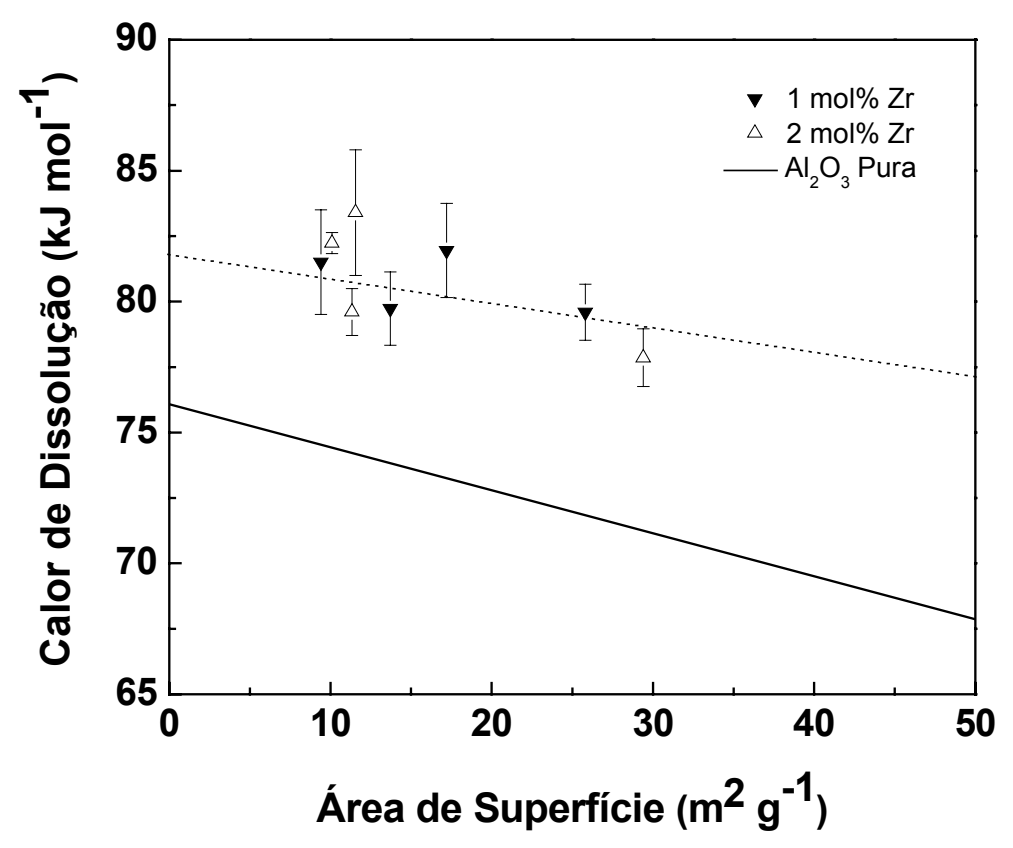

Figura 4.20 - Calor de dissolução em função da área de superfície específica do $\gamma$ $\mathrm{Al}_{2} \mathrm{O}_{3}$ contendo $\mathrm{Zr}$. A linha reta contínua mostra os valores extrapolados de $\gamma$ $\mathrm{Al}_{2} \mathrm{O}_{3}$ sem aditivos. 
Os dados para $\mathrm{Al}_{2} \mathrm{O}_{3}$ extrapolados para áreas semelhantes às das amostras contendo Zr são mostrados para comparação na Figura 4.20. Vale notar que não foram preparados pós de alumina contendo $\mathrm{Zr}$ de áreas de superfície mais elevadas devido a dificuldades experimentais relacionadas à síntese do material. Sendo a energia de adsorção de $\mathrm{H}_{2} \mathrm{O}$ na superfície relativamente baixa, não há uma estabilização da superfície por moléculas de água durante o processo de síntese, permitindo um coalescimento significativo a baixas temperaturas. 
Tabela 4.3A. Sumário dos dados de calorimetria de dissolução de alta temperatura das amostras dopadas com $\mathrm{Zr}$ e dos resultados dos conteúdos de $\mathrm{H}_{2} \mathrm{O}$. As amostras de $1 \mathrm{Z1}$ a $1 \mathrm{Z} 4$ são $\gamma-\mathrm{Al}_{2} \mathrm{O}_{3}$ contendo $1 \mathrm{~mol} \% \mathrm{Zr}$, de $2 \mathrm{Z1}$ a $2 \mathrm{Z} 4$ são $\gamma-\mathrm{Al}_{2} \mathrm{O}_{3}$ contendo 2 mol\% $\mathrm{Zr}$. $\Delta H_{s o l}$ é o calor de dissolução e $\Delta H_{c 2}$ é o valor corrigido para o conteúdo $\mathrm{H}_{2} \mathrm{O}$. Os erros apresentados são desvios padrões. * $\mathrm{O}$ conteúdo de $\mathrm{H}_{2} \mathrm{O}$ adsorvido foi medido por perda de massa (gramas de $\mathrm{H}_{2} \mathrm{O}$ por grama de $\mathrm{Al}_{2} \mathrm{O}_{3}$ ) e transformado calculando o número de moléculas de $\mathrm{H}_{2} \mathrm{O}$ dividido pela área de superfície específica de cada amostra em $\mathrm{nm}^{2}$.

\begin{tabular}{|c|c|c|c|c|c|c|}
\hline Amostra & $\begin{array}{c}\mathrm{x} \text { em } \\
\mathrm{Al}_{2} \mathrm{O}_{3} \cdot \mathrm{x} \mathrm{H}_{2} \mathrm{O} \\
\text { (equilíbrio) }\end{array}$ & $\begin{array}{c}\mathrm{H}_{2} \mathrm{O} \text { Quimissorvida } \\
(\mathrm{OH} \mathrm{nm})^{-2} *\end{array}$ & $\begin{array}{c}\Delta H_{\text {sol }} \\
\left(\mathrm{J} \mathrm{g}^{-1} \mathrm{Al}_{2} \mathrm{O}_{3} \cdot \mathrm{xH}_{2} \mathrm{O}\right)\end{array}$ & $\begin{array}{c}\Delta H_{\text {sol }} \\
\left(\mathrm{kJ} \mathrm{mol}^{-1} \mathrm{Al}_{2} \mathrm{O}_{3} \cdot \mathrm{xH}_{2} \mathrm{O}\right)\end{array}$ & $\begin{array}{l}\text { Número de } \\
\text { ensaios }\end{array}$ & $\begin{array}{c}\Delta H_{c}\left(\mathrm{~kJ} \mathrm{~mol}^{-1}\right. \\
\left.\mathrm{Al}_{2} \mathrm{O}_{3}\right)\end{array}$ \\
\hline $1 \mathrm{Z1}$ & 0,212 & 36,3 & $867,2 \pm 11,2$ & $88,6 \pm 1,0$ & 7 & $79,6 \pm 1,1$ \\
\hline $1 Z 2$ & 0,186 & 40,9 & $884,4 \pm 23,5$ & $90,2 \pm 2,1$ & 6 & $81,9 \pm 1,8$ \\
\hline $1 \mathrm{Z3}$ & 0,183 & 65,1 & $859,4 \pm 32,0$ & $87,7 \pm 2,9$ & 6 & $79,7 \pm 1,4$ \\
\hline $1 \mathrm{Z4}$ & 0,077 & 36,4 & $829,9 \pm 28,3$ & $84,6 \pm 2,5$ & 4 & $81,5 \pm 2,0$ \\
\hline $2 Z 1$ & 0,148 & 28,3 & $814,4 \pm 14,9$ & $83,1 \pm 1,3$ & 3 & $77,8 \pm 1,3$ \\
\hline $2 \mathrm{Z2}$ & 0,137 & 44,1 & $869,3 \pm 6,3$ & $88,7 \pm 0,5$ & 6 & $82,2 \pm 0,4$ \\
\hline $2 \mathrm{Z3}$ & 0,223 & 98,5 & $853,4 \pm 9,9$ & $87,3 \pm 1,1$ & 5 & $79,6 \pm 0,9$ \\
\hline $2 \mathrm{Z} 4$ & 0,105 & 40,3 & $859,5 \pm 3,9$ & $87,7 \pm 2,3$ & 4 & $83,4 \pm 2,5$ \\
\hline
\end{tabular}


Tabela 4.3B. Áreas de superfície específica das amostras preparadas nas temperaturas indicadas na tabela. As fases foram identificadas como exclusivamente $\gamma-\mathrm{Al}_{2} \mathrm{O}_{3}$ por difração de raios $\mathrm{X}$ e as áreas de superfície foram medidas por adsorção de $\mathrm{N}_{2}(\mathrm{BET})$.

\begin{tabular}{|c|c|c|c|}
\hline Amostra & $\%$ mol de $\mathrm{Zr}$ & Temperatura $\left({ }^{\circ} \mathrm{C}\right)$ & $\begin{array}{c}\text { Área de superfície } \\
\text { específica }\left(\mathrm{m}^{2} \mathrm{~g}^{-1}\right)\end{array}$ \\
\hline $1 \mathrm{Z} 1$ & 1 & 1000 & 25,8 \\
\hline $1 \mathrm{Z} 2$ & 1 & 1155 & 17,2 \\
\hline $1 \mathrm{Z3}$ & 1 & 1175 & 13,7 \\
\hline $1 \mathrm{Z} 4$ & 1 & 1190 & 9,4 \\
\hline $2 \mathrm{Z} 1$ & 2 & 1000 & 29,4 \\
\hline $2 \mathrm{Z} 2$ & 2 & 1170 & 10,1 \\
\hline $2 \mathrm{Z3}$ & 2 & 1190 & 11,33 \\
\hline $2 \mathrm{Z} 4$ & 2 & 1200 & 11,56 \\
\hline
\end{tabular}

Na Figura 4.20 notam-se dois pontos importantes: há um aumento no calor de dissolução da $\gamma-\mathrm{Al}_{2} \mathrm{O}_{3} 1 \mathrm{~mol} \% \mathrm{Zr}$ em relação a $\gamma-\mathrm{Al}_{2} \mathrm{O}_{3}$ sem aditivos e também uma diminuição na inclinação da reta referente à amostra contendo aditivo. $\mathrm{O}$ aumento no calor absoluto de solução da rede cristalina pode ser observado na extrapolação das curvas para área de superfície específica zero, simulando uma situação de partículas coalescidas. Esse resultado é semelhante àquele apresentado para $\mathrm{Al}_{2} \mathrm{O}_{3}$ contendo $\mathrm{Mg}$, onde a solubilização está relacionada com uma estabilização da rede. Para $\gamma-\mathrm{Al}_{2} \mathrm{O}_{3}$ um valor de $76,08 \mathrm{~kJ} \mathrm{~mol}^{-1}$ foi medido, enquanto que para $\mathrm{Al}_{2} \mathrm{O}_{3} 1 \mathrm{~mol} \% \mathrm{Zr}$ foi de $81,81 \mathrm{~kJ} \mathrm{~mol}^{-1}$. Esta estabilização da rede é coerente com um aumento na temperatura de transformação, mas se por alguns instantes desconsiderarmos os fatores cinéticos, pode-se dizer que, comparando os resultados obtidos para energia de dissolução de $\mathrm{Al}_{2} \mathrm{O}_{3} 5 \mathrm{~mol} \%$ $\mathrm{Mg}\left(112,40 \mathrm{~kJ} \mathrm{~mol}^{-1}\right)$ e $\mathrm{Al}_{2} \mathrm{O}_{3} 1 \mathrm{~mol} \% \mathrm{Zr}\left(81,81 \mathrm{~kJ} \mathrm{~mol}^{-1}\right)$, as amostras contendo 
$\mathrm{Mg}$ seriam mais estáveis e portanto deveriam apresentar temperaturas de transformação mais elevadas do que as contendo $\mathrm{Zr}$.

Neste ponto, o efeito da variação na energia de superfície gerada pela presença do íon deve ser considerado. Sendo o tamanho crítico, e assim a temperatura de transformação, dependente de um balanço de energias entre a superfície e a rede cristalina, a diminuição na energia de superfície gerada pelo íon $\mathrm{Zr}$ tem conseqüências relevantes. Uma energia de superfície de $0,82 \mathrm{~J} \mathrm{~m}^{-2}$ para $\gamma-\mathrm{Al}_{2} \mathrm{O}_{3} 1 \mathrm{~mol} \% \mathrm{Zr}$ foi determinada (Figura 4.20), enquanto que para o $\gamma-\mathrm{Al}_{2} \mathrm{O}_{3}$ sem aditivos é $1,61 \mathrm{~J} \mathrm{~m}^{-2}$. Este resultado confirma a diminuição de energia de superfície conforme esperado pelos dados de tamanho crítico e de entalpia de adsorção de $\mathrm{H}_{2} \mathrm{O}$. Utilizando a Equação (1.1), que considera uma partícula esférica e um balanço entre a energia de volume e de superfície para determinação do tamanho crítico, pode-se calcular a variação de tamanho crítico gerada pela diminuição da energia de superfície de $\gamma-\mathrm{Al}_{2} \mathrm{O}_{3}$ medida. Uma variação de aproximadamente $55 \mathrm{~m}^{2} \mathrm{~g}^{-1}$ na área crítica foi calculada considerando a diferença na energia de volume entre a amostra sem aditivos e a contendo Zr. Este valor é coerente com os dados apresentados de áreas de superfície críticas $\left(\sim 75 \mathrm{~m}^{2} \mathrm{~g}^{-1}\right.$ para $\mathrm{Al}_{2} \mathrm{O}_{3} \mathrm{e} \sim 10 \mathrm{~m}^{2} \mathrm{~g}^{-1}$ para $\mathrm{Al}_{2} \mathrm{O}_{3} 1 \mathrm{~mol} \% \mathrm{Zr}$ ), indicando que o aditivo age fundamentalmente na termodinâmica do fenômeno de transformação, colocando o efeito do aditivo na cinética do sistema em um plano secundário. Apesar disto, o efeito cinético não pode ser desconsiderado completamente. Assim como para as amostras dopadas com $\mathrm{Mg}$, apesar da semelhança nas energias determinadas para aos pós contendo 1 e $2 \mathrm{~mol} \% \mathrm{Zr}$, inclusive para a energia de superfície, há uma diferença significativa nas temperaturas de transformação de $15{ }^{\circ} \mathrm{C}$ sendo, no entanto, os tamanhos críticos são bastante semelhantes. Esta diferença pode estar tanto relacionada às imprecisões nas determinações das energias (ou dos tamanhos críticos) ou a fatores cinéticos. Estes últimos estariam ligados às mudanças de composição da superfície devido à segregação do íon $\mathrm{Zr}$, como será descrito em mais detalhes na próxima seção através de análises de XPS. Esta mudança de composição certamente modifica os mecanismos de difusão, interferindo na temperatura final da transformação $[3,4]$. 
Note que o calor de dissolução elevado para amostras coalescidas de alumina contendo Zr não é incoerente com a segregação do íon na superfície, isto porque a segregação de um íon ocorre geralmente após a saturação (em termos energéticos) da rede [1-4]. Esta pequena porção de íons em solução sólida é responsável por uma mudança significativa na energia de volume, visto seu elevado raio iônico.

\subsection{Detecção da segregação do íon $\mathrm{Zr}$ na superfície da $\gamma-\mathrm{Al}_{2} \mathrm{O}_{3}$}

Tendo sido observado o relevante efeito do íon $\mathrm{Zr}$ na diminuição da energia de superfície da $\gamma-\mathrm{Al}_{2} \mathrm{O}_{3}$ e, por conseqüência, no aumento da temperatura de transformação de fase, o próximo passo é estudar a causa deste efeito tão pronunciado na superfície da partícula, relacionando, se possível, com a posição do íon na rede e suas características químicas. Como descrito, espera-se que esta ação do íon esteja intimamente relacionada à segregação deste na superfície [1,14,1-4] . Isto é, a diminuição da energia de superfície pela presença de um excesso de superfície é termodinamicamente predita, mas esta relação para óxidos é apenas descrita indiretamente através de análises microestruturais na literatura [14,1-4] . A verificação de uma diminuição do tamanho médio de partículas com o aumento da concentração de um aditivo é vista como uma destas evidências. A proposição é feita a partir do modelo de coalescimento de Ostwald, que considera a energia superficial como uma das variáveis controladoras do tamanho final da partícula. Djuricic e colaboradores [3] verificaram este comportamento para $\mathrm{Al}_{2} \mathrm{O}_{3}$ contendo $\mathrm{Zr}$ como aditivo. No entanto, naquela ocasião não foi proposta relação entre tal fenômeno e uma diminuição na energia de superfície causada pela segregação do íon.

A posição do íon na rede pôde ser definitivamente determinada utilizando técnica de fotoelétrons excitados por raios X - XPS (X-ray Photoelectron Spectroscopy). Esta técnica fornece dados sobre a composição atômica da superfície, a identificação elementar, o estado químico e o número de coordenação dos átomos locados próximos à superfície da amostra. Deste modo, é possível analisar a composição da superfície evidenciando qualquer processo de segregação. A Tabela 4.4 apresenta os dados de XPS para amostras de $\gamma-\mathrm{Al}_{2} \mathrm{O}_{3}$ 
contendo 1 e 2 mol\% de $\mathrm{Zr}$. $\mathrm{N}_{\mathrm{Zr}}$ e $\mathrm{N}_{\mathrm{Al}}$ representam os números de mols de $\mathrm{Zr}$ e Al respectivamente. Para detecção dos átomos de $\mathrm{Al}$ foi utilizado o nível $2 p$ com energia 74,6 eV; para o $\mathrm{Zr}$ foi usado o nível $3 d^{5}$ com energia de 182,9 eV; e padrão $C_{1 s}$ determinado à $285,15 \mathrm{eV}$. Os dados apresentados para a razão atômica na rede cristalina são os dados nominais utilizados para síntese. Nota-se um excesso de Zr na superfície das partículas representado pelas razões apresentadas na tabela. $\mathrm{O}$ mesmo comportamento é observado para ambas concentrações, mas o efeito é mais pronunciado em $2 \mathrm{~mol} \% \mathrm{Zr}$.

Tabela 4.4 - Resultados das medidas XPS das amostras de $\gamma-\mathrm{Al}_{2} \mathrm{O}_{3}$ contendo $\mathrm{Zr}$ (tratadas a $50{ }^{\circ} \mathrm{C}$ da temperatura de início da transformação de fase) mostrando a razão entre o número de mols calculado segundo a concentração de preparação das amostras e aquele obtido por XPS

\begin{tabular}{|c|c|c|}
\hline$\% \mathrm{~mol} \mathrm{Zr}$ & $\left(\mathrm{N}_{\mathrm{Zr}} / \mathrm{N}_{\mathrm{Al}}\right)_{\text {rede }}$ & $\left(\mathrm{N}_{\mathrm{Zr}} / \mathrm{N}_{\mathrm{Al}}\right)_{\mathrm{XPS}}$ \\
\hline $1 \%$ & 0,0050 & 0,0062 \\
\hline $2 \%$ & 0,010 & 0,0156 \\
\hline
\end{tabular}

Os conjuntos dos dados de XPS e calorimetria de dissolução confirmam assim que a segregação do íon $\mathrm{Zr}$ na superfície está intimamente relacionada à diminuição da energia de superfície. Este efeito abre uma nova perspectiva no estudo dos aditivos na transformação de fase da alumina, deixando clara uma relação entre posicionamento do íon e sua ação na termodinâmica do fenômeno.

Uma explicação química para a segregação do íon $\mathrm{Zr}$ na superfície, que não é esperada para o $\mathrm{Mg}$ ou para o Mn como será apresentado a seguir, pode ser sugerida não apenas considerando o elevado número atômico do elemento em conjunto com seu raio iônico (também elevado se comparado com aquele do $\mathrm{Al}^{3+}$ ), mas também considerando a estrutura cristalina mais termodinamicamente estável de cada óxido. Isto é, sabe-se que o íon $\mathrm{Zr}$ não é propenso à formação de estruturas espinélio, o que poderia induzir sua segregação na superfície como observado. Existem, no entanto, estruturas espinélio estáveis para ambos $\mathrm{Mg}$ e 
Mn, mostrando que sua alocação na rede cristalina espinélio com defeito de $\gamma$ $\mathrm{Al}_{2} \mathrm{O}_{3}$ é estável, desfavorecendo a segregação superficial.

\subsection{Efeito do íon Mn na transformação de fase $\gamma-\alpha$ da $\mathrm{Al}_{2} \mathrm{O}_{3}$}

Visto o efeito dos íons retardadores da transformação, nesta seção será abortada a ação aceleradora do íon Mn no processo. A Figura 4.21 mostra o efeito do íon manganês na temperatura de transformação de fase $\gamma-\alpha$ da alumina. Notase uma diminuição significativa da temperatura de transformação progressiva com o aumento na concentração do aditivo, observada pelo pico exotérmico do DTA e pela derivada destas curvas (apenas a derivava para 10 mol\% Mn é mostrada), sendo a transformação decrescida para $1015^{\circ} \mathrm{C}$ com adição de $5 \mathrm{~mol} \% \mathrm{Mn}$ e para $980{ }^{\circ} \mathrm{C}$ com $10 \mathrm{~mol} \% \mathrm{Mn}$. Na mesma figura são apresentadas as áreas de superfície específica das amostras calcinadas anteriormente à transformação para avaliação da presença de um tamanho crítico.

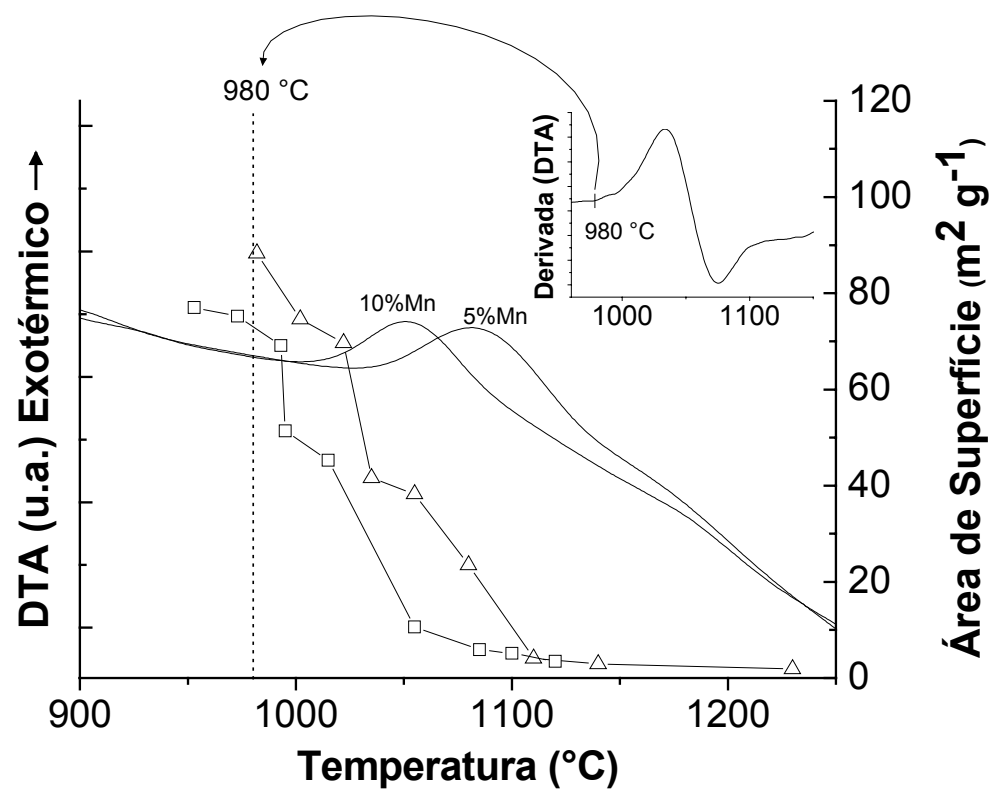

Figura 4.21 - Análise Térmica Diferencial (DTA) e áreas de superfície da $\mathrm{Al}_{2} \mathrm{O}_{3}$ contendo Mn como aditivo. As áreas de superfície específica são referentes a ( $\Delta) 5 \mathrm{~mol} \% \mathrm{Mn}$ e ( $\square$ ) $10 \mathrm{~mol} \% \mathrm{Mn}$. No detalhe a derivada da curva de DTA para amostra contendo $10 \mathrm{~mol} \%$ Mn para determinação da temperatura de início da reação. 
Nota-se uma área de superfície específica crítica similar para o início da transformação em ambas amostras contendo $\mathrm{Mn}$ assim como para $\gamma-\mathrm{Al}_{2} \mathrm{O}_{3}(\sim 75$ $\mathrm{m}^{2} \mathrm{~g}^{-1}$ ). Este efeito de área similar foi também observado para o $\mathrm{Mg}$, mas neste caso as medidas de energia de superfície e calor de dissolução indicaram que a semelhança esta relacionada a imprecisões na determinação do valor crítico. Para as amostras dopadas com $\mathrm{Mn}$, no entanto, torna-se mais complicada uma avaliação do efeito deste aditivo nas energias do sistema devido aos diversos estados de oxidação deste elemento.

Análises de XPS mostram a presença de dois ou mais estados de oxidação para o $\mathrm{Mn}$ nas amostras de $\gamma-\mathrm{Al}_{2} \mathrm{O}_{3}$. A impossibilidade de detecção precisa da fração de cada estado de oxidação na estrutura pelas técnicas disponíveis tornou o ensaio de calorimetria de dissolução inadequado para este sistema. Isso porque quando da introdução da amostra no solvente, há redução ou oxidação do manganês para o estado estável dissolvido no solvente, $\mathrm{Mn}^{2+}$. Estas reações são associadas a liberações ou absorções de calor, interferindo nas medidas. Desta maneira, o estudo restringe-se à medida da energia de adsorção de $\mathrm{H}_{2} \mathrm{O}$ e a uma análise microestrutural que pôde revelar importantes informações sobre a ação deste íon.

O mecanismo de atuação do aditivo na redução da temperatura de transformação pode ser analisado, primeiramente, avaliando as hipóteses apresentadas na literatura sobre os reguladores deste fenômeno. Supondo a hipótese de segregação do aditivo na superfície da $\gamma$-alumina [3], assim como para o fenômeno observado para o íon $\mathrm{Zr}^{2+}$, o valor da energia livre por volume da rede não seria portanto alterado, pois as ligações não são rompidas ou distorcidas, mantendo-se a simetria da rede. Assim, a energia livre de volume do material sem aditivo e contendo o aditivo seria a mesma. A energia de superfície, por sua vez, seria modificada pelo excesso do aditivo na região e alteraria o tamanho crítico da transformação, desde que este é fundamentalmente dependente da relação entre as energias de superfície e de rede.

No entanto, observando os tamanhos críticos semelhantes, aplicando o modelo de tamanho crítico com partículas esféricas (Equação 1.1) e fixando o valor da energia de volume como constante, obtêm-se como resultados valores de 
energias de superfície também semelhantes para cada material. Isto é, a hipótese de variação de energia superficial para este sistema pode não ser verdadeira, a menos que acompanhada por uma variação proporcional de energia na rede.

A Figura 4.22 mostra a entalpia de adsorção de $\mathrm{H}_{2} \mathrm{O}$ na superfície de uma amostra de $\gamma-\mathrm{Al}_{2} \mathrm{O}_{3}$ contendo $5 \mathrm{~mol} \% \mathrm{Mn}$. Apesar de não poder ser diretamente relacionada à energia de superfície do material, este ensaio pode indicar a energia relativa dos sítios presentes. Comparando os resultados obtidos para $\gamma-\mathrm{Al}_{2} \mathrm{O}_{3}$ e $\gamma$ $\mathrm{Al}_{2} \mathrm{O}_{3}$ contendo $\mathrm{Mn}$, nota-se a presença de sítios de energias bastante semelhantes para as duas amostras. Isto é coerente com uma distribuição sem segregação na superfície, gerando energias de superfície parecidas, mas indicando possíveis modificações na energia de volume. A presença de tamanhos críticos bastante semelhantes, no entanto, indica que mesmo havendo diferença de energia entre a rede sem aditivos e contendo $\mathrm{Mn}$, essa diferença não altera significativamente a transformação. $\mathrm{O}$ caso é semelhante ao do aditivo $\mathrm{Mg}$ previamente estudado, mas com ação inversa, i.e. a presença do íon na rede deveria desestabilizar a rede o pouco suficiente para manter os tamanhos críticos dentro dos erros de detecção. Os dados, portanto sugerem que há um fator cinético determinante na ação deste aditivo que está relacionado à solubilização do íon. 

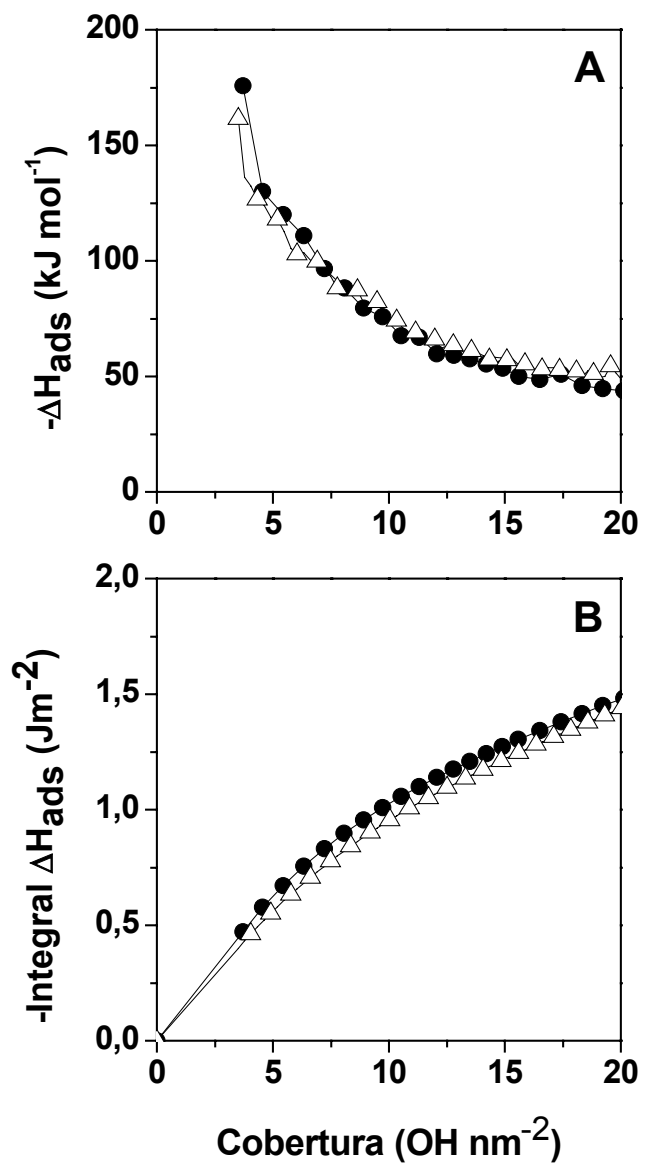

Figura 4.22 - Entalpia de adsorção de $\mathrm{H}_{2} \mathrm{O}$ na superfície da $\gamma-\mathrm{Al}_{2} \mathrm{O}_{3} 5 \mathrm{~mol} \% \mathrm{Mn}$ em função da cobertura de $\mathrm{OH}$. (A) Entalpia de adsorção medida da $\gamma-\mathrm{Al}_{2} \mathrm{O}_{3}$ pura $(\bullet)$ e $\gamma-\mathrm{Al}_{2} \mathrm{O}_{3}$ contendo $\mathrm{Mn}(\Delta)$. (B) Integral das medidas de calor de adsorção $(\bullet) \gamma-\mathrm{Al}_{2} \mathrm{O}_{3}$ pura e $(\Delta) \gamma-\mathrm{Al}_{2} \mathrm{O}_{3}$ contendo $\mathrm{Mn}$.

Contudo, levando em consideração o sinal Mn $2 p^{3}(642,45+/-0,15 \mathrm{eV})$, que pode ser atribuído ao $\mathrm{Mn}^{4+}$, e o sinal $\mathrm{Al} 2 p^{3}$ da alumina à 74,6 eV fica evidente que não existe um excesso de superfície quando a razão dos sinais é comparada a razão atômica calculada a partir das quantidades de preparação dos óxidos (Tabela 4.5) 
Tabela 4.5 - Resultados das medidas XPS das amostras de $\gamma-\mathrm{Al}_{2} \mathrm{O}_{3}$ contendo $\mathrm{Mn}$ mostrando a razão entre o número de mols calculado segundo a concentração de preparação das amostras e aquele obtido por XPS

\begin{tabular}{|c|c|c|c|}
\hline $\begin{array}{c}\% \text { mol } \\
\mathrm{Mn}\end{array}$ & $\mathrm{Mn} 2 p^{3}$ & $\left(\mathrm{~N}_{\mathrm{Mn}} / \mathrm{N}_{\mathrm{Al}}\right)_{\text {rede }}$ & $\left(\mathrm{N}_{\mathrm{Mn}} / \mathrm{N}_{\mathrm{Al}}\right)_{\mathrm{XPS}}$ \\
\hline $5 \%$ & 642,3 & 0,026 & 0,025 \\
\hline $10 \%$ & 642,6 & 0,055 & 0,057 \\
\hline
\end{tabular}

A solubilização na rede foi estudada por difração de raios $\mathrm{X}$ onde foi analisando o deslocamento de picos na curva de DRX das amostras com estruturas tratadas nas temperaturas ao longo da transformação. A curva de difração na Figura 4.23 mostra a presença de reflexões características dos planos do espinélio $\gamma-\mathrm{Al}_{2} \mathrm{O}_{3}$ tanto para $\gamma-\mathrm{Al}_{2} \mathrm{O}_{3}$ como para $\gamma-\mathrm{Al}_{2} \mathrm{O}_{3}$ contendo manganês. Uma observação mais detalhada das curvas de difração de raios $\mathrm{X}$ revela uma influência considerável do aditivo Mn na estrutura do espinélio, podendo ser associada a uma solubilização do íon na rede, o que poderia interferir em fatores difusionais para a transformação de fase da alumina. 


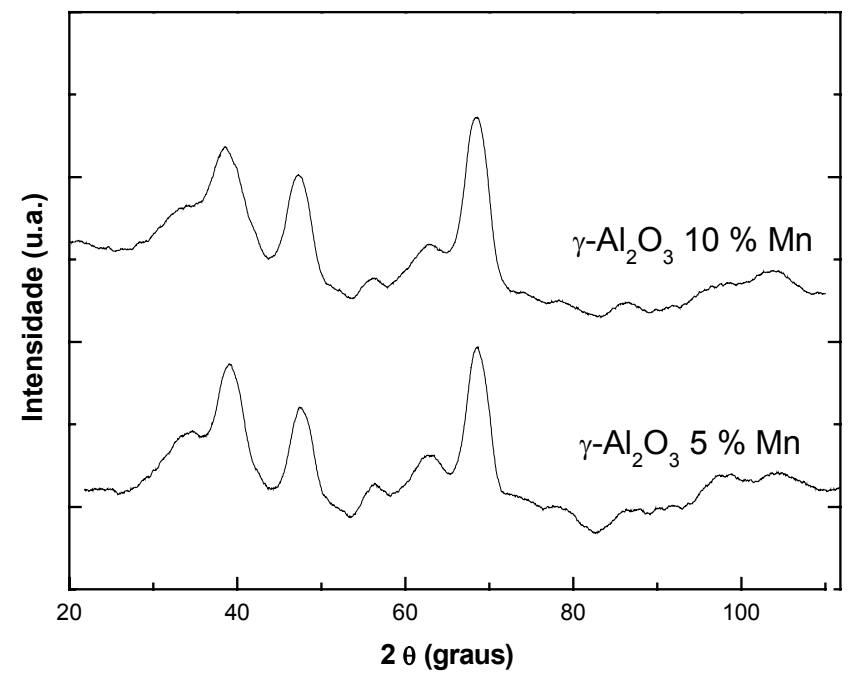

Figura 4.23 - Difração de raios $\mathrm{X}$ de amostras de $\gamma-\mathrm{Al}_{2} \mathrm{O}_{3}$ contendo Mn como aditivo e tratadas à $10{ }^{\circ} \mathrm{C}$ da temperatura de início da transformação de fase.

A Figura 4.24 ressalta um deslocamento do pico de reflexão do plano (220) com a inclusão do aditivo. Através de refinamentos Rietveld de DRX e cálculos da estrutura sobre os resultados de difração propôs-se a associação das zonas de reflexão com sub-redes de alumínios tetraédricos, octaédricos e subredes de oxigênio presentes no espinélio. Desta maneira, o plano (220) seria relacionado exclusivamente a sub-rede de Al tetraédricos, o que caracteriza uma substituição acentuada do Mn nestes sítios. 


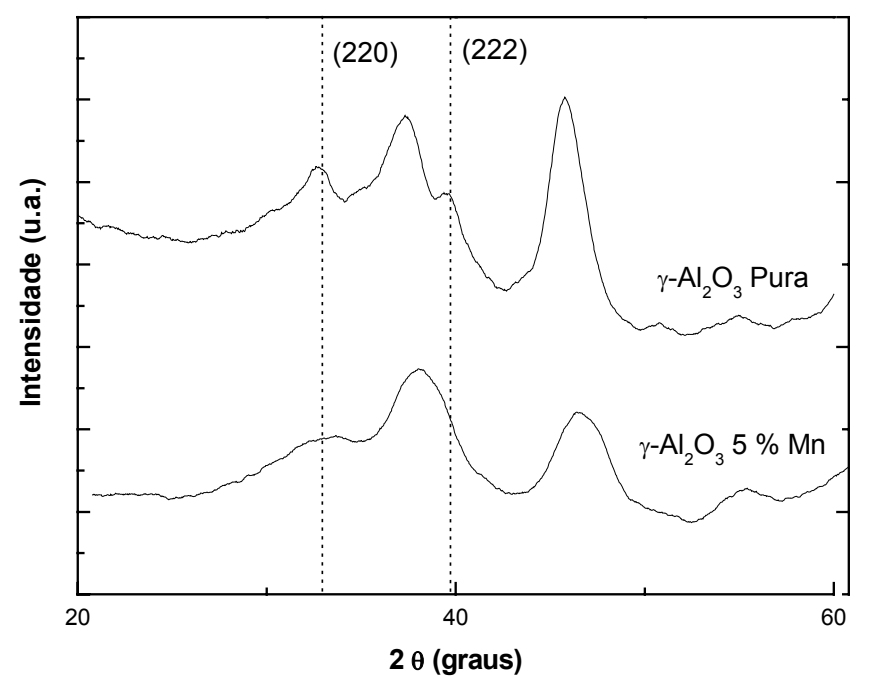

Figura 4.24 - Difração de raios $\mathrm{X}$ de amostras de $\gamma-\mathrm{Al}_{2} \mathrm{O}_{3}$ e $\gamma-\mathrm{Al}_{2} \mathrm{O}_{3}$ contendo $5 \%$ Mn como aditivo e tratadas anteriormente à transformação de fase. Nos detalhes a diminuição dos picos de reflexão.

Apesar da ausência de reflexões particulares dos sítios da sub-rede de Al octaédrico, reflexões com participação pronunciada destes sítios também apontam deslocamentos, como por exemplo: os planos (440) e (222). O plano (222) (Figura 4.24) foi correlacionado à ação conjunta dos sítios octaédricos e sub-rede de oxigênio . Observando o deslocamento para ângulos menores, bem como diminuição da intensidade do pico. Acredita-se que haja substituição do $\mathrm{Mn}$ também nos sítios octaédricos e ainda uma diminuição na ordenação da sub-rede.

Sendo a maior parte dos íons Mn com valência quatro neste sistema e considerando a semelhança entre os raios atômicos de $\mathrm{Mn}^{4+}$ e $\mathrm{Al}^{3+}$, espera-se a substituição com formação de vacâncias catiônicas de alumínio [4]. Estas vacâncias em conjunto com a desordenação da rede seriam responsáveis pelo aumento da difusão no sistema e conseqüente aumento do crescimento de grão, como observado nas análises de área superficial, onde o pó contendo o aditivo tem tamanho de partícula maior numa temperatura de calcinação menor (Figura 4.21).

A coincidência dos valores críticos de transformação observada para as estruturas contendo ou não o aditivo desacredita a origem destes na nucleação 
heterogênea como proposto. Os dados reforçam a idéia de que a origem da transformação baseia-se na associação de fatores energéticos e cinéticos. $\mathrm{O}$ tamanho crítico é fundamental para transformação, tendo sua origem na razão de energia de superfície e de rede do material, mas o alcance da configuração crítica pelo sistema é controlado por fatores cinéticos, que são modificados pela inclusão de aditivos tais como o íon $\mathrm{Mn}$.

O efeito do $\mathrm{Mn}$ é progressivo com a concentração, desde que a substituição na rede e desordenação da sub-rede do oxigênio são graduais. Deste modo, quanto maior a concentração do aditivo, maior a cinética de crescimento, e portanto menor a temperatura necessária para o alcance do tamanho crítico. Uma saturação da rede pelo aditivo causaria a diminuição do efeito deste como agente redutor da temperatura de transição, desde que a cinética não seria por mais alterada já que a quantidade de defeitos é estável. 


\section{CONCLUSÕES}

Uma nova abordagem para a avaliação da ação de íons aditivos na transformação de fase $\gamma-\alpha$ do $\mathrm{Al}_{2} \mathrm{O}_{3}$ foi apresentada. Os calores de dissolução dos sistemas sem aditivos e contendo $\mathrm{Mg}, \mathrm{Mn}$ ou $\mathrm{Zr}$ foram medidos e as energias de superfície puderam ser determinadas. Análises microestruturais foram realizadas nos pós em temperaturas anteriores à transformação de fase de modo a avaliar a presença de um tamanho crítico de partícula para a transformação e correlacionálos com os dados de energia determinados. As seguintes conclusões foram obtidas:

1. Houve um aumento na temperatura de transformação de fase $\gamma-\alpha$ da alumina para as amostras contendo $\mathrm{Mg}$ em relação à amostra sem aditivos. Foi observada solubilização do aditivo na rede cristalina do $\gamma-\mathrm{Al}_{2} \mathrm{O}_{3}$ que aumentou sua estabilidade, medida através do calor de dissolução. A maior estabilidade, em conjunto com a ação cinética do aditivo que diminui o transporte de massa na rede cristalina, é responsável pelo efeito de aumento na temperatura de transformação;

2. A presença do íon $\mathrm{Zr}$ na estrutura aumentou a temperatura de transformação $\gamma-\alpha$. Não foi detectada solubilização significativa do Zr na rede de $\gamma-\mathrm{Al}_{2} \mathrm{O}_{3}$, mas segregação superficial foi confirmada por XPS. Esta segregação foi relacionada com uma diminuição da energia de superfície das partículas, medida por calorimetria de dissolução, que levou a uma maior estabilidade da fase $\gamma-\mathrm{Al}_{2} \mathrm{O}_{3}$ e postergação da transformação de fase. Em decorrência da menor energia de superfície da amostra contendo Zr em relação à amostra sem aditivos, o tamanho crítico de partícula foi maior, coerente com a teoria relacionando o tamanho crítico com um balanço entre as energias de rede e de superfície.

3. O íon Mn foi relatado como diminuidor da temperatura da transformação $\gamma-\alpha$ da alumina. A presença de um tamanho crítico de partícula comum 
para o $\mathrm{Al}_{2} \mathrm{O}_{3}$ contendo 5 e $10 \mathrm{~mol} \% \mathrm{Mn}$ e para aquele livre de aditivo indicou que o ion não muda a razão entre as energias de rede e de superfície. $\mathrm{O}$ ensaio de energia de adsorção de $\mathrm{H}_{2} \mathrm{O}$ na superfície sugeriu pouca ação deste na energia de superfície, indicando que a ação deste aditivo no sistema é fortemente difusional.

Este conjunto de dados abre um novo conceito na avaliação da ação de aditivos nos processos de alta temperatura, onde as mudanças nos parâmetros termodinâmicos dos processos devem ser avaliadas. Ressalta-se a relação observada entre segregação do íon $\mathrm{Zr}$ e diminuição da energia de superfície como uma inédita colaboração quando tratando de óxidos cerâmicos. 


\section{LISTA DE REFERÊNCIAS}

[1] ANSELl, S., KRISHNAN, S., WEBER, J.K.R., FELTEN, J.J., NORDINE, P.C., BENO, M.A., PRICE, D.L., SABOUNGI, M.L. (1997). Structure of liquid aluminum oxide. Physical Review Letters 78, 464-466.

[2] AUROUX, A., GERVASINI, A. (2003). Infrared spectroscopic study of the acidic character of modified alumina surfaces. Adsorption Science \& Technology 21, 721-737.

[3] BAGWELL, R.B., MESSING, G.L. (1999). Effect of seeding and water vapor on the nucleation and growth of alpha- $\mathrm{Al}_{2} \mathrm{O}_{3}$ from gamma- $\mathrm{Al}_{2} \mathrm{O}_{3}$. Journal of the American Ceramic Society 82, 825-832.

[4] BAGWELL, R.B., MESSING, G.L., HOWELL, P.R. (2001). The formation of alpha- $\mathrm{Al}_{2} \mathrm{O}_{3}$ from theta- $\mathrm{Al}_{2} \mathrm{O}_{3}$ : The relevance of a "critical size" and: Diffusional nucleation or "synchro-shear"? Journal of Materials Science 36, 1833-1841.

[5] BAUMANN, T.F., GASH, A.E., CHINN, S.C., SAWVEL, A.M., MAXWELL, R.S.SATCHER, J.H. (2005). Synthesis of high-surface-area alumina aerogels without the use of alkoxide precursors. Chemistry of Materials 17, 395-401.

[6] BERNARDI, M.I.B., CRISPIM, S.C.L., MACIEL, A.P., SOUZA, A.G., CONCEICAO, M.M., LEITE, E.R.LONGO, E. (2004). Synthesis and characterization of $\mathrm{Al}_{2} \mathrm{O}_{3} / \mathrm{Cr}_{2} \mathrm{O}_{3}$-based ceramic pigments. Journal of Thermal Analysis and Calorimetry 75, 475-480.

[7] BLONSKI, S., GAROFALINI, S.H. (1993). Molecular-Dynamics Simulations of Alpha-Alumina and Gamma-Alumina Surfaces. Surface Science 295, 263-274.

[8] BOZZOLO, G., FERRANTE, J., NOEBE, R.D., GOOD, B., HONECY, F.S., ABEL, P. (1999). Surface segregation in multicomponent systems: Modeling of surface alloys and alloy surfaces. Computational Materials Science 15, 169-195. 
[9] BYE, G.C., SIMPKIN, G.T. (1974). Influence of Cr and Fe on Formation of Alpha- $\mathrm{Al}_{2} \mathrm{O}_{3}$ from Gamma- $\mathrm{Al}_{2} \mathrm{O}_{3}$. Journal of the American Ceramic Society 57, 367-371.

[10] BYE, G.C., SIMPKIN, G.T. (1978). Effect of Chromium and Iron in SolidSolution on Point of Zero Charge of Alumina. Journal of Applied Chemistry and Biotechnology 28, 116-118.

[11] CALVET, E., PRAT, H. (1954). Microcalorimetrie. (Masson et Cie, Paris, France).

[12] CASTRO, R.H.R., GOUVEA, D. (2003). Study of the influence of the Mn ion on the gamma-alpha alumina phase transition. Cerâmica 49, 55-60.

[13] CASTRO, R.H.R., HidAlgO, P., MUCCILlO, R., GOUVEA, D. (2003). Microstructure and structure of $\mathrm{NiO}-\mathrm{SnO}_{2}$ and $\mathrm{Fe}_{2} \mathrm{O}_{3}-\mathrm{SnO}_{2}$ systems. Applied Surface Science 214, 172-177.

[14] CHIANG, Y.-M., BIRNIE, D., KINGERY, W.D. (1997). Physical Ceramics - Principles for Ceramic Science and Engineering. (John Wiley \& Sibs Inc., New York).

[15] DE LEEUW, N.H., PARKER, S.C. (1999). Effect of chemisorption and physisorption of water on the surface structure and stability of alphaalumina. Journal of the American Ceramic Society 82, 3209-3216.

[16] DJURICIC, B., PICKERING, S., GLAUDE, P., MCGARRY, D., TAMBUYSER, P. (1997). Thermal stability of transition phases in zirconia-doped alumina. Journal of Materials Science 32, 589-601.

[17] DÖRRE, E. (1984). Alumina: processing, properties, and applications. (Springer-Verlag, Berlin).

[18] DOWDEN, D.A. (1949). Heterogeneous Catalysis .1. Theoretical Basis. Chemistry \& Industry, 320-320.

[19] DYNYS, F.W., HALLORAN, J.W. (1980). Formation of Alpha Al2o3 in Alum-Derived Gamma $\mathrm{Al}_{2} \mathrm{O}_{3}$. American Ceramic Society Bulletin 59, $361-361$

[20] DYNYS, F.W., HALLORAN, J.W. (1982). Alpha-Alumina Formation in Alum-Derived Gamma-Alumina. Journal of the American Ceramic Society $65,442-448$. 
[21] FERET, F.R., ROY, D., BOULANGER, C. (2000). Determination of alpha and beta alumina in ceramic alumina by X-ray diffraction. Spectrochimica Acta Part B-Atomic Spectroscopy 55, 1051-1061.

[22] FERKEL, H., HELLMIG, R.J. (1999). Effect of nanopowder deagglomeration on the densities of nanocrystalline ceramic green bodies and their sintering behaviour. Nanostructured Materials 11, 617-622.

[23] FLASCHEN, S.S. (1955). An Aqueous Synthesis of Barium Titanate. Journal of the American Chemical Society 77, 6194-6194.

[24] GARVIE, R.C., GOSS, M.F. (1986). Intrinsic Size Dependence of the PhaseTransformation Temperature in Zirconia Microcrystals. Journal of Materials Science 21, 1253-1257.

[25] GATTA, G.D. (1985). Direct Determination of Adsorption Heats. Thermochimica Acta 96, 349-363.

[26] GAVRILOV, K.L., BENNISON, S.J., MIKESKA, K.R., LEVI-SETTI, R. (1999). Grain boundary chemistry of alumina by high-resolution imaging SIMS. Acta Materialia 47, 4031-4039.

[27] GLEITER, S.H. (2000). Nanostructured materials: Basic concepts and microstructure. Acta Materialia 48, 1-29.

[28] GONZALEZ-MARTIN, M.L., LABAJOS-BRONCANO, L., JANCZUK, B., BRUQUE, J.M. (1999). Wettability and surface free energy of zirconia ceramics and their constituents. Journal of Materials Science 34, 59235926.

[29] GOUVEA, D., SMITH, A., BONNET, J.P. (1996). Manganese segregation on the surface of $\mathrm{SnO}_{2}$ based powders. European Journal of Solid State and Inorganic Chemistry 33, 1015-1023.

[30] GOUVEA, D., VILLALOBOS, R.L., CAPOCCHI, J.D.T. (1999). Polymeric precursor synthesis of alumina containing manganese oxide. Materials Science Forum 299, 91-96.

[31] GUTIERREZ, G., TAGA, A., JOHANSSON, B. (2002). Theoretical structure determination of gamma- $\mathrm{Al}_{2} \mathrm{O}_{3}$. Physical Review B 65. 
[32] HARDING, J.H., ATKINSON, K.J.W., GRIMES, R.W. (2003). Experiment and theory of diffusion in alumina. Journal of the American Ceramic Society 86, 554-559.

[33] HASS, K.C., SCHNEIDER, W.F., CURIONI, A., ANDREONI, W. (1998). The chemistry of water on alumina surfaces: Reaction dynamics from first principles. Science 282, 265-268.

[34] HASS, K.C., SCHNEIDER, W.F., WOLVERTON, C.M. (2000). Structure and surface chemistry of aluminas. Abstracts of Papers of the American Chemical Society 220, U174-U174.

[35] HERNANDEZ, T., BAUTISTA, M.C. (2005). The role of the synthesis route to obtain densified $\mathrm{TiO}_{2}$-doped alumina ceramics. Journal of the European Ceramic Society 25, 663-672.

[36] HRABE, Z., KOMARNENI, S., PACH, L., ROY, R. (1992). The Influence of Water-Vapor on Thermal Transformations of Boehmite. Journal of Materials Research 7, 444-449.

[37] IONESCU, A., ALlOUCHE, A., AYCARD, J.P., RAJZMANN, M., HUTSCHKA, F. (2002). Study of gamma-alumina surface reactivity: Adsorption of water and hydrogen sulfide on octahedral aluminum sites. Journal of Physical Chemistry B 106, 9359-9366.

[38] JANBEY, A., PATI, R.K., TAHIR, S., PRAMANIK, P. (2001). A new chemical route for the synthesis of nano-crystalline alpha- $\mathrm{Al}_{2} \mathrm{O}_{3}$ powder. Journal of the European Ceramic Society 21, 2285-2289.

[39] JOHNSTON, G.P., MUENCHAUSEN, R., SMITH, D.M., FAHRENHOLTZ, W., FOLTYN, S. (1992). Reactive Laser Ablation Synthesis of Nanosize Alumina Powder. Journal of the American Ceramic Society 75, 3293-3298.

[40] KLEPPA, O.J. (1972). Oxide melt solution calorimetry. In Colloq. Intern. CNRS N 201 - Thermochimie.pp. 119-127.

[41] KOCHUBEI, D.I., KRIVENTSOV, V.V., KUSTOVA, G.N., ODEGOVA, G.V., TSYRULNIKOV, P.G., KUDRYA, E.N. (1998). Thermal activation of a post-combustion manganese-alumina catalyst studied by IR, UV spectroscopy, and EXAFS. Kinetics and Catalysis 39, 274-281. 
[42] KORYABKINA, N.A., LITVAK, G.S., SHKRABINA, R.A., ISMAGILOV, Z.R. (1993). The Investigation of the Catalysts of Fuel Combustion Reactions .13. The Study of an Alumina Magnesia System Using the Thermal-Analysis Method. Kinetics and Catalysis 34, 820-821.

[43] KORYABKINA, N.A., SHKRABINA, R.A., USHAKOV, V.A., MOROZ, E.M., LANSBERG, M.F. ISMAGILOV, Z.R. (1996). Investigation of the catalysts of fuel combustion .15. Thermal stability of the $\mathrm{CeO}_{2}-\mathrm{Al}_{2} \mathrm{O}_{3}$ system. Kinetics and Catalysis 37, 117-122.

[44] KRELL, A.MA, H. (1999). Nanocorundum - Advanced synthesis and processing. Nanostructured Materials 11, 1141-1153.

[45] KRYUKOVA, G.N., KLENOV, D.O., IVANOVA, A.S., TSYBULYA, S.V. (2000). Vacancy ordering in the structure of gamma-A12O3. Journal of the European Ceramic Society 20, 1187-1189.

[46] KUMAR, P.M., BORSE, P., ROHATGI, V.K., BHORASKAR, S.V., SINGH, P., SASTRY, M. (1994). Synthesis and Structural Characterization of Nanocrystalline Aluminum-Oxide. Materials Chemistry and Physics 36, 354-358.

[47] LAS, W.C., GOUVEA, D., SANO, W. (1999). EPR of Mn as densifying agent in $\mathrm{SnO}_{2}$ powders. Solid State Sciences 1, 331-337.

[48] LEE, H.C., KIM, H.J., RHEE, C.H., LEE, K.H., LEE, J.S., CHUNG, S.H. (2005). Synthesis of nanostructured gamma-alumina with a cationic surfactant and controlled amounts of water. Microporous and Mesoporous Materials 79, 61-68.

[49] LESSING, P.A. (1989). Mixed-Cation Oxide Powders Via Polymeric Precursors. American Ceramic Society Bulletin 68, 1002-1007.

[50] LEVIN, I., BRANDON, D. (1998). Metastable alumina polymorphs: Crystal structures and transition sequences. Journal of the American Ceramic Society 81, 1995-2012.

[51] LI, J.G., SUN, X.D. (2000). Synthesis and sintering behavior of a nanocrystalline alpha-alumina powder. Acta Materialia 48, 3103-3112. 
[52] LIPPENS, B.C., DEBOER, J.H. (1964). Study of Phase Transformations During Calcination of Aluminum Hydroxides by Selected Area Electron Diffraction. Acta Crystallographica 17, 1312-\&.

[53] LODZIANA, Z., NORSKOV, J.K., STOLTZE, P. (2003). The stability of the hydroxylated (0001) surface of alpha- $\mathrm{Al}_{2} \mathrm{O}_{3}$. Journal of Chemical Physics 118, 11179-11188.

[54] LOONG, C.K., RICHARDSON, J.W., OZAWA, M. (1997). Structural phase transformations of rare-earth modified transition alumina to corundum. Journal of Alloys and Compounds 250, 356-359.

[55] MChale, J.M., AUrouX, A., PERrotta, A.J., NAVrotsky, A. (1997). Surface energies and thermodynamic phase stability in nanocrystalline aluminas. Science $\mathbf{2 7 7}$, 788-791.

[56] MCHALE, J.M., NAVROTSKY, A., KIRKPATRICK, R.J. (1998). Nanocrystalline spinel from freeze-dried nitrates: Synthesis, energetics of produce formation, and cation distribution. Chemistry of Materials 10, 1083-1090.

[57] MCHALE, J.M., NAVROTSKY, A., PERROTTA, A.J. (1997). Effects of increased surface area and chemisorbed $\mathrm{H}_{2} \mathrm{O}$ on the relative stability of nanocrystalline gamma- $\mathrm{Al}_{2} \mathrm{O}_{3}$ and alpha- $\mathrm{Al}_{2} \mathrm{O}_{3}$. Journal of Physical Chemistry B 101, 603-613.

[58] MESSING, G.L., KUMAGAI, M. (1994). Low-Temperature Sintering of Alpha-Alumina-Seeded Boehmite Gel. American Ceramic Society Bulletin 73, 88-91.

[59] MOnCEAU, D., PETOT, C., PETOTERVAS, G., FRASER, J.W., GRAHAM, M.J.SPROULE, G.I. (1995). Surface Segregation and Morphology of Mg-Doped Alpha-Alumina Powders. Journal of the European Ceramic Society 15, 851-858.

[60] NAVROTSKY, A. (1977). Progress and New Directions in HighTemperature Calorimetry. Physics and Chemistry of Minerals 2, 89-104.

[61] NAVROTSKY, A. (2001). Thermochemistry of nanomaterials. Nanoparticles and the Environment 44, 73-103. 
[62] NAVROTSKY, A. (2003). Energetics of nanomaterials: The competition between polymorphism and surface energy. Abstracts of papers of the American Chemical Society 225, U939-U939.

[63] NAVROTSKY, A. (2003). Energetics of nanoparticle oxides: interplay between surface energy and polymorphism. Geochemical Transactions 4, 34-37.

[64] NAVROTSKY, A. (2003). Materials and nanotechnology. Mrs Bulletin 28, 92-94.

[65] NAVROTSKY, A., RAPP, R.P., SMELIK, E., BURNLEY, P., CIRCONE, S., CHAI, L., BOSE, K. (1994). The Behavior of $\mathrm{H}_{2} \mathrm{O}$ and $\mathrm{CO}_{2}$ in HighTemperature Lead Borate Solution Calorimetry of Volatile-Bearing Phases. American Mineralogist 79, 1099-1109.

[66] OKADA, K., HATTORI, A., KAMESHIMA, Y., YASUMORI, A. (2000). Concentration effect of $\mathrm{Cs}^{+}$additive on the gamma- $\mathrm{Al}_{2} \mathrm{O}_{3}$-to-alpha- $\mathrm{Al}_{2} \mathrm{O}_{3}$ phase transition. Materials Letters 42, 175-178.

[67] OKADA, K., HATTORI, A., KAMESHIMA, Y., YASUMORI, A., DAS, R.N. (2000). Effect of monovalent cation additives on the gamma- $\mathrm{Al}_{2} \mathrm{O}_{3}$ to-alpha- $\mathrm{Al}_{2} \mathrm{O}_{3}$ phase transition. Journal of the American Ceramic Society 83, 1233-1236.

[68] OKADA, K., HATTORI, A., TANIGUCHI, T., NUKUI, A., DAS, R.N. (2000). Effect of divalent cation additives on the gamma- $\mathrm{Al}_{2} \mathrm{O}_{3}$-to-alpha$\mathrm{Al}_{2} \mathrm{O}_{3}$ phase transition. Journal of the American Ceramic Society 83, 928932.

[69] OVERBURY, S.H., BERTRAND, P.A., SOMORJAI, G.A. (1975). Surface composition of binary-systems - Prediction of surface phase diagrams of solid solutions. Chemical Review 75, 547-560.

[70] PECHINI, M. (1967). Method of preparing lead and alkaline earth titanates and niobates and coating method using the same form a capacitor. $\mathrm{n}^{\mathrm{o}}$ 3330697

[71] PEREIRA, G.J., CASTRO, R.H.R., GOUVEA, D. (2002). Surface segregation od additives based powders and their relationship with macroscopic properties. Applied Surface Science 195, 274-280. 
[72] PERROTTA, A.J. (1998). Nanosized corundum synthesis. Materials Research Innovations 2, 33-38.

[73] PETROVIC, R., MILONJIC, S., JOKANOVIC, V., KOSTICGVOZDENOVIC, L., PETROVIC-PRELEVIC, I., JANACKOVIC, D. (2003). Influence of synthesis parameters on the structure of boehmite sol particles. Powder Technology 133, 185-189.

[74] PIJOLAT, M., DAUZAT, M., SOUSTELlE, M. (1987). Influence of Additives and Water-Vapor on the Transformation of Transition Aluminas into Alpha-Alumina. Thermochimica Acta 122, 71-77.

[75] PIJOLAT, M., DAUZAT, M., SOUSTELLE, M. (1992). Influence of WaterVapor and Additives on the Surface-Area Stability of Gamma-Al2o3. Solid State Ionics 50, 31-39.

[76] PITCHER, M.W., NAVROTSKY, A. (2003). Synthesis and stability of zirconia nanocrystals. Abstracts of papers of the American Chemical Society 225, U49-U49.

[77] RUBAN, A.V., SKRIVER, H.L., NORSKOV, J.K. (1999). Surface segregation energies in transition-metal alloys. Physical Review B: Condensed Matter 59, 15990-16000.

[78] SANTOS, P.S., SANTOS, H.S., TOLEDO, S.P. (2000). Standard transition aluminas. Electron microscopy studies. Materials Research 3, 104-114.

[79] SHRIVER, D.F., ATCKINS, P.W., LANGFORD, C.H. (1994). Inorganic Chemistry. In (Oxford University Press, EUA).

[80] SOHLBERG, K., PENNYCOOK, S.J., PANTELIDES, S.T. (1999). Hydrogen and the structure of the transition aluminas. Journal of the American Chemical Society 121, 7493-7499.

[81] STUMPF, H.F., RUSSEL, A.S., NEWSOME, J.W. (1949). Thermal Transformations of Aluminas and Alumina Hydrates. Industrial Engineering and Chemistry 42, 1298-1403.

[82] TREADWELl, D.R., SUTORIK, A.C., NEO, S.S., LAINE, R.M., SVEDBERG, R.C. (1998). Synthesis of beta "-alumina polymer precursor and ultrafine beta "-alumina composition powders. In Synthesis and Characterization of Advanced Materials. pp. 146-156. 
[83] TSYGANENKO, A.A., MARDILOVICH, P.P. (1996). Structure of alumina surfaces. Journal of the Chemical Society-Faraday Transactions 92, 48434852.

[84] USHAKOV, S.V., BROWN, C.E., NAVROTSKY, A. (2004). Effect of La and $\mathrm{Y}$ on crystallization temperatures of hafnia and zirconia. Journal of Materials Research 19, 693-696.

[85] USHAKOV, S.V., NAVROTSKY, A., YANG, Y., STEMMER, S., KUKLI, K., RITALA, M., LESKELA, M.A., FEJES, P., DEMKOV, A., WANG, C., NGUYEN, B.Y., TRIYOSO, D., TOBIN, P. (2004). Crystallization in hafnia- and zirconia-based systems. Physica Status Solidi B-Basic Research 241, 2268-2278.

[86] VINNIK, I.V., ZENKOV, V.S., SIROTYUK, M.M., KOVAL'SKII, L.M.UVAROVA, I.V. (1998). Ceramic humidity sensors based on magnesium aluminate spinel. II. Relation between the parameters of water adsorption kinetics and the service characteristics of ceramic humidity sensors in the $\mathrm{MgAl}_{2} \mathrm{O}_{4}$ system. Powder Metallurgy and Metal Ceramics 37, 382-385.

[87] WEFERS, K., MISRA, C. (1987). Oxides and Hydroxides of Aluminum. Alcoa Technical Paper $\mathrm{N}^{\circ} 19$, revised.

[88] WOLVERTON, C., HASS, K.C. (2001). Phase stability and structure of spinel-based transition aluminas. Physical Review B 6302, -.

[89] WYNNYCKYJ, J.R., MORRIS, C.G. (1985). A Shear-Type Allotropic Transformation in Alumina. Metallurgical Transactions B-Process Metallurgy 16, 345-353.

[90] XUE, L.A., CHEN, I.W. (1992). Influence of Additives on the Gamma-toAlpha Transformation of Alumina. Journal of Materials Science Letters 11, 443-445.

[91] YOLDAS, B.E. (1976). Thermal Stabilization of an Active Alumina and Effect of Dopants on Surface-Area. Journal of Materials Science 11, 465470 . 
[92] ZENG, W.M., GAO, L., GUO, J.K. (1998). A new sol-gel route using inorganic salt for synthesizing $\mathrm{Al}_{2} \mathrm{O}_{3}$ nanopowders. Nanostructured Materials 10, 543-550.

[93] ZHOU, R.S., SNYDER, R.L. (1991). Structures and Transformation Mechanisms of the Eta, Gamma and Theta Transition Aluminas. Acta Crystallographica Section B-Structural Science 47, 617-630. 